\title{
Effect of the nutrient microenvironment of an ovarian follicle on gap junction activity in cumulus-oocyte complexes in
}

post-partum cows By

\section{Norma Lorraine Hudson}

A thesis submitted to Victoria University of Wellington in fulfilment of the requirements for the degree of Master of Science in Cell and Molecular Biology

Victoria University of Wellington 2012

School of Biological Science 


\section{Acknowledgements}

I would like to acknowledge, with appreciation, everyone who has contributed to this research.

Firstly I would like to thank my primary supervisor Professor Ken McNatty for making it possible for me to do this research and for his patience and understanding in the face of some dumb moments on my part. I couldn't have completed this without his guidance and support and encouragement.

My secondary supervisor Dr Janet Pitman has been a source of knowledge and expertise especially on writing, without which this would have been a bigger task than it was. Her suggestions were extremely beneficial and helpful for experimental design. Her patience as I struggled with the statistics was exceptional.

My colleagues Dr Joy McIntosh, who convinced me to carry on when I felt it was all too much, yes the glass was half full, and Adrian Bibby who sorted out my computer problems for me of which there were many. Thank you so much.

The students in the Reproduction group for their good humour, friendship and encouragement. Thanks guys.

My thanks to the staff of Assure Quality at Taylor Preston Abattoirs: without their help I would not have had any tissue to work with. Your help was very much appreciated.

Lastly, I wish to thank the School of Biological Sciences for allowing me to do this study.

This study was funded by a University of Auckland/FRST grant UOAX0814: Improving Dairy Cow Fertility. 


\begin{abstract}
For mammalian oocyte maturation it is important for the oocyte to communicate with the surrounding somatic cells in a bidirectional manner. In part, this is achieved through gap junction connections between cumulus cells and the oocyte. These gap junctions permit the transfer of essential metabolites, nucleotides, amino acids and ions from the cumulus cells to the oocyte in order for growth and development to occur. It is hypothesized that one reason for post-partum infertility in dairy cows is poor oocyte quality due to an inappropriate nutrient microenvironment in the developing antral follicle. In turn, this might compromise the nutrient and/or energy delivery by cumulus cells to the oocyte and thus affect oocyte quality. The objectives of this study were to: (1) -develop a reliable in vitro measure of gap junction activity for bovine cumulus-oocyte-complexes (COC) using a fluorescent (calcein) dye technique, and (2)- assess the effects of different amino acid compositions, cholesterol and fatty acid concentrations on gap junction activity in COC.
\end{abstract}

The development and validation of the bovine COC gap junction assay was undertaken using a standard commercial medium (M199). Thereafter, media were prepared representing the amino acid concentrations in follicular fluid of both non-lactating and lactating dairy cows as measured in a NZ pastoral situation. These media formed the basis for subsequent measures of COC gap junction activity with differing concentrations of cholesterol and the essential fatty acids- oleic acid, stearic acid and palmitic acid.

The major findings from this study were that the different amino acid concentrations typical of that in the follicular fluid of the non-lactating and lactating dairy cow and M199 do not significantly affect the gap junction activity in COC. Given that the amino acid compositions in lactating and non-lactating cows were approximately 50\% of those in M199; this indicates that the amino acid concentrations within the ovarian follicle are not a critical factor affecting 
oocyte quality. However, high concentrations of cholesterol or of the essential fatty acids significantly compromised gap junction activity in bovine COC. High concentrations of the fatty acids were identified in a number of lactating dairy cows during the post-partum interval. In times of negative energy balance, which is common in pasture fed NZ dairy cows during the early post-partum interval and lactation, a significant mobilisation of fatty acids occurs. In turn, this is known to result in an increase in lipid concentrations within the ovarian follicle. The results from this study support the hypothesis that the nutrient environment of the ovarian follicle during early lactation is detrimental to the quality and developmental competence of the oocyte and thus may account for post-partum infertility in some animals. 


\section{Table of Contents}

$\begin{array}{lr}\text { Acknowledgements } & 2\end{array}$

Abstract 3

Table of Contents 3

List of Figures and Tables $\quad 8$

\section{Chapter 1: Introduction}

$\begin{array}{lll}1.1 & \text { Background } & 11\end{array}$

$\begin{array}{lll}1.2 & \text { The ovary } & 13\end{array}$

$\begin{array}{lll}1.3 & \text { Ovarian follicular development } & 16\end{array}$

1.4 (i) The oocyte 18

1.4 (ii) Oocyte growth factors 20

1.4(iii) Oestrous cycle and ovulation 21

1.5 Gap junctions 25

$\begin{array}{ll}1.6 & \text { Meiosis and oocyte maturation }\end{array}$

1.7 Cyclic adenosine monophosphate (cAMP) 30

1.8 (i) Phosphodiesterases (PDEs) 31

1.8(ii) Phosphodiesterase inhibitors 31

1.9 Aims of the study 32

\section{Chapter 2: Material and Methods}

2.1 Media composition 33

2.1a. Collection media for COCs (HTCM) 33

2.1b. Wash media (BTCM) 33

2.1c Incubation media (CTCM) 33

2.2 Stock solutions 33 
2.4 Ovaries 35

2.5 Isolation of cumulus-oocyte complexes (COC) 36

2.6(i) Gap junction assay 38

2.6(ii) Gap junction assay: Effect of time $\quad 40$

2.6(iii) Gap junction assay: Effect of various PDE inhibitors 41

2.6(iv) Gap junction assay: Effect of forskolin 41

2.6(v) Gap junction assay: Effect of $\mathrm{pH}$

2.7(i): In-house media representing the composition of follicular fluid in non- 42 lactating and lactating cows

2.7 (ii): Effects of cholesterol 43

2.7(iii) Effects of fatty acids 44

2.7(iii) (a) Oleic acid 45

2.7(iii) (b) Stearic acid 46

2.7(iii) (c) Palmitic acid 47

$\begin{array}{lll}2.8 & \text { Statistical analysis } & 48\end{array}$

\section{Chapter 3: Results}

3.1 Effect of time on calcein dye transfer via gap junctions in bovine COC

3.2(a) Effects of phosphodiesterase inhibitors (PDE) on calcein dye transfer via 50 gap junctions in bovine COC

3.2(b) Effects of phosphodiesterase inhibitors(PDE) on GVBD in bovine oocytes

3.3 Effect of combining PDE inhibitors on dye transfer in the gap junction assay 54

3.4 Effect of forskolin on dye transfer in the gap junction assay 55

3.5 Effect of media $\mathrm{pH}$ on dye transfer in the gap junction assay 58

\section{Chapter 4 Studies with in-house media}


4.1 Comparison of M199, non-lactating and lactating media on calcein dye 61 transfer via gap junctions in the bovine COC

4.2 Effect of differing amounts of cholesterol on calcein dye transfer via gap 62 junctions in the bovine COC

4.3 Effect of differing amounts of fatty acids on calcein dye transfer via gap 64 junctions in the bovine COC

4.3(i) Effect of oleic acid

4.3(ii) Effect of stearic acid 66

4.3(iii) Effect of palmitic acid 67

5. Discussion 69

6. Conclusion 78

7. Appendix 80

8. References 84 


\section{List of Tables and Figures}

$\begin{array}{lll}\text { Figure 1.1 } & \text { Ovarian sections showing structures }\end{array}$

$\begin{array}{lll}\text { Figure 1.2 Classification of bovine follicles } & 17\end{array}$

$\begin{array}{lll}\text { Figure 1.3 } & 18\end{array}$

Figure 1.4 Bidirectional communication between oocyte and 19 cumulus/granulosa cells

Figure 1.5 Hypothalamic-pituitary-gonadal axis 24

Figure 1.6 Structure of a gap junction 25

Figure 1.7 Stages of follicular growth and timing of acquisition of meiotic 28 competence in a primate model

Figure 1.8 Possible mechanisms involved in the resumption of meiosis 29

$\begin{array}{lll}\text { Figure 1.9 } & \text { Chemical structure of cAMP } & 30\end{array}$

Figure 2.1 Leica inverted microscope with CRAIC fluorescent detection 35 system on the left-hand side of the eye pieces

Figure 2.2 A bovine ovary showing follicles and a corpus luteum 36

$\begin{array}{lll}\text { Figure 2.3 The venturi pump system } & 36\end{array}$

Figure 2.4 COC suitable for selection for gap junction assay 38

$\begin{array}{lll}\text { Figure 2.5 } & \text { COC showing cumulus cell expansion } & 38\end{array}$

Figure 2.6 Comparison of oocyte types under bright field and fluorescent 40 intensity

Table 2.1 Concentrations of additives in each well for testing the effects 45 of oleic acid

Table 2.2 Concentrations of additives in each well for testing the effects 46 of stearic acid 
Table 2.3 Concentrations of additives in each well for testing the effects

of palmitic acid

Figure 3.1 Effect of time on the transfer of calcein dye from the cumulus 49 cell to the oocyte

Figure 3.2 Effect of various PDE inhibitors on fluorescent intensity in 51 oocytes after 240 min incubation

Figure 3.3 Effect of various PDE inhibitors on fluorescent intensity in 52 oocytes after $18.5 \mathrm{~h}$ incubation

Figure 3.4 Bovine oocyte in GV 53

Figure 3.5 Stages of meiosis in bovine oocytes 53

Figure 3.6 Examples of bovine oocytes after $18.5 \mathrm{~h}$ incubation with 54 dipyridamole

Figure 3.7 Effect of no PDE treatment on dye transfer in the gap junction 55 assay

Figure 3.8 Effect of PDE inhibitor \pm forskolin on dye transfer in the gap 56 junction assay after a 240 min incubation

Figure 3.9 $\quad$ Effect of PDE inhibitor \pm forskolin on dye transfer in the gap 57 junction assay after an $18.5 \mathrm{~h}$ incubation

Figure 3.10 Effect of $\mathrm{pH} 6.8-\mathrm{pH} 7.4$ on the transfer of calcein dye from 59 the cumulus cells to the oocyte

Figure 3.11 Effect of $\mathrm{pH} 7.4-\mathrm{pH} 8.0$ on the transfer of calcein dye from 60 the cumulus cells to the oocyte

Figure 4.1 Comparison of M199, non-lactating and lactating media on 62 calcein dye transfer via gap junctions

Figure 4.2 Effect of different concentrations of cholesterol. 
Figure 4.3 Effect of different concentrations of oleic acid 65

Figure 4.4 Effect of different concentrations of stearic acid 66

$\begin{array}{lll}\text { Figure 4.4 } & \text { Effect of different concentrations of palmitic acid. }\end{array}$ 


\section{Introduction}

\subsection{Background}

In the 2009/2010 season, 4.4 million dairy cows in New Zealand were farmed for milk production. Most of this milk (98\%), was exported, accounting for \$NZ210 billion in earnings (Dairy NZ 2010). The major challenge for any dairy farmer is to induce mating behaviour in cows after calving so that each pregnancy and calving is fitted into a calendar year and the spread in the calving interval each year is as small as possible. The production of calves at regular intervals during the cow's lifespan is a prerequisite for good lactation performance, so ideally the cow should have a calf each year. However, as milk yield per cow increases, the return to normal fertility after calving is often delayed. Moreover since 1957, fertility in dairy cows has been progressively declining (Lucy, 2007). This is of major concern to the industry as reproductive efficiency is a critical component for sustainable dairying.

Cows which do not become pregnant after three inseminations despite no clinically detectable reproductive disorders, (e.g. pyometra, ovarian cysts, endometritus), are known as repeat breeders whereas a cow which becomes pregnant within three inseminations is considered to have normal fertility (Yusuf et al., 2010). Additionally cows that produce a high milk yield display a shorter oestrus duration (e.g. $\sim 7$ h), thus reducing the opportunity for detection and subsequent insemination (Thatcher et al., 2010). The interval between birth and the first postpartum follicular wave has increased by approximately 10 days over the past 40 years to 2431 days (Lucy, 2001a). During this early post-partum period, the uterus involutes and the hypothalamo-hypophyseal-ovarian communication system reinitiates the cyclical secretions of gonadotrophic and gonadal hormones. Cyclical follicle stimulating hormone (FSH) production leads to the emergence of a follicular wave (Peter et al., 2009). As the FSH 
concentration declines, the continued growth of most follicles in this wave is compromised but one of the emerging follicles in this wave is able to maintain development. This follicle is described as the dominant follicle and its ability to go on to ovulate depends on the production of a critical level of oestradiol and growth factors and a rising level of luteinising hormone (LH) concentrations followed by preovulatory LH surge (see Scaramuzzi et al, 2011 for review). These events lead to the onset of oestrous behaviour and the first post-partum ovulation and thereafter regular oestrous-cycle activity until a pregnancy occurs. Normally these events take place within 6 weeks of calving but can sometimes take several weeks longer in dairy cows that have been selected for high lactation performance. In the early postpartum cow, the involuting uterus, hypothalamus, pituitary and the ovaries all need to be fully restored to a normal functional state for the expression of oestrus, mating and pregnancy to occur (Peter et al., 2009).

Over the last 30 years, NZ has imported genetic material (i.e. semen straws) from the North American Holstein-Friesian breed of dairy cattle. These cows are heavier, have lower concentrations of protein and fat, produce a higher volume of milk with higher protein but have lower fertility and embryo survival than the NZ Holstein-Friesian breed (Harris \& Kolver, 2001). At present, approximately $50 \%$ of the genetics of the NZ dairy cow population is derived from the Holstein-Friesian breed thereby exacerbating the issue of lower fertility rate. Partitioning of nutrients in cows selected for high milk production favours lactation, which can lead to a negative energy balance affecting the endocrine system and preventing the commencement of cyclical FSH and steroid hormone production. Moreover, the provision of more energy to these cows results in the portioning of the additional nutrients towards milk production and not reproduction, thereby leading to lower body condition and greater infertility (Lucy, 2001b). 
A negative energy balance also contributes to suppressed circulating levels of $\mathrm{LH}$, insulin and insulin-like growth factor-1(IGF-1), thereby compromising preovulatory follicular development (Butler, 2000; Lucy, 2007). The metabolites and metabolic hormones, e.g. nonessential fatty acids (NEFA), insulin, glucose and IGF-1, directly and indirectly influence fertility at the level of the ovary, and uterus. For example, elevated NEFA can have a harmful effect on the oocyte and granulosa cells (Leroy et al., 2005) and the higher bioavailability of intrafollicular IGF-1 and increased insulin concentration due to a high concentrate diet (Leroy et al., 2008c). This indicates that the level of nutrition an animal receives has the potential to influence the developmental competence of the oocyte, and therefore embryo viability in a direct or indirect way (Leroy et al., 2008c).

There are also other aspects of dairy cow nutritional and metabolic inputs that can influence fertility. For example, during the latter stages of pregnancy when cows are in negative energy balance, the immune system is strongly suppressed which leaves the cow open to infection such as metritis. The uterus can become infected during the calving process but most infections clear within $2-3$ weeks. Persistent infections can cause infertility but this only occurs in a small percentage of cows and is not a major contributor to infertility (Chagas et al., 2007).

To improve reproduction efficiency in dairy cows, there is a need to have a better understanding of the physiological and biological processes that lead to the production of a healthy oocyte for fertilisation, pregnancy and calf production.

\subsection{The ovary}

The ovary, of which there are two in mammals, is a ductless gland that is located on either side of the uterus that contains all the eggs (oocytes) for offspring production. A major function of the ovary is to maintain and mature the oocytes throughout reproductive life. The 
ovary also secretes the steroid hormones progesterone and oestradiol-17 $\beta$ as well as the protein hormone, inhibin: these hormones act on the pituitary gland to modulate the synthesis and secretion of the gonadotrophins ( $\mathrm{LH}$ and follicle-stimulating hormone, FSH) and to regulate the timing of ovulation. The surface of the ovary is covered by an epithelium which encloses the ovarian cortex. The cortex contains collagenous connective tissue, fibroblasts, fibres and oocyte-enclosed follicles (Figure 1.1a). Below the cortex lies the medulla which contains the nerve fibres and the major blood and lymphatic vessels.

During foetal life, primordial germ cells migrate into the developing ovary and to the cortex close to the ovarian surface epithelium. During this interval the germ cells develop into oogonia, enter meiosis and then, during the meiotic prophase, become known as oocytes. In the cow, the maximum number of oocytes that form is thought to be $\sim 2,000,000$ but by the time of birth only 150,000 remain (Aerts \& Bols, 2010b). This dramatic reduction in the number of oocytes occurs during the entry of oogonia into meiosis during follicular formation. The pathway of germ cell loss appears to be by programmed cell death known as apoptosis. The surviving meiotic oocytes attach to adjacent pregranulosa cells which then separate from other oocyte-pregranulosa cell complexes to form primordial follicles (Burkhart et al., 2010). These primordial follicles are characterised as structures containing an oocyte surrounded by a single layer of flattened granulosa cells and a basement membrane. In the cow, these primordial follicles are first evident around day 90 of gestation (Aerts \& Bols, 2010b). Later in gestation the foetal ovary contains both growing preantral and antral follicles (Figure 1.1b) because follicles begin to leave the resting pool while other follicles are still being formed (Fortune, 2003; Burkhart et al., 2010). 


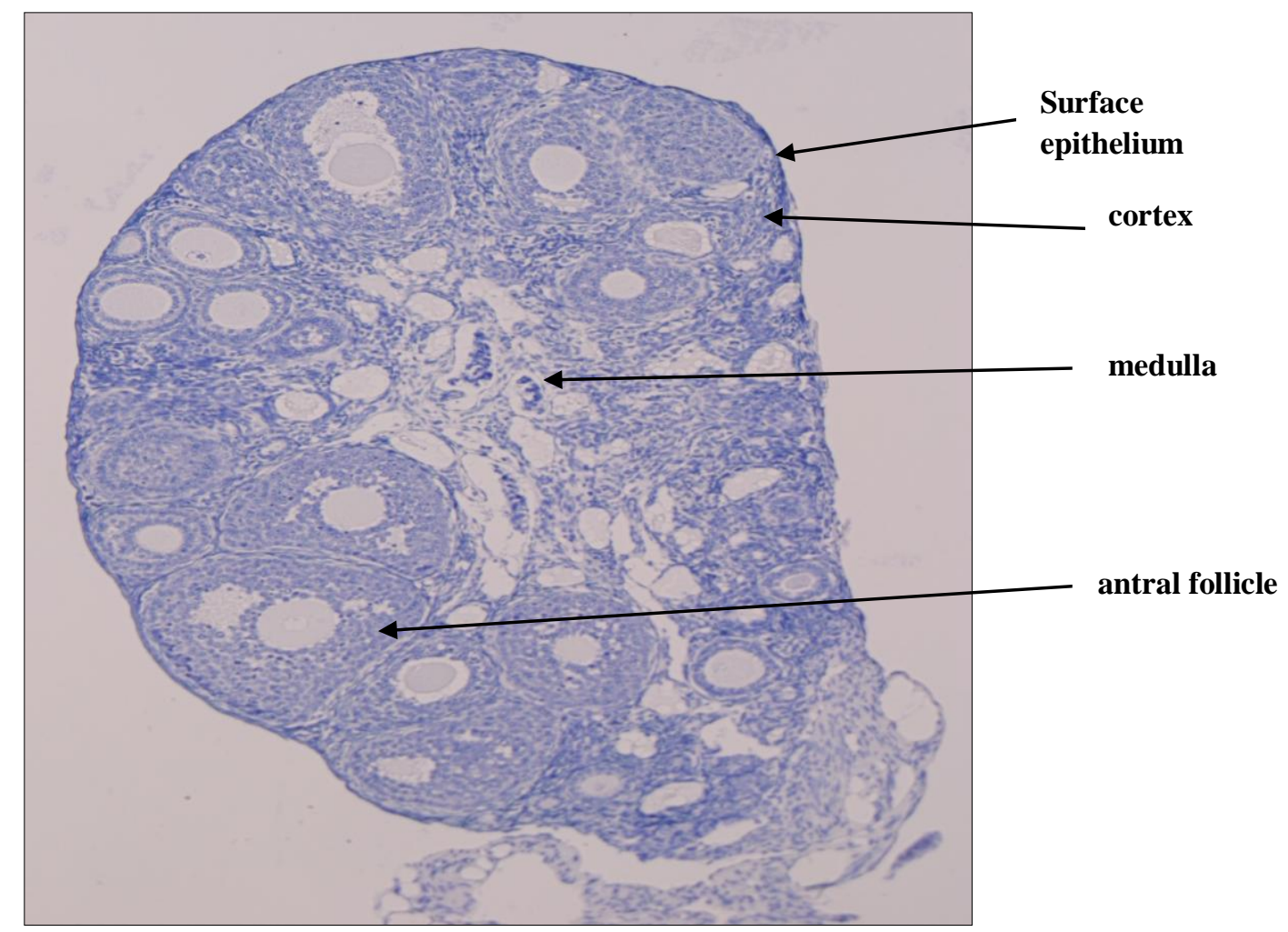

Figure 1.1a: Section of an ovary showing some of the main structural features (from McNatty, with permission).

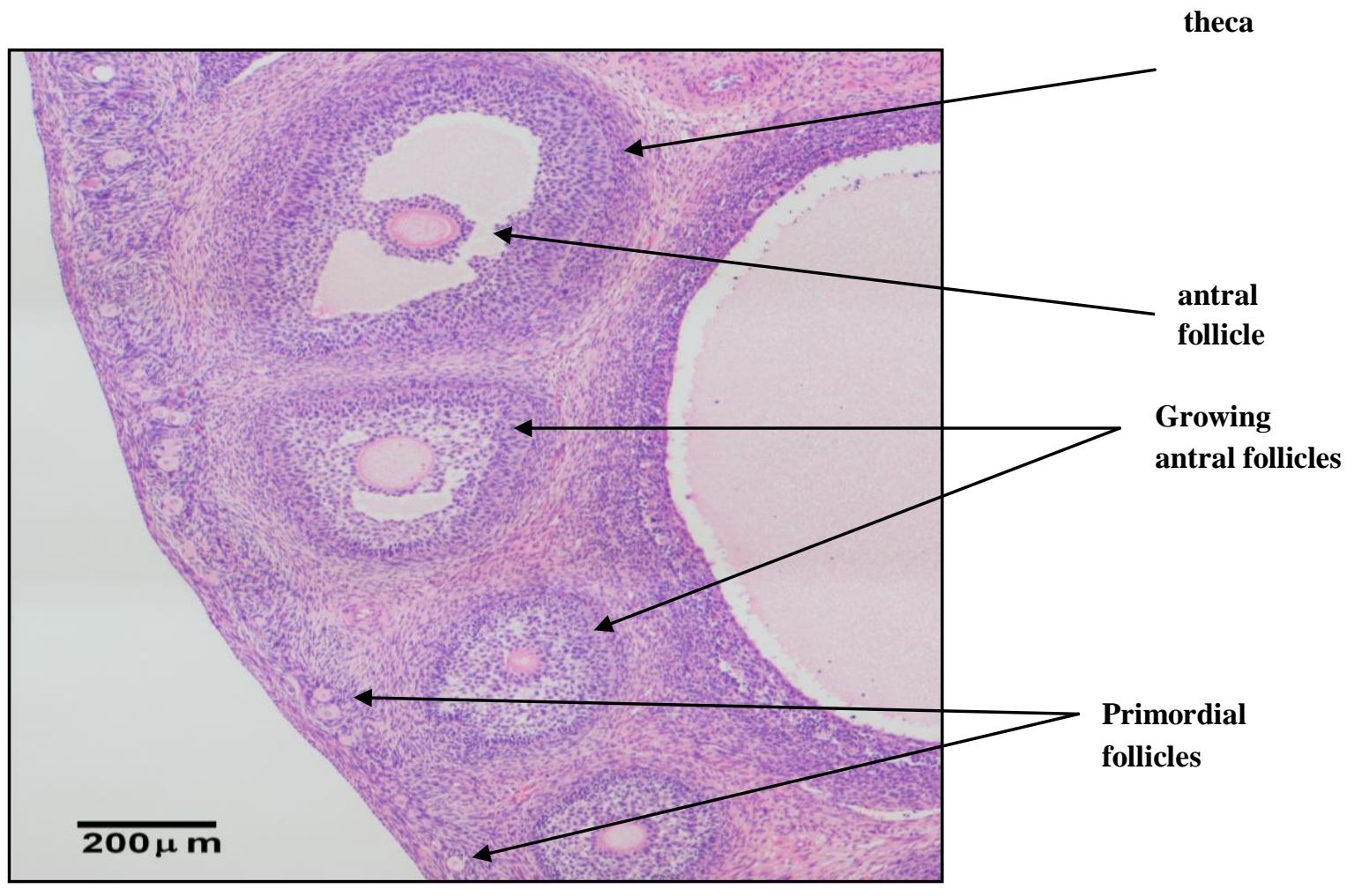

Figure 1.1b: Section of ovary showing primordial and growing follicles (from McNatty, with permission). 


\subsection{Ovarian follicular development}

The primordial follicles constitute the 'ovarian reserve' from whence follicles are recruited for development. Primordial or type 1 follicles contain an oocyte surrounded by $<10$ flattened granulosa cells and together these are bounded by a basement membrane, with an overall follicular diameter $<40 \mu \mathrm{m}$, and oocyte diameter $<30 \mu \mathrm{m}$ (Braw-Tal, 2002). In cattle, follicular growth involves primordial follicles moving from an arrested and relatively low metabolic state into a growth phase (Figure 1.2). The first transition to a primary follicle comprises three main events whereby the granulosa cells change from squamous to cuboidal shape followed by an increase in cell number, and then an enlargement of the oocyte (BrawTal, 2002). Thereafter, the follicle grows without rest through a number of developmental stages including those described as the preantral and antral stages (Figure 1.1b and 1.2) (Braw-Tal, 2002; Fortune, 2003).

During the transition from a primordial (Type 1) to a primary follicle (Type 2), 1-1.5 layers of cuboidal granulosa cells accumulate with $10-40$ cells. The follicle diameter is at this stage between $40-80 \mu \mathrm{m}$ and the oocyte diameter is $\sim 31 \mu \mathrm{m}$. After approximately 40 granulosa cells have accumulated, the oocyte begins to grow and this growth induces zona pellucida formation (ZP). Outside the basement membrane of the follicle, the theca cells which are localised in the stromal tissue can now be identified, although a clearly distinguished theca interna layer does not develop until the large preantral stage (see Figure 1.1b). The theca is made up of 2 layers referred to as the theca interna and theca externa. The theca interna is densely vascularised thus being capable of providing the follicle with its supply of endocrine factors. The follicle at the next stage of growth is referred to as the preantral or type 3 follicle: these follicles have two or three layers of granulosa cells ranging in number from 41100 cells with a follicular diameter of $81-130 \mu \mathrm{m}$ and an oocyte diameter of $50 \mu \mathrm{m}$. There are only a few clearly defined theca cells at this stage. Subsequently, the large preantral or type 4 
follicles have four or more layers of granulosa cells ranging from 101-250 cells and the theca layer is much clearer. The follicular diameter is $131-250 \mu \mathrm{m}$ and the oocyte diameter is 69 $\mu \mathrm{m}$. By this stage the oocyte is completely enclosed by ZP. As the follicles develop from the large preantral stage they are referred to as small antral or type 5 follicles. These follicles have $>6$ layers of granulosa cells, $>250$ in number. At this point the theca interna layer is very well defined. The antrum is a fluid-filled cavity with the oocyte now eccentrically located within the follicle and surrounded by discrete layers of granulosa cells which are termed cumulus cells to differentiate them from the more distantly located granulosa cells around the basement membrane of the developing follicle (Figures1.1b, 1.2 and 1.3). These more distantly located granulosa cells surrounding the follicle wall are often referred to as mural granulosa cells. The follicle diameter is $250-500 \mu \mathrm{m}$ and the oocyte has a diameter of $93 \mu \mathrm{m}$ (Braw-Tal \& Yossefi, 1997; Aerts \& Bols, 2010b; Aerts \& Bols, 2010a).

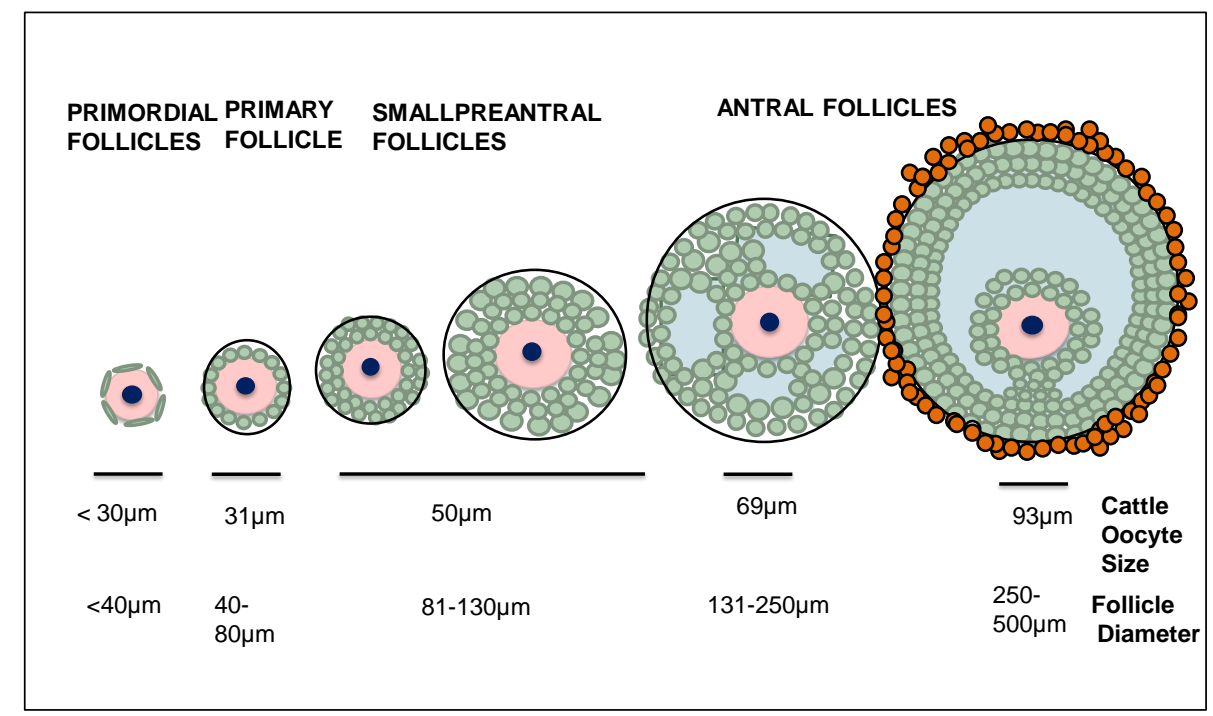

Figure 1.2: Classification of bovine follicles (modified from a diagram supplied by Lisa Johnson, VUW BSc Honours student, 2010). 


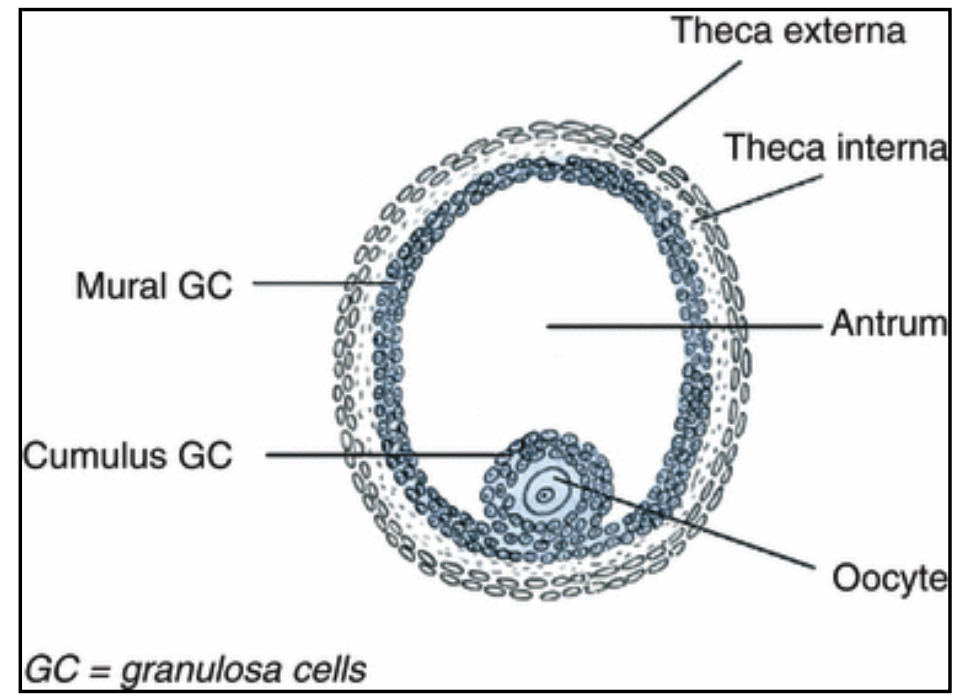

Figure 1.3: Morphology of an antral follicle. (from Aerts 2010 with permission).

In cattle, antral follicular growth can be divided into two stages of development. The first stage is the relatively slow, early antral growth phase of more than 30 days in duration. During this time, the follicle progresses from antrum acquisition at $0.3 \mathrm{~mm}$ to $\sim 3-5 \mathrm{~mm}$ in diameter. During this growth phase, the oocyte attains its final size and its full developmental competence but many follicles undergo apoptosis during this interval (Palumbo \& Yeh, 1995). The second growth phase is more rapid taking on average 5-7 days. It is during this period that one of the large antral follicles $>8 \mathrm{~mm}$ in diameter emerges as the presumptive ovulatory follicle (Mihm \& Bleach, 2003; Adams et al., 2008).

\section{4 (i) The oocyte}

Mammalian oocytes grow and develop in a mutually dependent and intimate relationship with their adjacent somatic cells. During the late pre-antral follicular growth stage, the oocyte becomes more closely associated with the immediately adjacent granulosa cells. This closer association leads to the granulosa cells immediately adjacent to the oocyte differentiating into cumulus cells and corresponds to the time when antrum formation occurs. The early antral stage of follicular growth is the time when the oocyte reaches its maximum diameter. The cumulus cells thereafter become increasingly subservient to the oocytes whereas the mural 
granulosa cells, which line the wall of the follicle, become a major source of follicular oestrogen and inhibin (Gilchrist et al., 2008). The cumulus cells and oocyte are commonly referred to as the cumulus cell-oocyte complex (COC). The cumulus cells play a major role in relaying nutrients (amino acids), energy substrates, metabolites and second messengers to the oocyte to enhance oocyte growth and maturation (Sugiura et al., 2005; Gilchrist et al., 2008; Yeo et al., 2009).

The communication between the somatic cells and the oocytes is bi-directional and essential for the development of both (Figure 1.4). This communication occurs via gap junctions (Sugiura et al., 2005; Scaramuzzi et al., 2011).

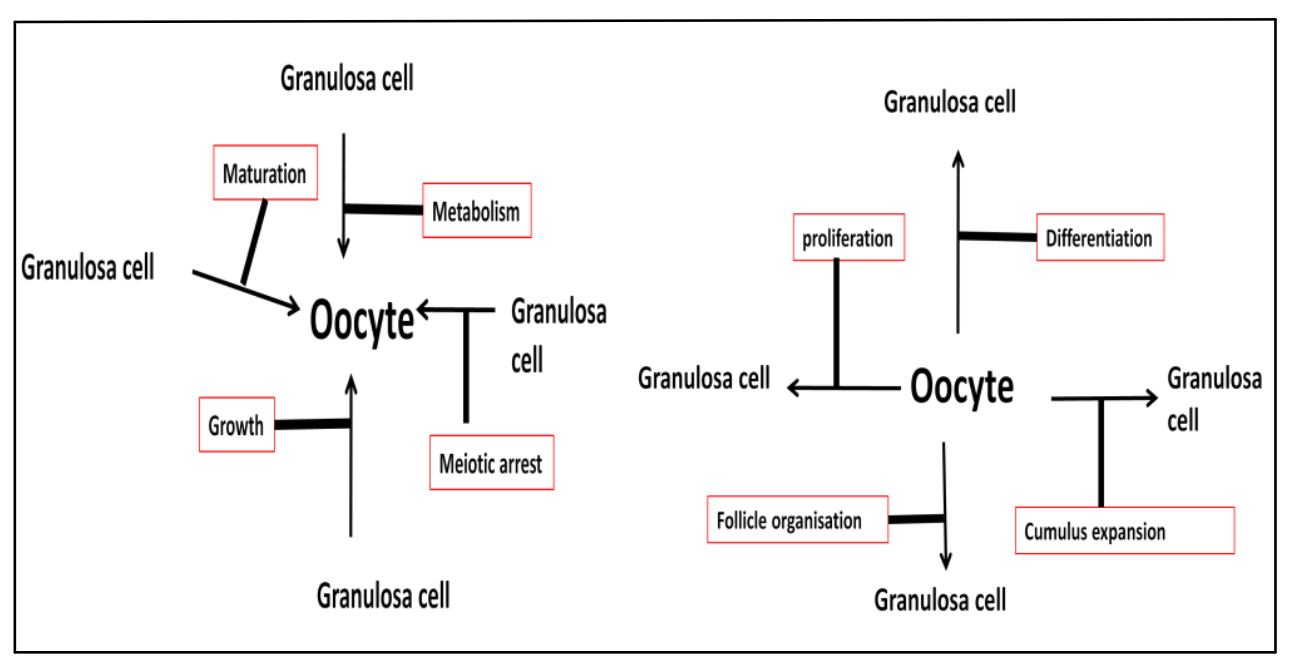

Figure 1.4: Bidirectional communication between oocyte and cumulus/granulosa cells. (modified from Eppig, 1991)

The oocyte plays an essential role throughout follicular formation and growth (Dong et al., 1996; Galloway et al., 2000; Yan et al., 2001; Juengel et al., 2002; Reik \& Dean, 2002). In the absence of the oocyte, follicles do not form and if all oocytes are lost prematurely, as is the case in mice with the homozygous inactivating mutations in the DAZL gene, the ovary undergoes major changes in morphology (Ruggiu M, 1997; McNeilly et al., 2011). Many, if 
not all, of the effects of the oocyte on somatic cell functions are regulated by paracrine factors (Gilchrist et al., 2008).

\section{4 (ii) Oocyte growth factors}

Two key oocyte growth factors are growth differentiation factor 9 (GDF9) and bone morphogenetic protein 15 (BMP15). Both factors are members of the TGF $\beta$ family and have been identified in oocytes of all species examined thus far, e.g. mouse, cow, sheep, rat, possum, pig (Bodensteiner et al., 1999; Galloway et al., 2000; Juengel et al., 2004). In most species, including the cow, it seems that GDF9 is expressed in oocytes from the primordial follicle stage and thereafter throughout follicular development (Bodensteiner et al., 1999; Juengel \& McNatty, 2005), whilst BMP15 is expressed in oocytes from the primary stage. GDF9 and/or BMP15 are involved in regulating the growth and differentiation of the granulosa cells (Shimasaki et al., 2004; Paulini \& Melo, 2010). Although GDF9 and BMP15 play important roles in fertility, their relative importance differs among species. Follicular growth is arrested at the primary stage in GDF9 knock out (KO) mice but BMP15-KO mice remain fertile (Dong et al., 1996; Yan et al., 2001). In contrast, sheep with naturally occurring homozygous mutations in GDF9 or BMP15 are infertile. However, ewes with a single inactive copy of either GDF9 or BMP15 have an increased ovulation rate (Hanrahan et al., 2004; Juengel et al., 2004). Both GDF9 and BMP15 appear to be key regulators of follicular development and ovulation in sheep and humans, and immunisation experiments have shown that this is true for cattle also (Juengel et al., 2009). The roles of GDF9 and BMP15 in cattle appear to be similar to those seen in other low ovulation phenotype species such as sheep and humans, rather than in mice which have a high ovulation rate phenotype (Juengel et al., 2009).

Thus, the oocyte via the paracrine actions of BMP15 and/or GDF9 influences granulosa cell function and in turn, the immediately adjacent granulosa/cumulus cells regulate oocyte 
development. In this way, the oocyte actively regulates its own microenvironment (Gilchrist et al., 2004).

\section{4 (iii) Oestrous cycle and ovulation}

The oestrous cycle refers to a cyclical pattern of ovarian activity which enables the reproductive system to synchronise the timing of ovulation and mating to maximise the opportunity for establishing a successful pregnancy. The onset of the oestrous cycle activity begins at puberty. In cattle, puberty occurs around 6 to 12 months of age and generally at a live weight of 200 to $250 \mathrm{~kg}$. In cattle, a normal oestrous cycle is 18 to 24 days in duration and consists of two phases known as the luteal and follicular phases. The luteal phase is the period following ovulation. After ovulation, the corpus luteum (CL) is formed from the ovulated follicle and in the absence of pregnancy, the duration of the CL and corresponding luteal phase is 14 to 18 days. In the absence of a pregnancy, the luteal phase is followed by a follicular phase of 4 to 6 days in duration. During the follicular phase, at least one follicle $>4$ $\mathrm{mm}$ in diameter develops into a dominant oestrogen-secreting follicle that will eventually reach a diameter of 10-20 mm at ovulation. Thus, although the growth of follicles up to $\sim 4$ $\mathrm{mm}$ occurs throughout the life of the cow, it is the follicular phase in which the endocrine signalling from the pituitary gland is coordinated by the ovary to promote the maturation of at least one antral follicle through to ovulation. The presumptive preovulatory follicle can be identified as the follicle that acquires LH receptors on its granulosa cells. In cattle, this normally occurs in the presumptive preovulatory follicles $\sim 8 \mathrm{~mm}$ in diameter (Driancourt, 2001).

Dairy cows generally have 'two but sometimes three waves' of follicular growth, during

either the luteal or follicular phase due to the emergence of a hierarchical cohort of follicles $>4 \mathrm{~mm}$ in diameter (Adams, 1999). During such a wave, a dominant follicle $>8 \mathrm{~mm}$ diameter emerges and either undergoes atresia or goes on to ovulate. However, only the 
dominant follicle from the wave leading to a follicular phase undergoes the final maturational processes and ovulates.

The oestrous cycle is regulated by hormones from the hypothalamus (gonadotrophin releasing hormone $\mathrm{GnRH}$, kisspeptin), anterior pituitary gland (follicle stimulating hormone, FSH and luteinising hormone, LH), ovaries (progesterone, oestradiol and inhibin) and the uterus (prostaglandin F2 $\alpha$ ). A system of positive and negative feedback events via endocrine signalling governs the oestrous cycle in cattle - (Figure 1.5). GnRH acts on the anterior pituitary gland which, in turn, regulates the secretion of the gonadotrophins (FSH and LH). The secretion of ovarian steroids, mainly progesterone and oestradiol, influences the secretions of FSH and LH. As part of the negative feedback system, oestradiol together with inhibin from the dominant follicle suppress FSH, thereby ensuring that the subservient follicles without LH receptors on granulosa cells undergo atresia. Inhibin is a peptide secreted by the granulosa cells and one of its major actions is to suppress FSH release. During the luteal phase, progesterone levels are high and this has a negative effect on the GnRH receptors in the pituitary gland thus down regulating its responsiveness and decreasing the frequency of LH pulses (Kanitz et al., 2001; Nett et al., 2002; Drummond, 2006). This means that while progesterone levels are high, pulsatile LH frequency is low. If pregnancy does not eventuate, the CL regresses as a consequence of increasing uterine prostaglandin F2 $\alpha$ secretion and the CL-derived progesterone levels decrease (luteolysis), thereby leading to a new follicular phase. In cattle, progesterone levels start to decrease after day 15 of the oestrous cycle. The resulting follicular phase is then associated with the emergence of a presumptive preovulatory (dominant) follicle. Increasing oestradiol synthesis and secretion by the dominant follicle is initiated by an increasing frequency of low amplitude LH pulses. The increased oestradiol allows a display of behavioural oestrus which is when the cow may be mated. At this time, the increasing plasma concentrations of oestradiol primes the pituitary 
gland leading to a surge of LH release, see Figure 1.5 (Kanitz et al., 2001) and ovulation (Ganong, 1995; Nett et al., 2002; Hunter et al., 2004).

Ovulation occurs $\sim 10-14 \mathrm{~h}$ after oestrus and marks the beginning of the luteal phase. The haemorrhagic thecal and granulosa cell remnants of the ovulated follicle remodel to form the $\mathrm{CL}$ and become the major source of ovarian-derived progesterone during the luteal phase. During the early luteal phase, the progesterone levels rise, reaching peak values during the mid-luteal phase. Progesterone is necessary for the establishment and maintenance of pregnancy. If pregnancy does not occur then the CL regresses and a new follicular phase begins. Pulses of prostaglandin F2 $\alpha$ from the uterus are the signal which induces luteolysis and the demise of the CL and thus switching from the luteal phase back to the follicular phase so that the cycle renews again (Forde et al., 2010).

It has been calculated that the average duration of oestrus for dairy cows - when a cow will stand to be mated - is $8.1 \mathrm{~h}$, but there is evidence that as milk production increases, the duration of oestrus decreases. For example, a cow yielding $25 \mathrm{~kg}$ milk will stand for $14.7 \mathrm{~h}$ whereas a cow yielding 55kg milk may stand for only $2.8 \mathrm{~h}$ (Forde et al., 2010). The standing events, i.e. the number of times a cow is mated were also lower for high producing cows -6.3 v 8.8 times. These differences may be a result of the oestradiol concentrations at oestrus. The decreased duration and intensity of oestrus that high producing cows exhibit, are reported to negatively impact on a positive pregnancy outcome (Lopez et al., 2004; Forde et al., 2010; Walsh et al., 2011). 


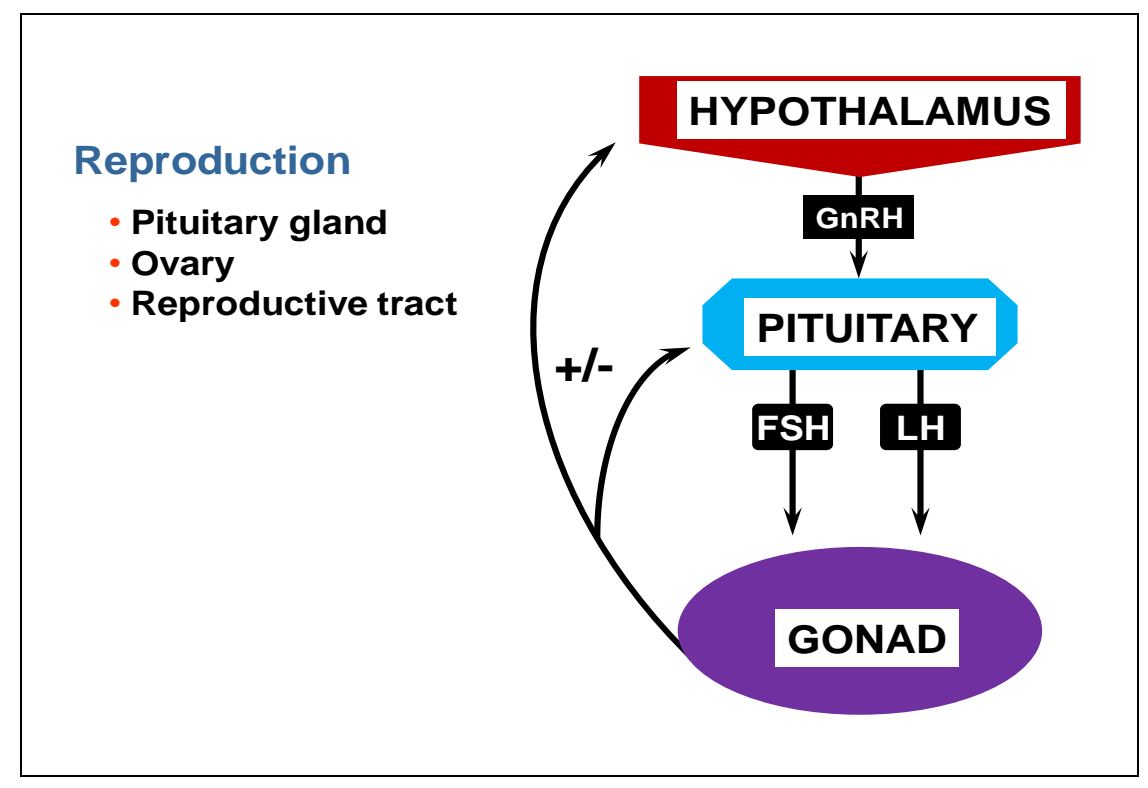

Figure 1.5: Hypothalamic- pituitary-gonadal axis.

The hypothalamus releases GnRH pulses which cause the pituitary to release LH and FSH pulses. These in turn act on the ovary causing the release of oestradiol, inhibin and progesterone. These ovarian secretions have either a positive or negative effect on the endocrine system in the hypothalamus and pituitary gland. Oestradiol together with inhibin from the dominant follicle suppress FSH. This ensures that the subservient follicles without LH receptors on the granulosa cells undergo atresia.

As a follicle develops it becomes more responsive to gonadotrophins and around $>4 \mathrm{~mm}$ in diameter, it becomes critically dependent upon gonadotrophins (Scaramuzzi et al., 2011). The primary hormones that control folliculogenesis are FSH and LH, but the metabolic hormones e.g. IGF-1, growth hormone and paracrine factors all interact to facilitate this process (Hunter et al., 2004). The endocrine system influences the growth of the follicle which in turn relies on the inter-relationship between the follicular cells and the oocyte. The coordination between the follicular cells (e.g. granulosa and cumulus) and the oocyte involves a communication system involving gap junctions. 


\subsection{Gap junctions}

Gap junctions play an important role in providing a direct pathway for metabolites to transfer from one cell to another (Sosinsky \& Nicholson, 2005). Gap junctions are clusters of intercellular channels which are formed by the end to end docking of connexons which are the fundamental units of the gap junction. A connexon is a hexamer of protein subunits called connexins (Figure 1.6). The gap junction is the result of the alignment of connexons from one cell to another to create hydrophilic channels that bridge the opposing membranes of neighbouring cells, Figure 1.6, (Kidder \& Mhawi, 2002; Segretain \& Falk, 2004; Goodenough \& Paul, 2009). They are the only known cellular structures that allow a direct transfer of signalling molecules from one cell to another.

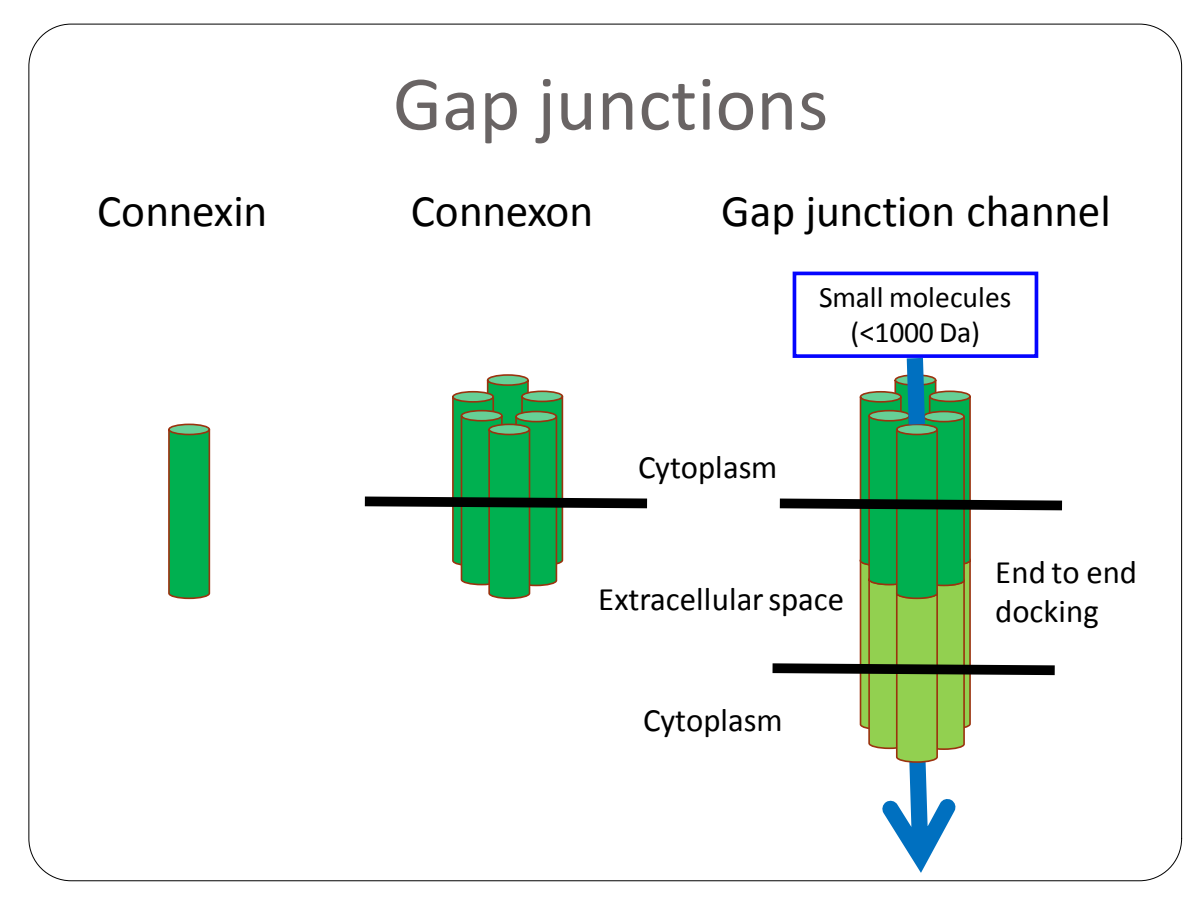

Figure 1.6: Structure of a Gap Junction (modified from Goodenough \& Paul, 2009).

Gap junctions are dynamic systems because connexons are able to open and close. Established stimuli for the opening and closing are intracellular calcium and low intracellular pH. Gap junctions allow inorganic ions, second messengers and small metabolites of less than 1000 Daltons to pass from cell to cell (Gittens et al., 2005). An important function is to 
mediate metabolic cooperation between neighbouring cells. Small water-soluble molecules can diffuse through gap junction channels and it has been shown that there is some selective permeability thus ensuring that the correct molecules pass through (Cruciani \& Mikalsen, 2005). The exchange of small molecules between follicular somatic cells and oocytes via gap junctions has been reported for ATP, sodium, chloride, calcium ions and cAMP (Sasseville et al., 2009b). There is evidence that the secretion of oocyte-derived growth factors such as GDF9 depend on gap junction coupling within the responding granulosa cell population (Kidder \& Vanderhyden, 2010). There is growing evidence for numerous interactions between paracrine signalling and gap junctional communication in developing follicles (Gilchrist et al., 2008; Scaramuzzi et al., 2011). It has, for example, been suggested that the granulosa cells the greatest distance from the oocyte maintain a proliferation rate equal to the cells that are adjacent to the oocyte through a gap-junction, as well as GDF9 mediated signalling (Gittens et al., 2005).

There are many connexin subtypes but two that are essential for ovarian follicular development are $\mathrm{Cx} 37$ and $\mathrm{Cx} 43$. The major connexin that builds the gap junctions between the oocyte and the somatic cells is Cx37, whereas the channels between the granulosa cells and oocyte or granulosa cell to granulosa cell are formed by $\mathrm{Cx} 43$ (Gershon et al., 2008). In the bovine follicle, $\mathrm{Cx} 43$ is present only in the granulosa cells (Johnson et al., 1999). Healthy developing antral follicles show an increase in concentrations of Cx43 (Gershon et al., 2008).

In the mouse, follicles lacking $\mathrm{Cx} 43$ arrest in the early preantral stage and oocytes are incompetent (Kidder \& Mhawi, 2002). In Cx37-KO mice, normal folliculogenesis takes place until the late preantral stage. However, mature follicles never develop and ovulation cannot be induced (Kidder \& Mhawi, 2002). This indicates that connexins in developing follicles are critical for follicular growth as they are essential for maintaining and coordinating both oocyte and somatic cell functions (Kidder \& Mhawi, 2002). 
A major role of the gap junctions is the transfer of cyclic adenosine 3, 5-monophosphate (cAMP) from the somatic cells to the oocyte which, in turn, maintains fully grown oocytes in meiotic arrest. If there is an uncoupling between the oocyte and the granulosa cell, meiosis is reinstated (Gershon et al., 2008).

\subsection{Meiosis and oocyte maturation}

Meiosis is the process of nuclear division in diploid germ cells, in which the chromosome complement is halved. This is in preparation for combining with a haploid cell of the opposite sex to create a genetically new diploid individual. In the female, the meiotic process is completed over a relatively long period of time. In mammals such as humans and cattle, meiosis is initiated during follicular formation in foetal life. The oogonia enter meiosis but become arrested at the diplotene stage of the first prophase. In rodents this occurs around birth when follicles are first formed (Mehlmann, 2005).

Both follicular and oocyte growth occurs while the oocyte remains arrested at prophase I (Figure 1.7). Meiosis then resumes following the preovulatory surge of LH during the follicular phase of an ovarian cycle. For bovine oocytes, they need to develop to at least 110 $\mu \mathrm{m}$ in diameter to be considered competent to resume meiosis and to complete their nuclear maturation (Mayes \& Sirard, 2002).

With the resumption of meiosis, the fully grown oocyte progresses to metaphase of the second meiotic division where it becomes arrested again. This process includes nuclear and cytoplasmic changes, that allow the egg to be fertilised, and is known as oocyte maturation. 


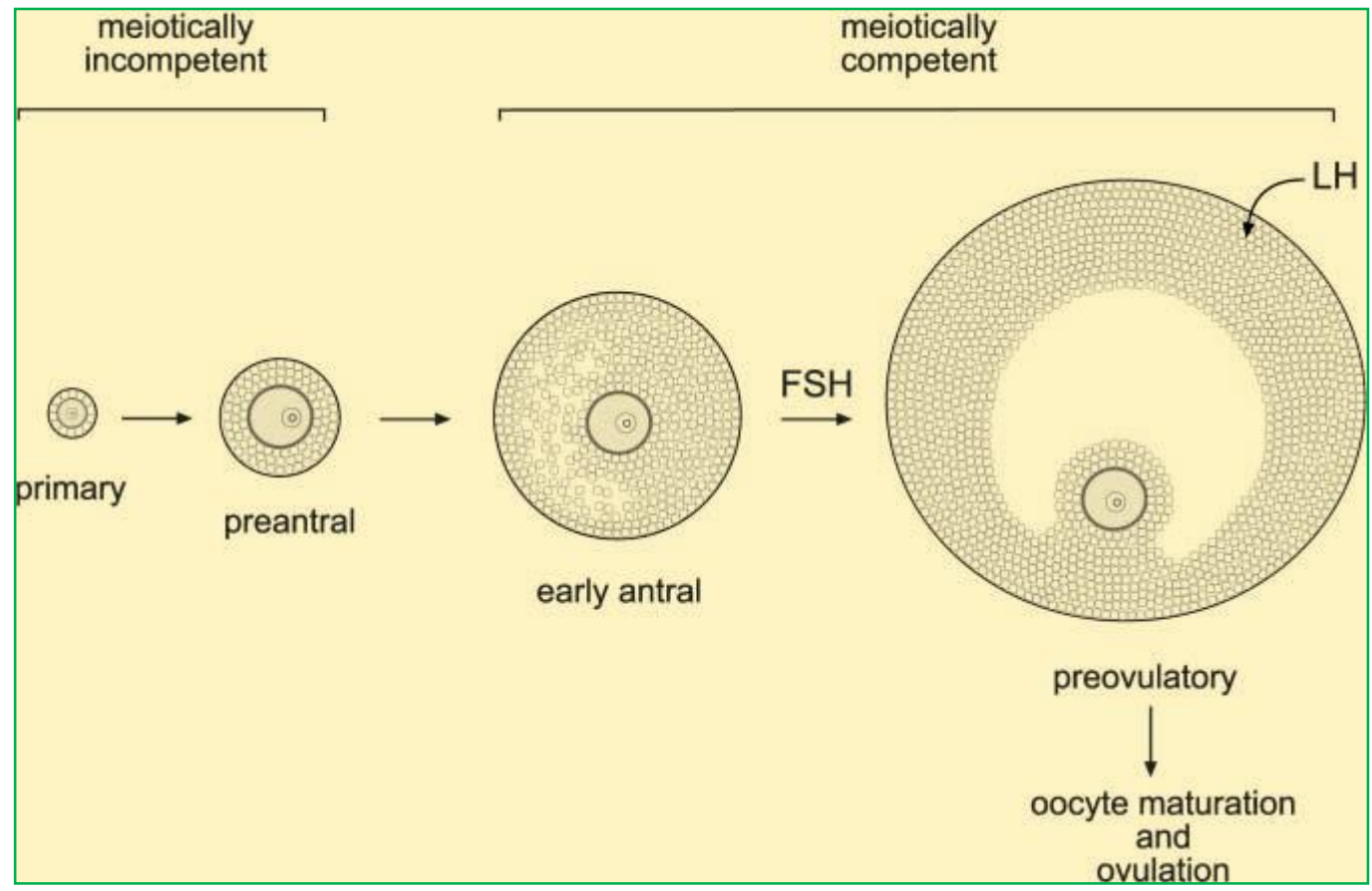

Figure 1.7: Stages of follicular growth and timing of acquisition of meiotic competence in a primate model. (modified from Mehlmann, 2005).

When meiosis resumes from the prophase stage in response to the LH surge, the first structural change observed is germinal vesicle breakdown (GVBD). The chromosomes condense and the homologous chromosomes separate and a spindle forms.

In all mammalian species that have been studied, once oocytes which have reached full size are removed from follicles that begin to form antral spaces, they undergo spontaneous GVBD (Figure 1.8). Thus, it is the architectural integrity of the follicle or the follicular environment that inhibits oocyte GVBD and the intercellular communications between the mural granulosa cells, cumulus cells and the oocyte (Edry et al., 2006). A critical factor is that the gap junctions mediate the transfer of cAMP from the granulosa/cumulus cells to the oocyte. This transfer is critical for maintaining the oocyte in meiotic arrest but with the disruption of gap junctions, the cAMP content in the oocyte declines rapidly thereby releasing the oocyte from meiotic arrest (Conti et al., 2002). 
If the inhibitory restraint is removed, the gap junction connections are disrupted, germinal vesicle breakdown (GVBD) occurs and meiosis resumes. In vivo, the preovulatory surge of $\mathrm{LH}$ is the initiating cause of the resumption of meiosis. However, LH receptors in the presumptive preovulatory follicles are located on the mural granulosa cell which indicates that the mechanism is indirect. The precise action of LH in triggering the resumption of meiosis is not fully understood but it is known that LH causes a breakdown in gap junctions which in turn results in reduction in transfer of meiosis-arresting substances from granulosa/cumulus cells and /or a fall in cAMP levels in oocytes (Mehlmann, 2005).

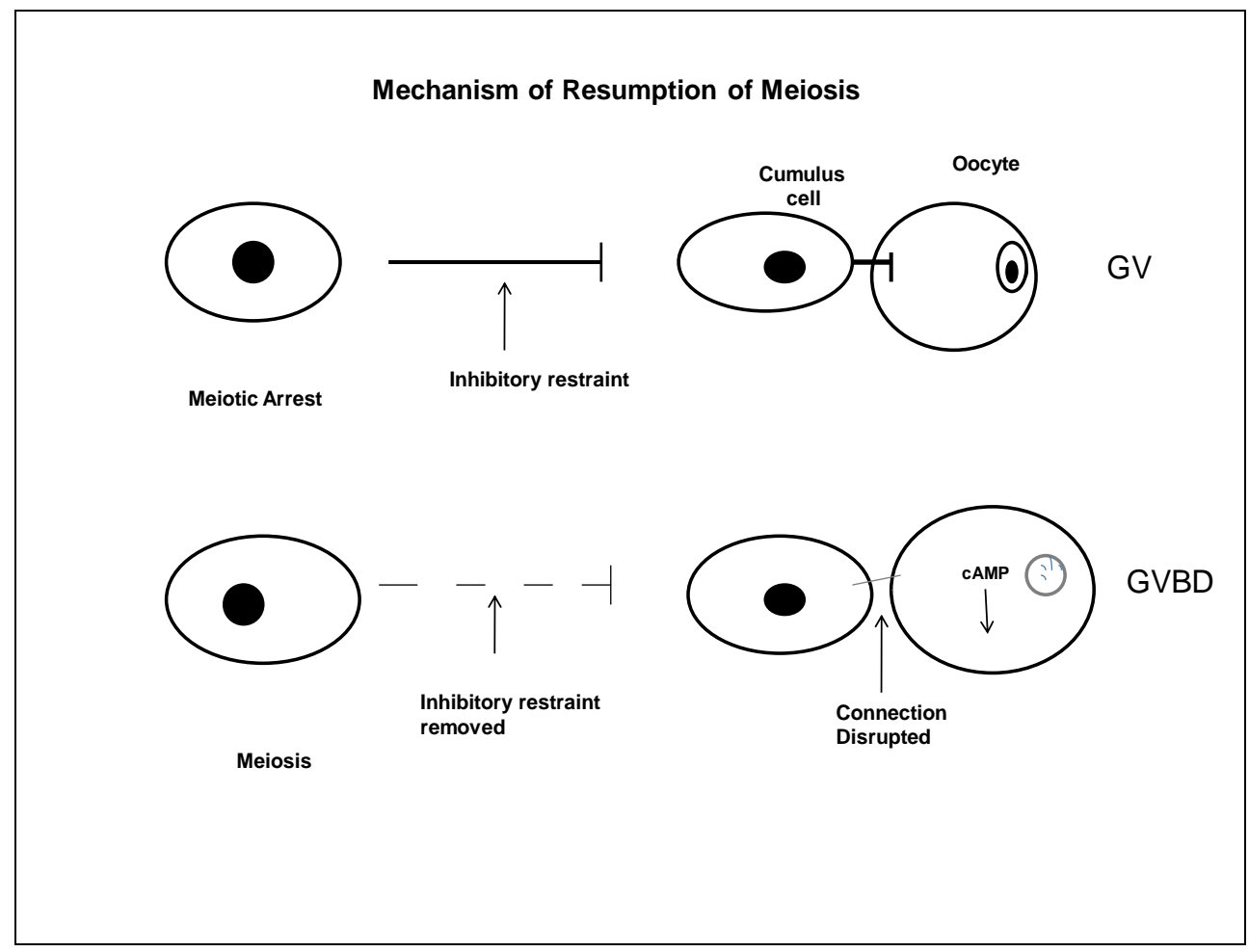

Figure 1.8: Possible mechanisms involved in the resumption of meiosis (modified from (Conti et al., 2002).

Irrespective of the mechanisms involved, loss of gap junctional communication between granulosa and cumulus cells is associated with the resumption of meiosis in the oocyte (Edry et al., 2006). 


\subsection{Cyclic adenosine monophosphate (cAMP)}

Cyclic AMP which is derived from adenosine triphosphate is a second messenger important in many biological processes (Figure 1.9). It is inactivated by metabolism to AMP by the enzyme phosphodiesterase.

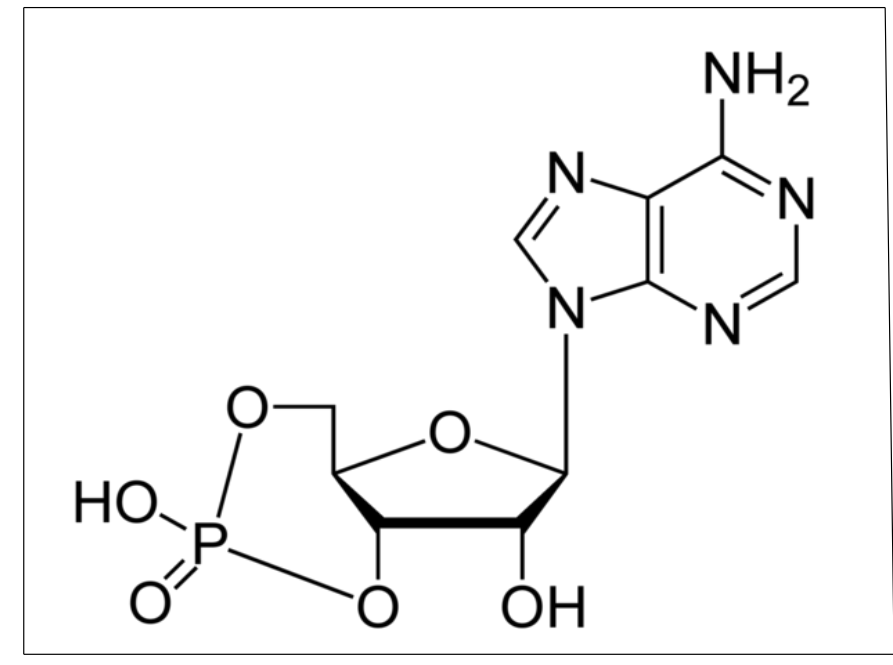

\section{Figure 1.9: Chemical structure of cAMP}

Cyclic AMP has a key role in the regulation of gene expression and somatic cell function and, as mentioned above, an important role in regulating meiotic maturation in oocytes. Cyclic AMP interacts with and regulates other proteins such as protein kinase A (PKA). To achieve this, cAMP activates the type I and II PKA pathways which are involved in the timing of oocyte meiotic maturation. The evidence suggests that the cumulus cells are the major contributors to the total cAMP content of the oocyte allowing the high levels required to be maintained (Dekel, 2005). Cyclic AMP is degraded by enzymes called phosphodiesterases (PDEs) and the use of PDE inhibitors has allowed the roles of PDEs in regulating meiotic arrest to be investigated (Thomas et al., 2002). 


\section{8(i) Phosphodiesterases}

Phosphodiesterases act on cAMP by hydrolysing the bond between the phosphate and the 3hydroxyl group of the ribose sugar, (Figure 1.9), thus inactivating this signalling molecule.

There are two classes of PDEs: class I and II. They are present either in the cytoplasm or bound to intracellular organelles or membranes. PDEs are composed of a catalytic domain that is connected to both the amino and carboxyl terminal domains and this is conserved across families within this class (Mayes \& Sirard, 2002). To date, eleven different families of PDEs have been identified most of which contain more than one gene product. Each PDE has a specific inhibitor and substrate specificity. Some inhibitors act on more than one PDE family (Sasseville et al., 2009a).

\section{8 (ii) Phosphodiesterase inhibitors}

The follicular environment is very important for the attainment of developmental competence in oocytes. As mentioned previously, when a COC is removed from the follicle and placed in a different environment, the oocyte will often undergo spontaneous GVBD and resume meiosis. PDE inhibitors can assist in preventing GVBD and by maintaining high intra-oocyte levels of cAMP to prevent meiotic resumption (Tsafriri et al., 1996; Thomas et al., 2004a).

The PDE inhibitor, 3-isobutyl-1-methylxanthine (IBMX) has been used as a universal PDE inhibitor and appears to act effectively in many cell-types except cumulus cells (Sasseville et al., 2009a). Milrinone, a PDE3 inhibitor, acts on the oocyte causing a delay in oocyte meiotic maturation. It inhibits the PDE3 enzyme thereby preventing intracellular cAMP degradation in the oocyte (Mayes \& Sirard, 2002). Rolipram is an inhibitor of the PDE4 enzyme which is the predominant form of phosphodiesterase in the granulosa/cumulus cells and has been used to promote oocyte maturation (Mayes \& Sirard, 2002). Dipyridamole is a PDE inhibitor that acts on PDE7, 8, 10 and 11 isoforms. PDE8 and PDE10 are found in the cumulus cells of 
cattle. Thus, inhibition of PDE8 and 10 activities can maintain high cAMP COC levels and therefore delay the onset of oocyte maturation (Sasseville et al., 2009a). This suggests that both PDE4 and PDE8 are important as granulosa cell PDEs in cattle and not PDE4 alone as had previously been thought. IBMX and milrinone have proven to be only partially effective at preventing bovine oocyte meiotic resumption but why this should be is unknown (Sasseville et al., 2009a).

\subsection{Aims of study}

There are two overall aims of this study. The first was to develop, validate and extend the utility of a bovine gap junction assay to assess the behaviour of bovine COCs incubated under different in vitro conditions. The assay was first validated using the commercially available media M199. The COCs recovered for this study were obtained from ovaries collected at a local slaughter house and gap junction activity was assessed by measuring the transfer of a fluorescent dye Calcein-acetoxymethyl (Calcein-AM) from the cumulus cells to the oocyte. The application of Calcein- AM for the measurement of the gap junction activity in bovine COCs was originally developed by Thomas et al., 2004a.

The second aim was to evaluate bovine COC gap junction activity in microenvironments typical of those experienced in lactating and non-lactating dairy cows. The media compositions and thus microenvironments to be tested were based on the follicular fluid concentrations of amino acids, cholesterol and fatty acids identified in lactating and nonlactating dairy cows under typical NZ pastoral conditions. The outcomes from these studies were compared with those for COCs cultured in M199. 


\section{Materials and Methods}

\subsection{Media composition}

The stock media used for collecting, washing and incubating COC and related stock solutions during the validation of the assay are indicated below in 2.1a, b, c and 2.2.

\section{1a. Collection media for COCs (HTCM)}

Leibovitz L-15 media, (Invitrogen- Auckland NZ; cat\# 11415-064) without phenol red was supplemented with $0.1 \%$ fatty acid free (FAF) BSA (Sigma-Aldrich-Auckland NZ; cat\# A8806), 100IU Penstrep (10,000 units penicillin and 10,000 $\mu \mathrm{g}$ streptomycin) (Invitrogen cat\#15140122) and $15 \mathrm{mM}$ Hepes buffer (Sigma-Aldrich; cat\# H4034), was used as the collection media.

\section{1b. Wash media (BTCM)}

The wash media consisted of phenol red free M199 (Invitrogen; cat\# 11043) supplemented with 100IU Penstrep, 0.23M sodium pyruvate (Sigma-Aldrich; cat\# P3662) and 0.1\% FAF BSA.

\section{1c. Incubation media (CTCM)}

The incubation media consisted of BTCM without the FAF BSA and with $0.3 \mathrm{mg} / \mathrm{ml}$ polyvinyl alcohol PVA (Sigma-Aldrich; cat\# P8136).

\subsection{Stock solutions}

All reagents were obtained from Sigma-Aldrich, New Zealand Ltd, Auckland, NZ.

The phosphodiesterase inhibitor milrinone (cat\# M4659) was dissolved in dimethyl sulphoxide ( DMSO; cat\# D8418) and made up in phenol red free M199 to a concentration of $1 \mathrm{mM}$ and stored in aliquots at $-20^{\circ} \mathrm{C}$. 
Dipyridamol (cat\# D9766) was dissolved in DMSO to a concentration of $1 \mathrm{mM}$ and stored at $4^{0} \mathrm{C}$

3-Isobutyl-1-methylxanthine (IBMX; cat\# I5879) was dissolved in DMSO to a concentration of $1 \mathrm{mM}$ and stored at $-20^{\circ} \mathrm{C}$.

The following reagents namely Tween 80 (cat\# P4780), cholesterol (cat\# C3045), oleic acid (cat\# O1383), stearic acid (cat\# S4751), palmitic acid (cat\# P5585), and linoleic acid (cat\# L1376) were each dissolved in ethanol and stored at $-20^{\circ} \mathrm{C}$.

Forskolin (cat\# F6886) was first dissolved in ethanol and then diluted in M199 to make a 1 mM solution (1 part ethanol: 9 parts M199) and stored at $4^{\circ} \mathrm{C}$.

\subsection{Microscopy}

For identification and isolation of cumulus-oocyte-complexes (COC), a Leica MZ 95 stereo microscope was used. For measures of the intensity of fluorescence within denuded oocytes, a Leica inverted microscope (CTR4000) fitted with a CRAIC technology fluorescence detection system was used (Leica microsysytems, Germany; Figure2.1). The fluorescent readings were captured using the CRAIC technology software. The settings on the detection system were $50 \mathrm{msec}$ over the wavelengths $300-700 \mathrm{~nm}$. 


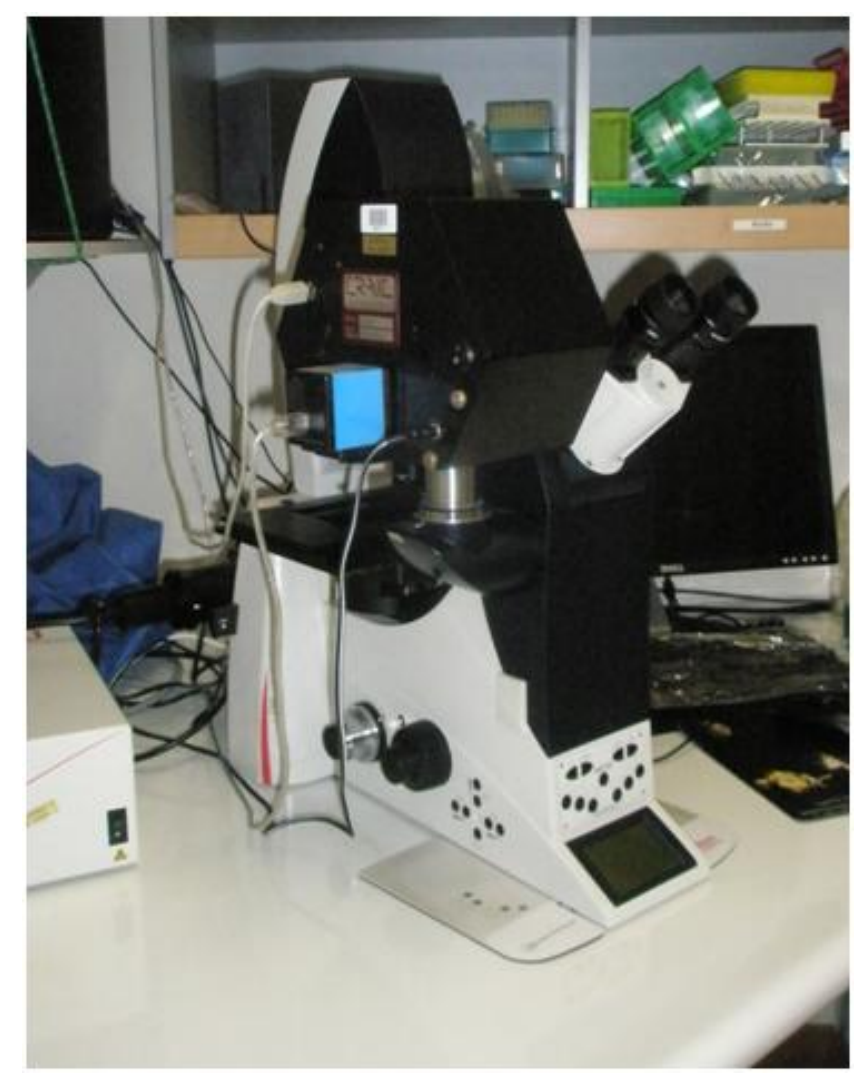

Fig 2.1: Leica inverted microscope with CRAIC fluorescent detection system on left-hand side of the eye pieces.

\subsection{Ovaries}

The bovine ovaries (Figure 2.2) were obtained from the Taylor Preston abattoir in Ngauranga Wellington, NZ. The ovaries were collected into a plastic bag and transported to the School of Biological Sciences at Victoria University Wellington in a polystyrene box. The time from killing to arrival at the University was between 1 and $2 \mathrm{~h}$. Often the ovaries were still warm when processed. 


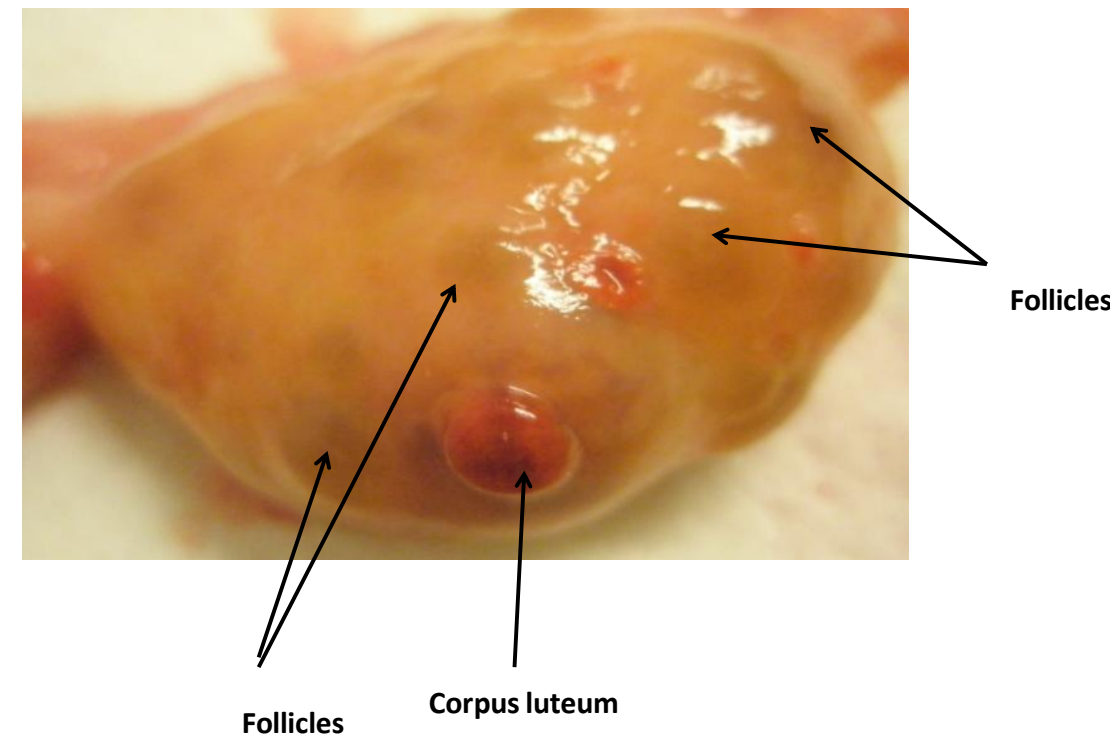

Figure 2.2: A bovine ovary showing follicles and a corpus luteum.

\subsection{Isolation of Cumulus -Oocyte - Complexes- (COC)}

Follicles were aspirated using a Venturi pump (Global Science \&Technology Ltd, Auckland NZ) (Figure 2.3). The follicular fluid and oocytes were aspirated into a Quickfit tube VT24/8

(Global Science \& Technology Ltd) containing a small amount of collection media (HTCM).

The Venturi pump was operated by water so that the vacuum pressure was kept low.

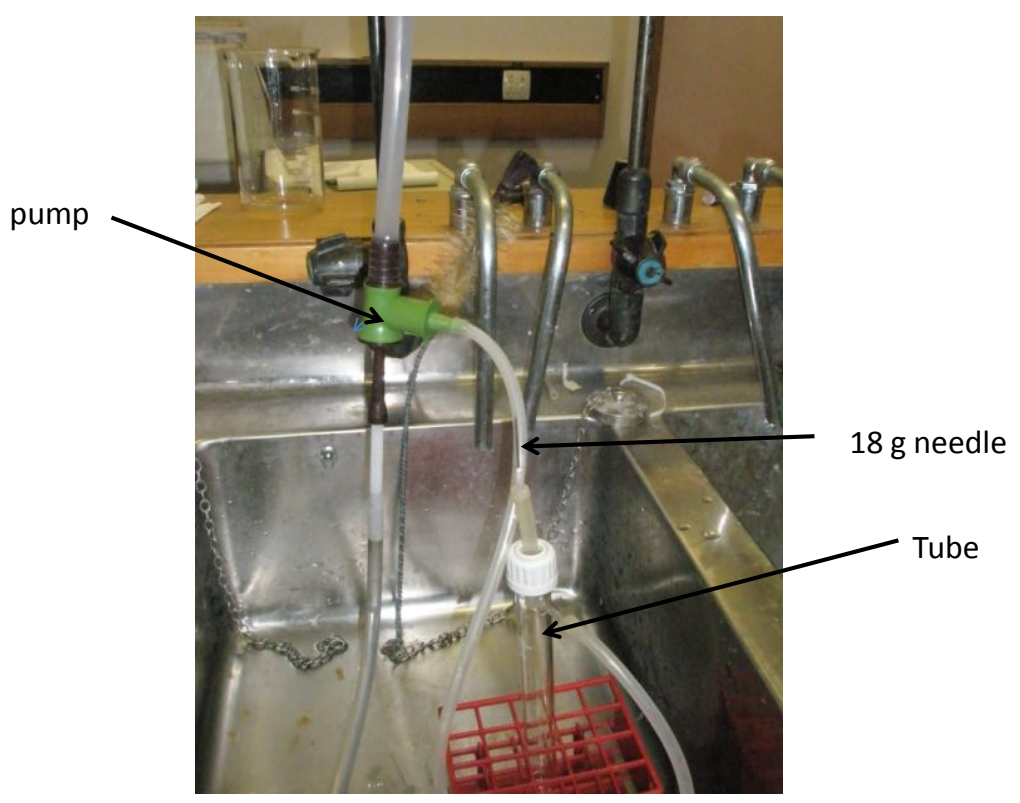

Figure 2.3: The Venturi vacuum pump system. 
Only follicles between 2 and $8 \mathrm{~mm}$ diameter were aspirated: these were follicles considered not to be gonadotrophin-dependent (Scaramuzzi et al., 2011). The larger diameter follicles were not considered for aspiration as they were more likely to be atretic with the likelihood of the follicular fluid clotting during recovery of the COC. The follicles were punctured and the contents aspirated using an 18 gauge hypodermic needle fitted to tubing directed to the collection tube which, in turn, was connected to the vacuum pump (Figure 2.3). The follicular fluid was transferred to a $15 \mathrm{ml}$ polystyrene conical centrifuge tube (Interlab, Wellington, NZ; cat\# KJ324) and allowed to sit for up to $15 \mathrm{~min}$ to allow the cells to settle. The supernatant was then decanted into another tube and the remaining debris and up to $2 \mathrm{ml}$ of liquid was transferred into a $3.5 \mathrm{~cm}$ Petri dish (Interlab Wellington, NZ; cat \#TCD-000-035). If more than one conical tube was used, the debris and liquid were pooled into a single petri dish. The dish was then viewed under the microscope and the COCs selected and transferred to another petri dish containing $2 \mathrm{ml}$ wash media (BTCM). The original supernatant that was left to stand to allow any residual debris to settle was then added to the collection dish and screened for additional COC. If the volume in the petri dish was too great, the excess fluid was carefully removed using a pipette until the COCs were clearly visualised.

Only COC with at least three complete layers of cumulus cells around the oocyte were selected (Figure 2.4). COC showing evidence of cumulus cell expansion were excluded (Figure 2.5). The objective was to collect $12 \mathrm{COC}$ for every incubation well with 10 COC/well being the minimum acceptable number. All COC were added in a minimum volume of liquid and the preferred transfer method was to use a biopet set to $2 \mu 1$. Thus, the COC in the BTCM were initially transferred individually into a petri dish containing $2 \mathrm{ml}$ BTCM and then transferred to another petri dish containing $2 \mathrm{ml} \mathrm{TCM}$ to ensure that all follicular fluid had been removed. Thereafter the COC were transferred to a 48 well 
polystyrene, non- treated, flat bottom tissue culture plate (10-12 COC per well; Interlab \#TCP 00048). Each well contained $200 \mu \mathrm{l}$ of BTCM.
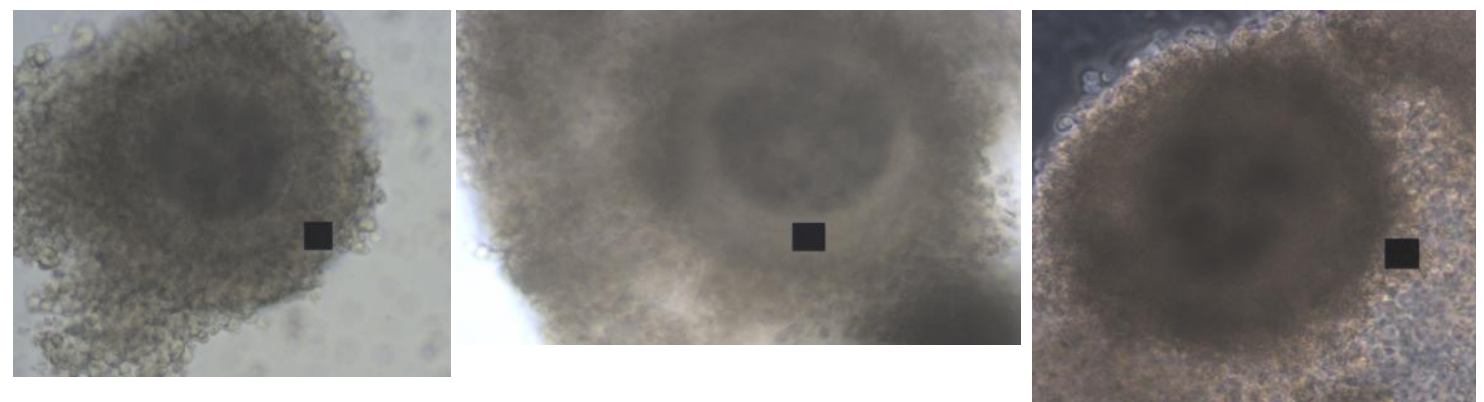

Figure 2.4: COC suitable for selection for gap junction assay.
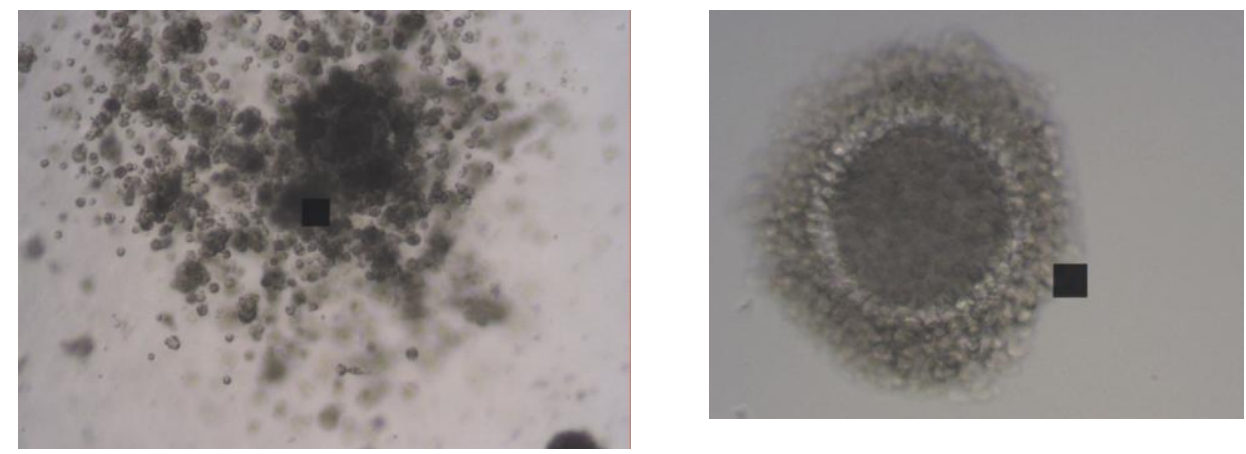

Figure 2.5: COC showing cumulus cell expansion: these were considered unsuitable for the gap junction assay.

\section{6(i) Gap Junction Assay}

The bovine gap junction assay was based on that previously reported by Thomas et al., 2004a. In order to assess the level of gap junction communication between the oocyte and the cumulus cells and thus have some measure of oocyte viability, the transfer of a fluorescent dye from the cumulus cells to the oocyte was measured. To achieve this, the COC were incubated in the presence of the acetoxymethyl (AM) ester derivative of the fluorescent indicator calcein. (Calcein AM; MW 994.87, Invitrogen, cat\# C3100MP). Calcein-AM is highly lipophilic and can rapidly permeate the cell. In live cells, Calcein-AM is converted from a non-fluorescent state to a green-fluorescent state after acetoxymethyl ester hydrolysis 
by intracellular esterases (Thomas et al., 2004a). This water, but not lipid, soluble form is unable to leak across the plasma membrane but is able to move between cells connected by gap junctions. The transfer is considered to be by passive diffusion. An increase in intensity of the fluorescence in the oocyte over time is indicative of the extent of gap junction connections between the oocyte and cumulus cells.

Individual vials of Calcein-AM $(50 \mu \mathrm{g})$ were reconstituted with DMSO to a concentration of $1 \mathrm{mM}$ and stored at $-20^{\circ} \mathrm{C}$. This stock was enough for three assays over 3 days. For the assay, the 10-12 COCs in the 48 well plate containing $200 \mu \mathrm{BTCM}$ were transferred to another well and incubated in $10 \mu \mathrm{M}$ Calcein-AM in $200 \mu \mathrm{l}$ incubation media (CTCM) containing $100 \mu \mathrm{M}$ milrinone for $15 \mathrm{~min}$ in a $37^{\circ} \mathrm{C}$ incubator gassed with $5 \% \mathrm{CO}_{2}$ in air and held at $96 \%$ humidity. The COC were then transferred to Calcein-AM free CTCM wells that included any of the treatments being tested along with $100 \mu \mathrm{M}$ milrinone and returned to the incubator for the appropriate incubation time. Following this incubation, the COC were transferred to another well and washed twice in $200 \mu$ l Calcein-AM free CTCM, then denuded by repeated pipetting up and down with a biopet until all the cumulus cells had been removed. Considerable care was needed at this step to avoid damage to the oocytes. The now intact and denuded oocytes were transferred to other wells containing $200 \mu \mathrm{l}$ CTCM and the fluorescence in the individual oocytes measured using the CRAIC fluorescence system.

Following incubation with Calcein-AM and denuding, the oocytes were measured for fluorescent intensity. Figure 2.6 shows the type of fluorescence seen in the gap junction assay with various types of oocytes. A decision was taken that all readings below 20 were due to background noise so these were not taken into consideration when averaging results. Oocytes were first visualised under the microscope using the 10x objective and a 10x eyepiece and bright field illumination. The fluorescent system was then turned on and the fluorescent 
intensity measured. All measurements were made between 549 and $550 \mathrm{~nm}$ wavelength and the integration time was 50 msec.

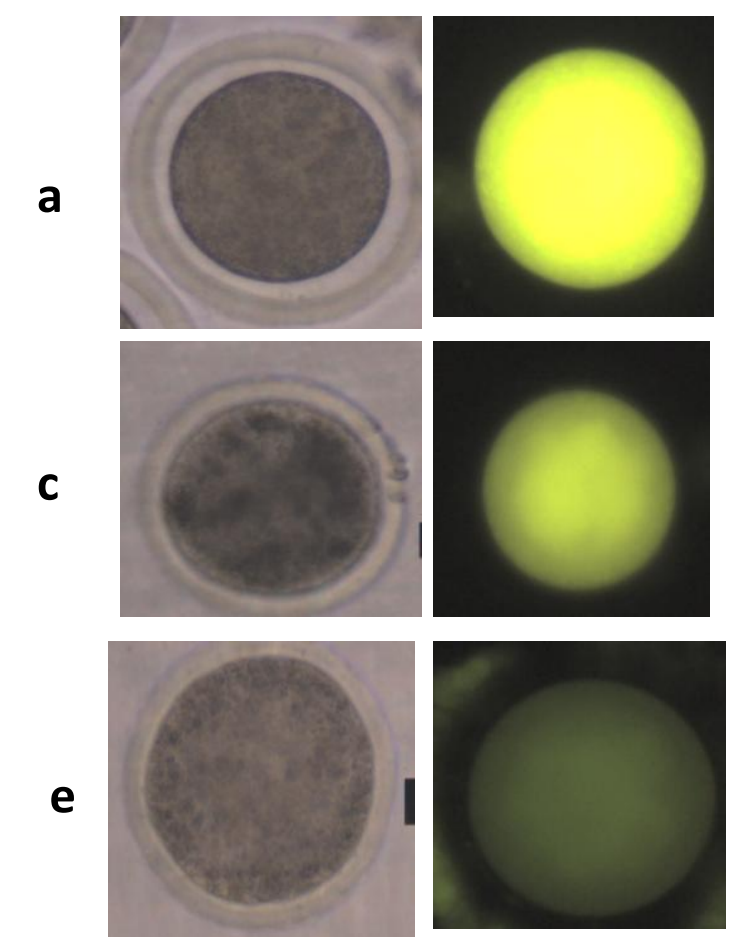

Figure 2.6: Comparison of oocyte type under bright field and fluorescent intensity.

A good quality denuded oocyte is shown in (a), and in (b) the same oocyte is shown under fluorescence; (c) an oocyte where the cytoplasm is not fully homogeneous and (d) is the same oocyte under fluorescence; (e) an oocyte that has a very heterogeneous cytoplasm although as can be seen in (f), there is still some fluorescence although at diminished intensity.

\section{6(ii) Gap junction assay: Effect of time}

In a 48 well plate, five wells of COC (10-12 per well)- containing $200 \mu \mathrm{l}$ milrinone and 10 $\mu \mathrm{M}$ Calcein-AM were prepared in order to examine calcein dye transfer for $0,60,120,240$, $300 \mathrm{~min}$ and $18.5 \mathrm{~h}$. The plate was incubated for $15 \mathrm{~min}$ in a $37^{\circ} \mathrm{C}, 5 \% \mathrm{CO} 2$ in air incubator at 96\% humidity. Thereafter, the COC were transferred into new wells containing $200 \mu 1$ CTCM with100 $\mu \mathrm{M}$ milrinone devoid of Calcein-AM. The COC were then incubated for their requisite times (i.e. $0,60,120,240,300 \mathrm{~min}$ and $18.5 \mathrm{~h}$ ). The $\mathrm{COC}$ at $0 \mathrm{~min}$ were 
immediately transferred to a well in another plate containing $200 \mu \mathrm{l}$ CTCM and washed twice by successively transferring to new wells with fresh media. After washing, the COC were denuded and transferred to a new well containing $200 \mu \mathrm{l} \mathrm{CTCM}$ and the fluorescent intensity read using the CRAIC fluorescent system. Each experiment was replicated three times.

\section{6(iii) Gap junction assay: Effect of various PDE inhibitors}

Different phosphodiesterase inhibitors are known to act on specific forms of phosphodiesterases (PDE) that affect cAMP and cGMP degradation in a species-specific manner (Tsafriri et al., 1996; Mayes \& Sirard, 2002; Thomas et al., 2002). In this study, the objective was to examine the effects of a range of PDE inhibitors, namely milrinone (a PDE3 selective inhibitor), IBMX-3-isobutyl-1-methylxanthine (a non selective PDE inhibitor), and dipyridamol (a PDE8 selective inhibitor) with the view of selecting the most appropriate forms to maximise calcein dye transfer to the oocyte.

In this study, the COC (10 -12 per well) were added to wells each containing 200 ug CTCM and $10 \mu \mathrm{M}$ Calcein-AM and either $100 \mu \mathrm{M}$ milrinone, $200 \mu \mathrm{M}$ IBMX, or $10 \mu \mathrm{M}$ dipyridamole. The plate was incubated for $15 \mathrm{~min}$ and thereafter the COC were transferred to new wells containing CTCM devoid of Calcein-AM with the appropriate PDE treatment and incubated for 0 and $240 \mathrm{~min}$ or $18.5 \mathrm{~h}$. After the incubation time, the COC were transferred to new wells containing $200 \mu \mathrm{l} \mathrm{CTCM}$ and washed twice. Thereafter the COC were denuded and the fluorescent intensities of the oocytes recorded as described previously. Each experiment was replicated three times.

\section{6(iv) Gap junction assay: Effect of Forskolin}

Forskolin stimulates cAMP synthesis in cumulus cells allowing more to be transferred to the oocyte and to assist in maintaining meiotic arrest (Thomas et al 2002). The above-mentioned PDE inhibitors were tested both with and without forskolin. 
As described above, COC (10 -12 per well) added to wells containing $200 \mu \mathrm{l}$ CTCM, $10 \mu \mathrm{M}$ Calcein-AM and either $100 \mu \mathrm{M}$ milrinone, $200 \mu \mathrm{M}$ IBMX, or $10 \mu \mathrm{M}$ dipyridamole and incubated for $15 \mathrm{~min}$. Thereafter, the COC were transferred to new wells containing CTCM devoid of Calcein-AM with the appropriate PDE inhibitor and $10 \mu \mathrm{M}$ forskolin and then incubated for $240 \mathrm{~min}$ or $18.5 \mathrm{~h}$. After the selected incubation time e.g. $0,240 \mathrm{~min}$ or $18.5 \mathrm{~h}$ the COC were transferred to new wells and washed twice, denuded and then the fluorescent intensity in individual oocytes was recorded. Each experiment was replicated three times.

\section{6(v) Gap junction assay: Effect of $\mathrm{pH}$}

The effect of $\mathrm{pH}$ on calcein dye transfer from the cumulus cells to the oocyte was tested in the presence of media containing dipyridamole. The $\mathrm{pH}$ levels that were examined were 6.8 and 8.0 for comparison with the standard assay $\mathrm{pH}$ of 7.4.

The COC were placed in wells with BTCM media adjusted to $\mathrm{pH} 6.8,7.4$ or 8.0 with dipyridamole with Calcein-AM for $15 \mathrm{~min}$ and thereafter incubated in Calcein-AM free media for 0 and $240 \mathrm{~min}$ or $18.5 \mathrm{~h}$. Following the appropriate incubation times, the COC were washed $(2 x)$, denuded and the fluorescent intensity recorded.

\section{7(i): In-house media representing the composition of follicular fluid in non-lactating and lactating cows}

The aim of these studies was to examine the effects of the molecular microenvironment as measured in the developing bovine antral follicles on gap-junction activity in bovine COC and to compare these results with those obtained with a synthetic M199 based culture media, CTCM. The in-house media, representing the amino acid concentrations measured in follicular fluid of non-lactating or lactating dairy cows were prepared (MP Green, AJ Peterson and KP McNatty, unpublished data). These were called non-lactating media and lactating media. These media were prepared free of both cholesterol and non-esterified fatty 
acids (NEFA). However, the effects of cholesterol and /or NEFA in these media were also tested in some experiments for their effects on gap junction activity. Details concerning the composition of these media are shown in Appendix I.

The in-house media were made using the basic recipe of M199 available on the Invitrogen website (http://www.invitrogen.com) under M199 (1x) liquid media formulations. The vitamins, inorganic salts and other compounds apart from cholesterol and Tween 80 (the source of fatty acids) were prepared for a volume of 1 litre. The DL $\alpha$-tocopherol phosphateNa was dissolved in $10 \mu \mathrm{l}$ acetic acid. The hypoxanthine was dissolved in a formic acid: $\mathrm{H}_{2} \mathrm{O}$ solution $(2: 1)$. As the amino acid concentrations differed for lactating and nonlactating media, each was prepared separately with distilled water and then sterile filtered using a 0.22micron filter (Thermo Fisher Auckland New Zealand). These media were prepared in the media preparation suite at the MAF facility at Wallaceville Upper Hutt NZ. The list of amino acids and the concentrations are shown in the Appendix.

\section{7(ii): Effects of Cholesterol}

Studies were undertaken to test the effects of cholesterol between 0 and $10 \mu \mathrm{M}$ on CalceinAM dye transfer from the cumulus cells to the oocyte using the gap junction assay. Both the non- lactating and lactating media preparations were tested under these conditions. Because there are no fatty acids in either of these media, $20 \mu \mathrm{g} / \mathrm{ml}$ of Tween 80 was added as this is the amount present in M199.

The range of cholesterol concentrations studied was $0,0.5,1,2,5$ and $10 \mu \mathrm{M}$. Following isolation, the COC were washed twice in $2 \mathrm{ml} \mathrm{BTCM}$ and 10-12 COC were transferred to each of 8 wells of a 48 well tissue culture plate containing $200 \mu 1$ of BTCM. Tests were carried out at 0 and 240 min with dipyridamole. Sets of wells were set up for both nonlactating and lactating media. Following washing, COC were transferred to wells containing 
$10 \mu \mathrm{M}$ Calcein-AM, $200 \mu \mathrm{l} \mathrm{CTCM}$ and $10 \mu \mathrm{M}$ dipyridamole and then incubated for $15 \mathrm{~min}$. Following incubation, the $\mathrm{COC}$ in the 0 min incubations were immediately transferred to a wash plate and the COC to be examined after 240 min were transferred to a well containing $200 \mu \mathrm{l}$ CTCM devoid of Calcein-AM with dipyridamole and returned to the incubator. The COC in the zero time incubation wells were washed twice in $200 \mu 1 \mathrm{CTCM}$, denuded and the fluorescent intensity recorded. Likewise after incubation of $240 \mathrm{~min}$, the remaining COC were treated in the same manner.

For the tests with the various concentrations of cholesterol, the concentration of cholesterol was added to the non- lactating and lactating media before the $\mathrm{pH}$ was adjusted to 7.4 at the beginning. For the $0 \mu \mathrm{M}$ cholesterol test, ethanol at $0.01 \%(\mathrm{v} / \mathrm{v})$ was added which was the amount present in the highest concentration of cholesterol used. Ethanol concentrations of up to $0.1 \%$ had shown no effect on the COC over the incubation period. The assays testing cholesterol concentrations between $0.5,1,2,5$ and $10 \mu \mathrm{M}$ were performed in the same manner as for the $0 \mu \mathrm{M}$ concentration and each experiment was replicated 3 times.

\section{7(iii): Effects of fatty acids.}

The effects of NEFA on COC gap junction activities were tested. As fatty acids are essential to COC well-being, oleic, palmitic, linoleic and stearic acid were each added to the media in the equivalent concentrations found in M199, except when the individual fatty acids were being tested. For example, when testing the effects of oleic acid, the linoleic, palmitic and stearic acids were added to the media in the concentrations found in M199 and then the appropriate concentrations of oleic acid were titrated. Stock solutions of each fatty acid was made at a concentration of $10 \mu \mathrm{g} / \mu \mathrm{l}$ and stored at $-20^{\circ} \mathrm{C}$. These fatty acids are those that seem to be the most important for COC viability (Leroy et al., 2005). 


\section{a): Oleic acid}

The concentrations of oleic acid tested were $0,50,100$, and $200 \mu \mathrm{g} / \mathrm{ml}$ (Table 2.1). Following isolation COC were washed twice in $2 \mathrm{ml} \mathrm{BTCM} \mathrm{pH} 7.4$ and 10-12 COC were transferred to each of 7 wells each containing $200 \mu \mathrm{BTCM}$. The COC were then transferred to another well containing $200 \mu \mathrm{l}$ non-lactating or lactating media, $\mathrm{pH} 7.4$ with $10 \mu \mathrm{M}$ Calcein-AM, 10 $\mu \mathrm{M}$ dipyridamole, $1 \mu \mathrm{M}$ cholesterol and fatty acids as in M199 Table 2.1). M199 was the reference reading.

Table 2.1: Concentrations of additives present in each well for the titration of oleic acid. The amount of oleic acid changed with the experiment being undertaken.

\begin{tabular}{|c|c|c|c|}
\hline 1 & 2 & 3 & \\
\hline $\begin{array}{l}\text { Non- lactating media } \\
1 \mu \mathrm{M} \text { cholesterol } \\
10 \mu \mathrm{M} \text { dipyridamole }\end{array}$ & $\begin{array}{l}\text { Non- lactating media, } \\
1 \mu \mathrm{M} \text { cholesterol } 10 \\
\mu \mathrm{M} \text { dipyridamole, } \\
50-200 \mu \mathrm{g} / \mathrm{ml} \text { oleic } \\
\text { acid }\end{array}$ & $\begin{array}{l}\text { Non- lactating media, } \\
1 \mu \mathrm{M} \text { cholesterol } 10 \\
\mu \mathrm{M} \text { dipyridamole, } \\
50-200 \mu \mathrm{g} / \mathrm{ml} \text { oleic } \\
\text { acid } \\
\text { linoleic, stearic and } \\
\text { palmitic acids all at } 2 \\
\mu \mathrm{g} / \mathrm{ml}\end{array}$ & \\
\hline 4 & 5 & 6 & 7 \\
\hline $\begin{array}{l}\text { Lactating media } \\
1 \mu \mathrm{M} \text { cholesterol } \\
10 \mu \mathrm{M} \text { dipyridamole }\end{array}$ & $\begin{array}{l}\text { Lactating media, } \\
1 \mu \mathrm{M} \text { cholesterol, } 10 \\
\mu \mathrm{M} \text { dipyridamole, } \\
50-200 \mu \mathrm{g} / \mathrm{ml} \text { oleic } \\
\text { acid }\end{array}$ & $\begin{array}{l}\text { Lactating media, } \\
1 \mu \mathrm{M} \text { cholesterol, } 10 \\
\mu \mathrm{M} \text { dipyridamole } \\
50-200 \mu \mathrm{g} / \mathrm{ml} \text { oleic } \\
\text { acid, } \\
\text { linoleic, stearic and } \\
\text { palmitic acids all at } 2 \\
\mu \mathrm{g} / \mathrm{ml}\end{array}$ & M199 \\
\hline
\end{tabular}

The plate was then incubated for $15 \mathrm{~min}$ at $37^{\circ} \mathrm{C}$ in $5 \% \mathrm{CO}_{2}$ in air and $96 \%$ humidity. Following incubation, the COCs were transferred to a well containing $200 \mu$ l Calcein-AMfree non- lactating or lactating media, $\mathrm{pH} 7.4,10 \mu \mathrm{M}$ dipyridamole, $1 \mu \mathrm{M}$ cholesterol and /or oleic acid or fatty acid or M199, and incubated for $240 \mathrm{~min}$. 
Following incubation, the COC were transferred to a well containing $200 \mu \mathrm{l}$ media the same as they had previously been incubated in, washed twice in this volume of media then denuded and read. The same procedure was used for the other concentrations for oleic acid (i.e. 100 $\mu \mathrm{g} / \mathrm{ml}$ and $200 \mu \mathrm{g} / \mathrm{ml}$, see Table 2.1).

\section{b): Stearic acid.}

The concentrations of stearic acid tested were $0,25,50$, and $100 \mu \mathrm{g} / \mathrm{ml}$ (see Table 2.2). Following isolation, $\mathrm{COC}$ were washed twice in $2 \mathrm{ml} \mathrm{BTCM} \mathrm{pH} 7.4$ and 10-12 COC were transferred to each of 7 wells each containing $200 \mu$ BTCM. The COC were then transferred to another well containing $200 \mu \mathrm{l}$ non-lactating or lactating media $\mathrm{pH} 7.4$ with10 $\mu \mathrm{M}$ Calcein -AM, $10 \mu \mathrm{M}$ dipyridamole, $1 \mu \mathrm{M}$ cholesterol and fatty acids or M199 as shown in Table 2.2. M199 was the reference reading.

Table 2.2: Concentrations of additives present in each well for the titration of stearic acid. The amount of stearic acid changed with the experiment being undertaken.

\begin{tabular}{|c|c|c|c|}
\hline 1 & 2 & 3 & \\
\hline $\begin{array}{l}\text { Non-lactating media } \\
1 \mu \mathrm{M} \text { cholesterol } \\
10 \mu \mathrm{M} \text { dipyridamole }\end{array}$ & $\begin{array}{l}\text { Non- lactating media, } \\
1 \mu \mathrm{M} \text { cholesterol, } 10 \\
\mu \mathrm{M} \text { dipyridamole, } \\
25-100 \mu \mathrm{g} / \mathrm{ml} \text { stearic } \\
\text { acid }\end{array}$ & $\begin{array}{l}\text { Non- lactating media, } \\
1 \mu \mathrm{M} \text { cholesterol, } 10 \\
\mu \mathrm{M} \text { dipyridamole, } \\
25-100 \mu \mathrm{g} / \mathrm{ml} \text { stearic } \\
\text { acid, linoleic and } \\
\text { palmitic acids both at } \\
2 \mu \mathrm{g} / \mathrm{ml}, \\
\text { oleic acid } 14 \mu \mathrm{g} / \mathrm{ml}\end{array}$ & \\
\hline 4 & 5 & 6 & 7 \\
\hline $\begin{array}{l}\text { Lactating media } \\
1 \mu \mathrm{M} \text { cholesterol } \\
10 \mu \mathrm{M} \text { dipyridamole }\end{array}$ & $\begin{array}{l}\text { Lactating media, } \\
1 \mu \mathrm{M} \text { cholesterol, } 10 \\
\mu \mathrm{M} \text { dipyridamole, } \\
25-100 \mu \mathrm{g} / \mathrm{ml} \text { stearic } \\
\text { acid }\end{array}$ & $\begin{array}{l}\text { Lactating media, } \\
1 \mu \mathrm{M} \text { cholesterol } 10 \\
\mu \mathrm{M} \text { dipyridamole } \\
25-100 \mu \mathrm{g} / \mathrm{ml} \text { stearic } \\
\text { acid, linoleic and } \\
\text { palmitic acids both at } \\
12 \mu \mathrm{g} / \mathrm{ml}, \\
\text { oleic acid } 14 \mu \mathrm{g} / \mathrm{ml}\end{array}$ & M199 \\
\hline
\end{tabular}

The plate was then incubated with Calcein-AM for $15 \mathrm{~min}$ at $37^{\circ} \mathrm{C}$ in $5 \% \mathrm{CO}_{2}$ in air and $96 \%$ humidity. Following incubation, the COCs were transferred to a well containing $200 \mu \mathrm{l}$ Calcein-AM-free non-lactating or lactating media $\mathrm{pH} 7.4,10 \mu \mathrm{M}$ dipyridamole, $1 \mu \mathrm{M}$ 
cholesterol and /or stearic acid or fatty acid or M199 and incubated for $240 \mathrm{~min}$. The same procedure was used for the other concentrations for stearic acid tested (i.e. $100 \mu \mathrm{g} / \mathrm{ml}$ and 200 $\mu \mathrm{g} / \mathrm{ml}$, see Table 2.2).

\section{c): Palmitic acid.}

The concentrations of palmitic acid tested were $0,25,50$, and $100 \mu \mathrm{g} / \mathrm{ml}$ (see Table 2.3). Following isolation, $\mathrm{COC}$ were washed twice in $2 \mathrm{ml} \mathrm{BTCM} \mathrm{pH} \mathrm{7.4.} 1012 \mathrm{COC}$ were transferred to each of 7 wells each containing $200 \mu 1$ BTCM. The COC were then transferred to another well containing $200 \mu \mathrm{l}$ non- lactating or lactating media $\mathrm{pH} 7.4$ with $10 \mu \mathrm{M}$ Calcein-AM, $10 \mu \mathrm{M}$ dipyridamole, $1 \mu \mathrm{M}$ cholesterol and fatty acids or M199, see Table 2.3. M199 was the reference reading.

Table 2.3: Concentrations of additives present in each well for the titration of palmitic acid. The amount of palmitic acid changed with the experiment being undertaken.

\begin{tabular}{|c|c|c|c|}
\hline 1 & 2 & 3 & \\
\hline $\begin{array}{l}\text { Non-lactating media } \\
1 \mu \mathrm{M} \text { cholesterol } \\
10 \mu \mathrm{M} \text { dipyridamole }\end{array}$ & $\begin{array}{l}\text { Non-lactating media, } \\
1 \mu \mathrm{M} \text { cholesterol, } 10 \\
\mu \mathrm{M} \text { dipyridamole, } \\
25-100 \mu \mathrm{g} / \mathrm{ml} \\
\text { palmitic acid }\end{array}$ & $\begin{array}{l}\text { Non-lactating media, } \\
1 \mu \mathrm{M} \text { cholesterol, } 10 \\
\mu \mathrm{M} \text { dipyridamole, } \\
25-100 \mu \mathrm{g} / \mathrm{ml} \\
\text { palmitic acid, } \\
\text { linoleic, and stearic } \\
\text { acids both at } 2 \mu \mathrm{g} / \mathrm{m} \text {, } \\
\text { oleic acid } 14 \mu \mathrm{g} / \mathrm{ml}\end{array}$ & \\
\hline 4 & 5 & 6 & 7 \\
\hline $\begin{array}{l}\text { Lactating media } \\
1 \mu \mathrm{M} \text { cholesterol } \\
10 \mu \mathrm{M} \text { dipyridamole }\end{array}$ & $\begin{array}{l}\text { Lactating media, } \\
1 \mu \mathrm{M} \text { cholesterol, } 10 \\
\mu \mathrm{M} \text { dipyridamole, } \\
25-100 \mu \mathrm{g} / \mathrm{ml} \\
\text { palmitic acid }\end{array}$ & $\begin{array}{l}\text { Lactating media, } \\
1 \mu \mathrm{M} \text { cholesterol, } 10 \\
\mu \mathrm{M} \text { dipyridamole, } \\
25-100 \mu \mathrm{g} / \mathrm{ml} \\
\text { palmitic acid, } \\
\text { linoleic, and stearic } \\
\text { acids both at } 2 \mu \mathrm{g} / \mathrm{ml} \text {, } \\
\text { oleic acid } 14 \mu \mathrm{g} / \mathrm{ml}\end{array}$ & M199 \\
\hline
\end{tabular}

The plate was then incubated with Calcein- $\mathrm{AM}$ for $15 \mathrm{~min}$ at $37^{\circ} \mathrm{C}$ in $5 \% \mathrm{CO}_{2}$ in air and $96 \%$ humidity. Following incubation, the COCs were transferred to a well containing $200 \mu 1$ 
Calcein-AM-free non-lactating or lactating media, $\mathrm{pH} 7.4,10 \mu \mathrm{M}$ dipyridamole, $1 \mu \mathrm{M}$ cholesterol and /or palmitic or fatty acid or M199 and incubated for 240 min. The same procedure was used for the other concentrations for palmitic acid tested (i.e.100 $\mu \mathrm{g} / \mathrm{ml}$ and $200 \mu \mathrm{g} / \mathrm{ml}$, see Table 2.3).

\section{8: Statistical Analyses}

The fluorescence readings of individual oocytes for each treatment was normalised against the time zero control and averaged to calculate the relative fluorescent intensity. One way analysis of variance (one-way ANOVA) or Kruskal Wallis tests were first performed, followed by an appropriate post-hoc test such as the Bonferroni or Dunn's test using the GraphPad Prism 4 statistics programme. Two-way ANOVA was performed when more than one parameter was being analysed (e.g. time and media) also using the GraphPad Prism 4 statistics programme. All data are represented as bar graphs showing normalised means and SEM to show comparisons between control and treatment groups at various times and treatment and media. 


\section{Results}

\section{1: Effect of time on calcein dye transfer via gap junctions in bovine COC}

The aim of this experiment was to determine the optimum incubation time for assessing gap junction activity in COC following a 15 min treatment with Calcein-AM. All fluorescent values were normalised as ratios against the mean \pm SEM fluorescent value at 0 absorbance (419 \pm 108$)$. In all studies, only fluorescent values $>20$ were included. The results showed that the fluorescent values reached a maximum at $240 \mathrm{~min}$ (Figure 3.1).

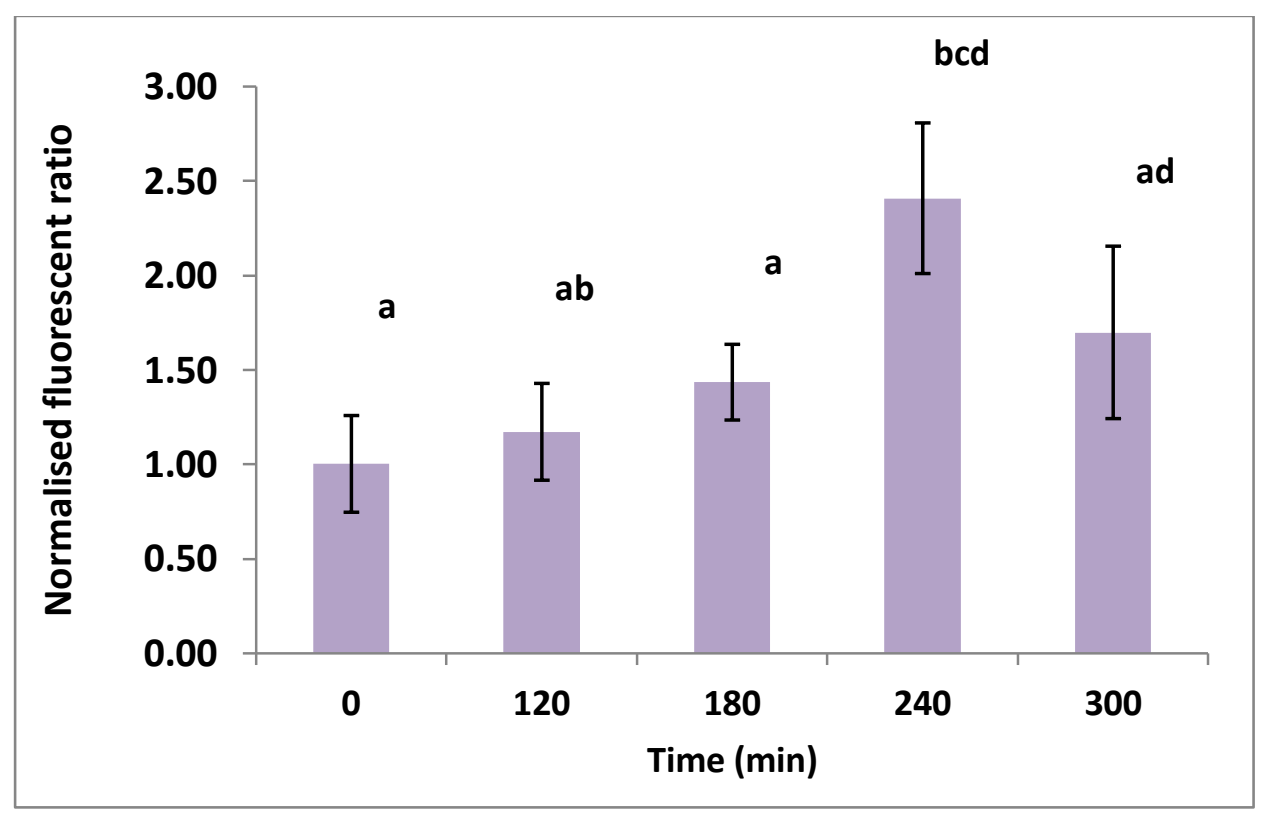

Figure 3.1: Effect of time on the transfer of calcein dye from the cumulus cells to the oocyte after a 15 minute pulse of Calcein-AM. Values are presented as mean $\pm S E M$ fluorescent ratios normalised against the values at 0 , assigned a value of 1 , from 5 separate experiments. Means not sharing a common alphabetical superscript are significantly different, $P<0.05$. 


\section{2a: Effects of phosphodiesterase inhibitors (PDE) on calcein dye transfer via gap junctions in bovine COC}

The inhibitors selected for this study included: 1) milrinone, a known inhibitor of the PDE3 isoform often found in oocytes of different species including the cow (Thomas et al., 2002);

2) 3-isobutyl-methylxanthine (IBMX) which is considered to be non-specific and acts on a number of different PDE isoforms (Sasseville et al., 2009a) and;

3) dipyridamole which is reported to act on PDE isoforms 7, 8, 10 and 11 (Sasseville et al., 2009a).

All fluorescent values were normalised as ratios against the mean \pm SEM fluorescent value at 0 min $(202 \pm 50)$. The presence of milrinone $(100 \mu \mathrm{M})$, IBMX $(200 \mu \mathrm{M})$, or dipyridamole (10 $\mu \mathrm{M})$ in the media at $0 \mathrm{~min}$ did not affect the fluorescent readings observed in the absence of PDE inhibitors (data not shown). Compared to controls, fluorescent values were significantly increased $(\mathrm{P}<0.01)$ in bovine oocytes after $\mathrm{COC}$ were incubated for $240 \mathrm{~min}$ in culture medium containing dipyridamole. (Figure 3.2) In contrast, fluorescent values in bovine oocytes following COC exposure to milrinone or IBMX were similar to that in controls at 240 min. 


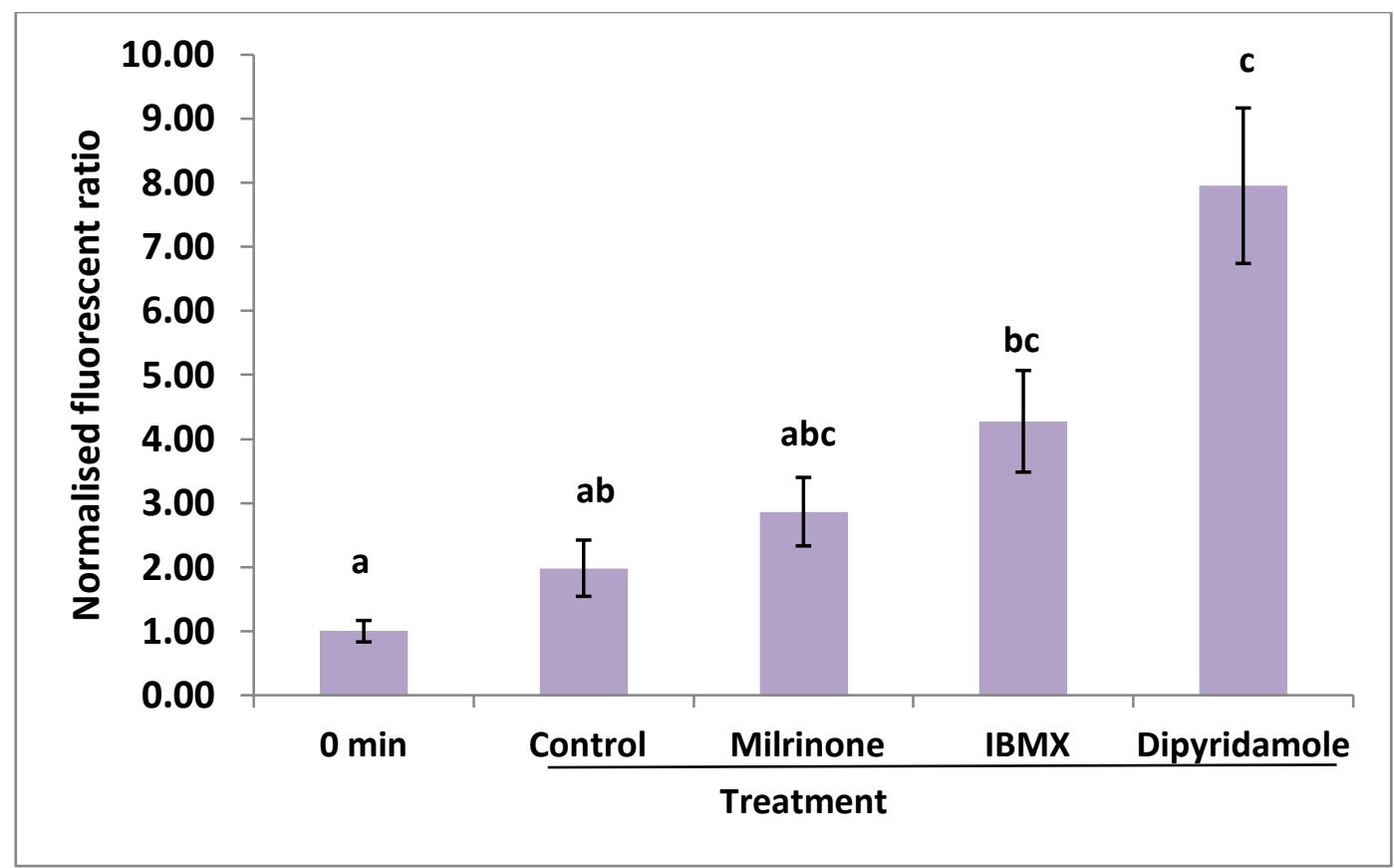

Figure 3.2: Effect of various PDE inhibitors on fluorescent intensity in oocytes after $240 \mathrm{~min}$ normalised against the mean fluorescent value at 0 min assigned a value of 1 .Values are expressed as means $\pm S E M(N=3$ separate experiments). Values not sharing a common alphabetical superscript are significantly different, $P<0.01$.

To further test the efficacy of dipyridamole, the experiment was repeated but the incubation period extended to $18.5 \mathrm{~h}$. All fluorescent values were corrected against the mean \pm SEM fluorescent value at $0 \mathrm{~min}(172 \pm 45)$. After $18.5 \mathrm{~h}$ the fluorescent values for milrinone and IBMX were similar to the values for the controls, indicating that the gap junction activity had decreased and the oocytes had entered GVBD. However the effect of dipyridamole was maintained over this time indicating that more oocytes had remained in GV (Figure 3.3). 


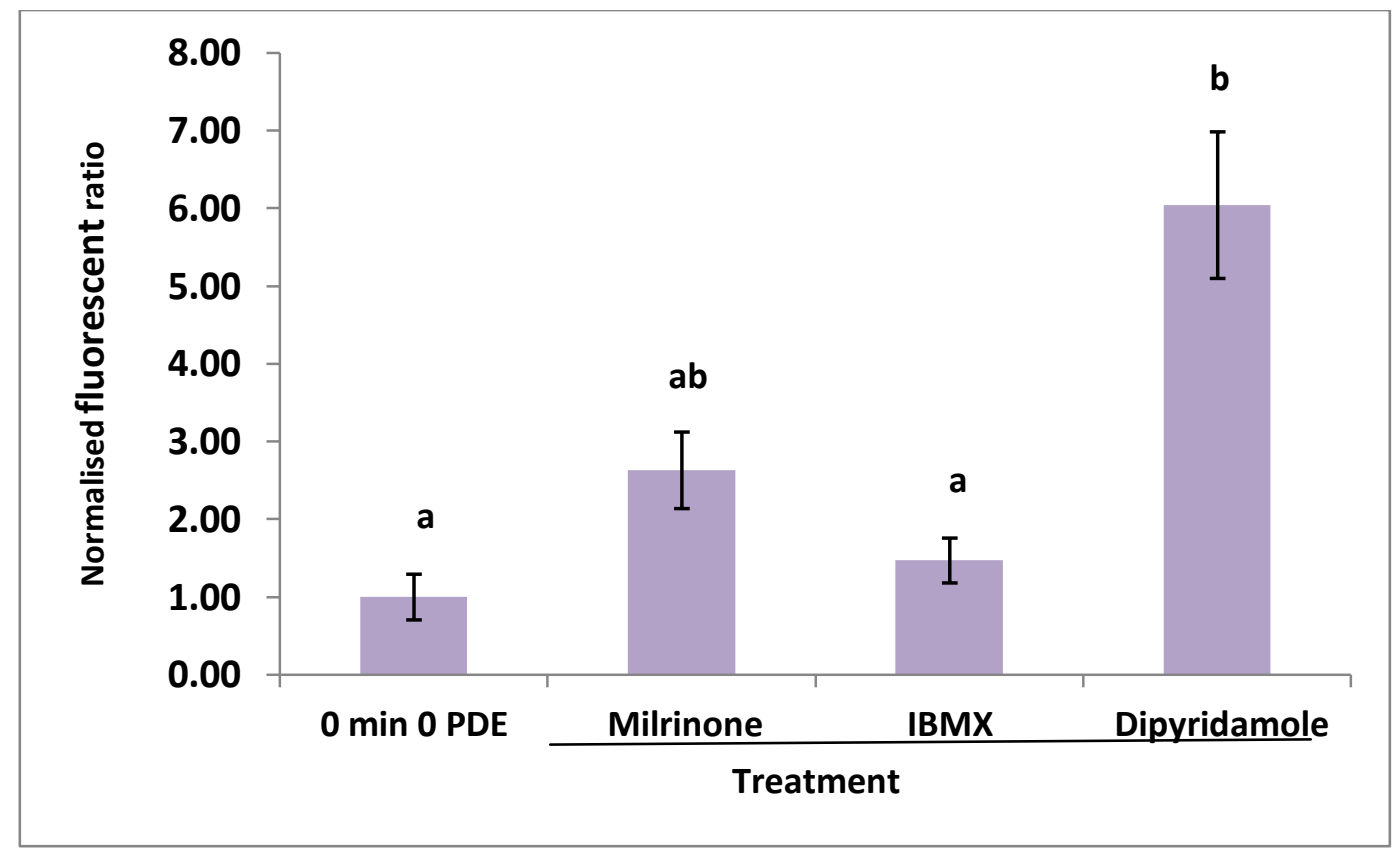

Figure 3.3: Effect of various PDE inhibitors on fluorescent intensity in oocytes after 18.5h normalised against the mean fluorescent value at 0 min assigned a value of 1 . Values are expressed as means $\pm S E M(N=3$ separate experiments). Values not sharing a common alphabetical superscript are significantly different, $P<0.05$.

\section{2b: Effects of phosphodiesterase inhibitors (PDE) on GVBD in bovine oocytes}

The addition of dipyridamole to the cultures appeared to prevent GVBD in oocytes. The proportion of oocytes that had undergone GVBD following incubation with dipyridamole for 240 min was $<10 \%$ and for $18.5 \mathrm{~h}$ was $<40 \%$. Whilst there was no control for these experiments, GVBD would normally occur after $7 \mathrm{~h}$ in the absence of any PDE inhibitors (Thomas et al., 2004a). Oocytes with GV were easily identified (Figure 3.4). With the initiation of GVBD, the chromatin in the nucleus becomes a dense mass (Figure 3.5). Just before the formation of the polar body and metaphase I, the nucleus migrates to the edge of the follicle (Figure 3.5a) and thereafter the chromatin separates (Figure 3.5b); the latter stage is referred to as diakinesis. Oocytes were orcein stained and the method for orcein staining is shown in the Appendix. 


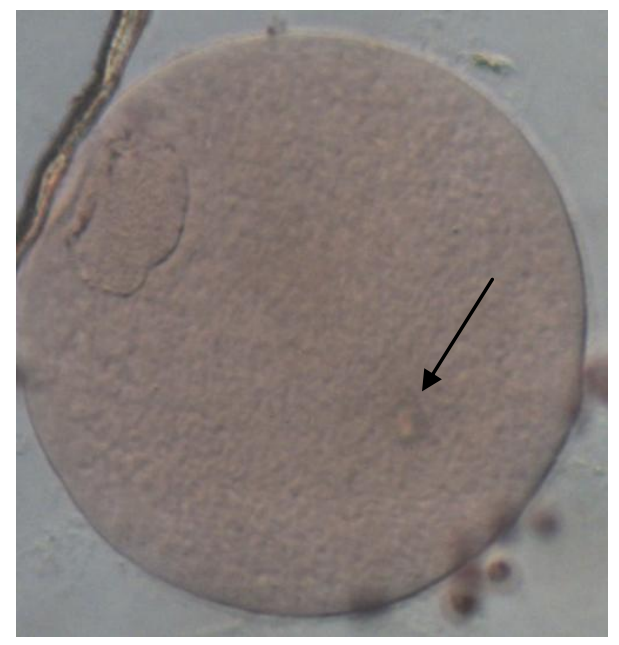

Figure 3.4 Bovine oocyte in GV orcein stained (x400mag). Arrow shows the GV that is compact with no obvious chromatin.
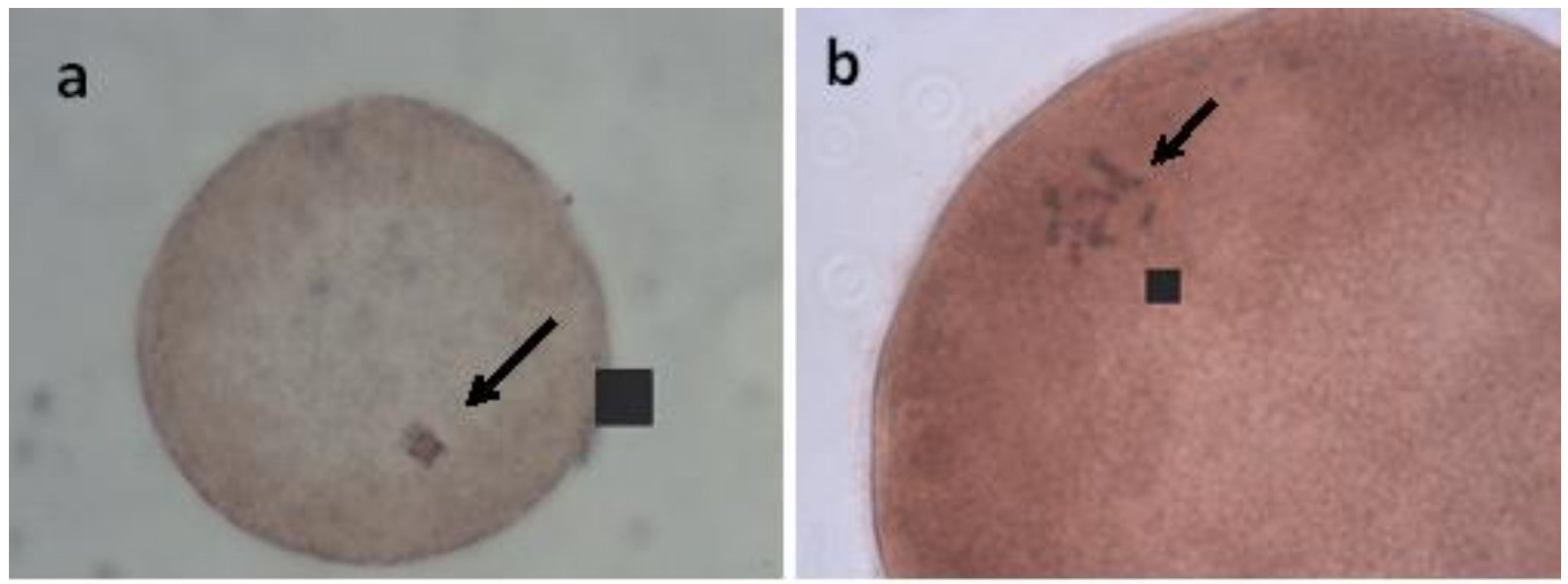

Figure 3.5: Stages of meiosis in bovine oocytes (orcein stained): (a) dense chromatin mass (arrowed) at beginning of GVBD (x100 mag) and (b) the nuclear membrane has broken down and the chromatin is undergoing separation (arrowed; i.e. diakinesis) (x400 mag). 

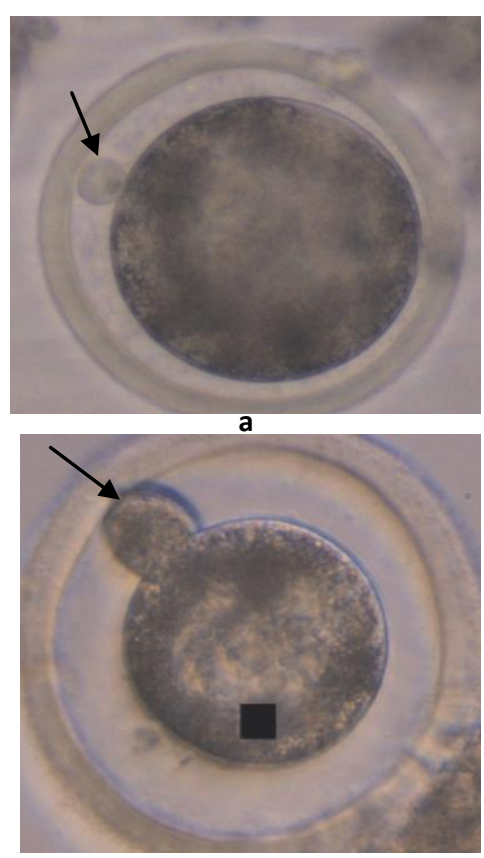

C

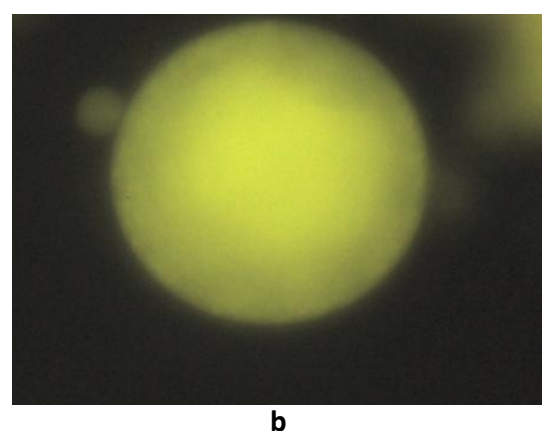

b

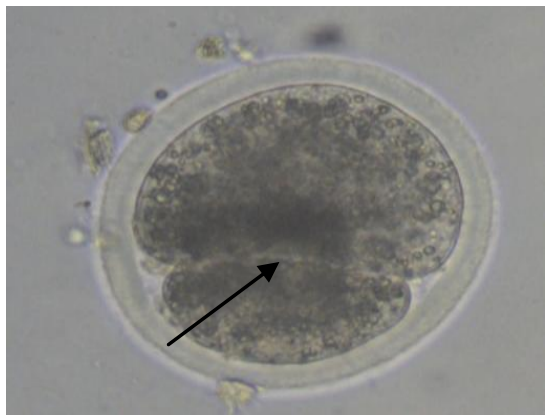

d

Figure 3.6: Examples of bovine oocytes after $18.5 \mathrm{~h}$ incubation with dipyridamole (all at 100x mag): (a) polar body emerging (arrowed); (b) same oocyte as in (a) indicating the fluorescence in both the oocyte and polar body; (c) oocyte with larger polar body( arrowed) and; (d) an oocyte undergoing cytokinesis. This represents the telophase stage of meiosis where the cytoplasm divides to make two daughter cells.

\section{3: Effect of combining PDE inhibitors on dye transfer in the gap junction assay}

In the previous experiment, dipyridamole was the most effective of the PDE inhibitors tested. The aim of this experiment was to investigate whether dipyridamole in combination with milrinone would further increase gap junction activity compared with dipyridamole alone. All fluorescent values were normalised as ratios against the mean \pm SEM fluorescent value of controls at $0 \min (401 \pm 127)$. 


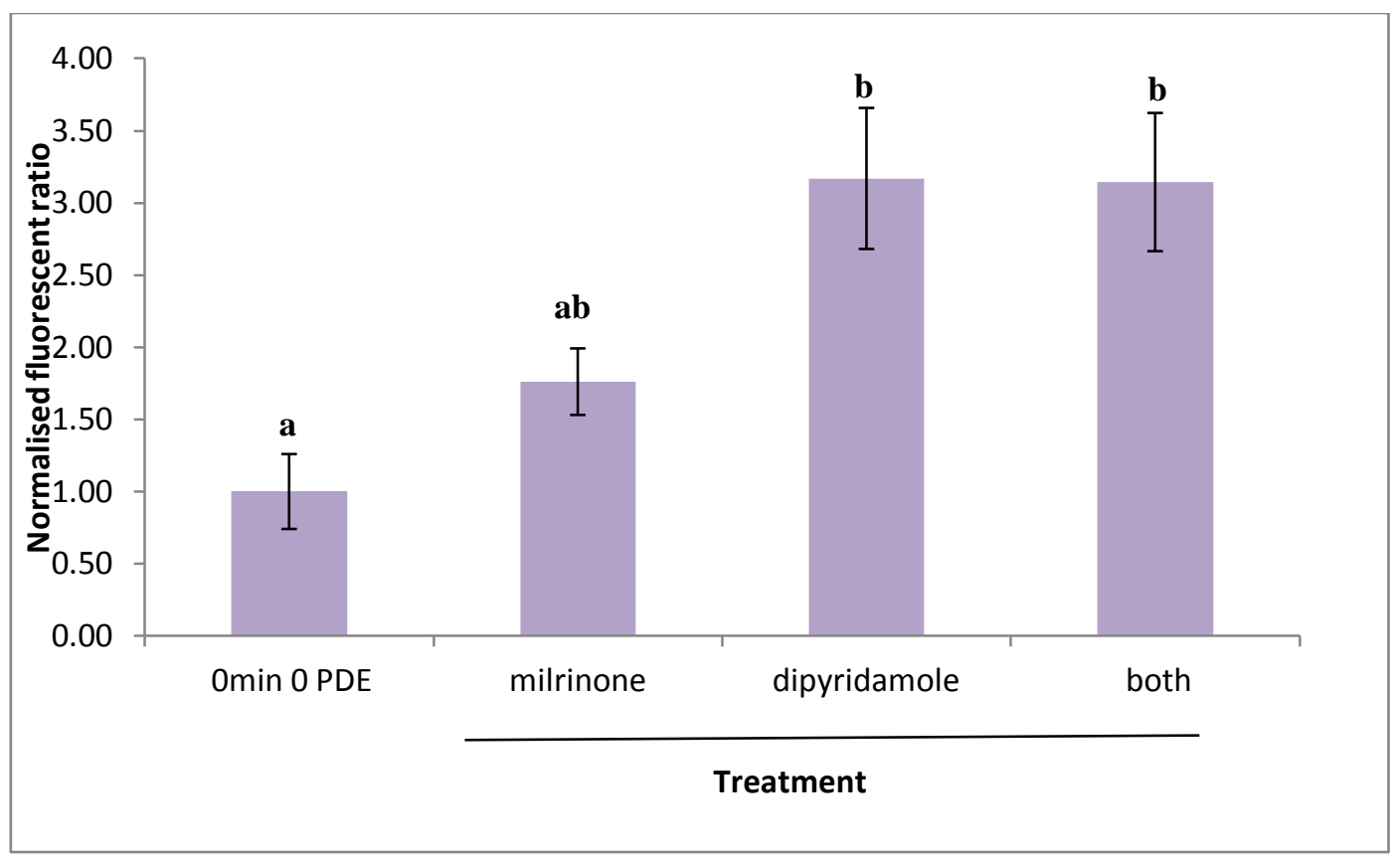

Figure 3.7: Effect of no PDE treatment $(0 \mathrm{~min})$, milrinone, dipyridamole and dipyridamole plus milrinone (both) on the transfer of calcein dye from the cumulus cells to the oocyte after a 240 min incubation following a 15 min pulse of Calcein-AM. The mean $\pm S E M$ values were generated from 5 separate experiments. Means not sharing common alphabetical superscripts are significantly different, $P<0.05$. The values were normalised against the fluorescent values at 0 min which was assigned a value of 1.

Compared to control (0 min 0 PDE) and milrinone treated groups, mean fluorescent values were higher $(\mathrm{P}<0.05)$ for dipyridamole or both dipyridamole plus milrinone. However, these results indicate that dipyridamole plus milrinone did not significantly improve dye transfer above that observed with dipyridamole alone.

\section{4: Effect of forskolin on dye transfer in the gap junction assay}

Forskolin is reported to elevate cAMP levels in cumulus cells and thus via the transfer through gap junctions, maintain high cAMP concentrations in oocytes. In turn, high concentrations of cAMP maintain meiotic arrest (Thomas et al., 2002). The aims of these 
experiments were to test the effectiveness of PDE inhibitors in the presence of forskolin on gap junction activity of COC incubated for either $240 \mathrm{~min}$ or $18.5 \mathrm{~h}$. For those COC that were incubated for $240 \mathrm{~min}$, all fluorescent values were normalised against the mean \pm SEM fluorescent value of controls $(345 \pm 131)$. Controls were incubated for $0 \mathrm{~min}$.

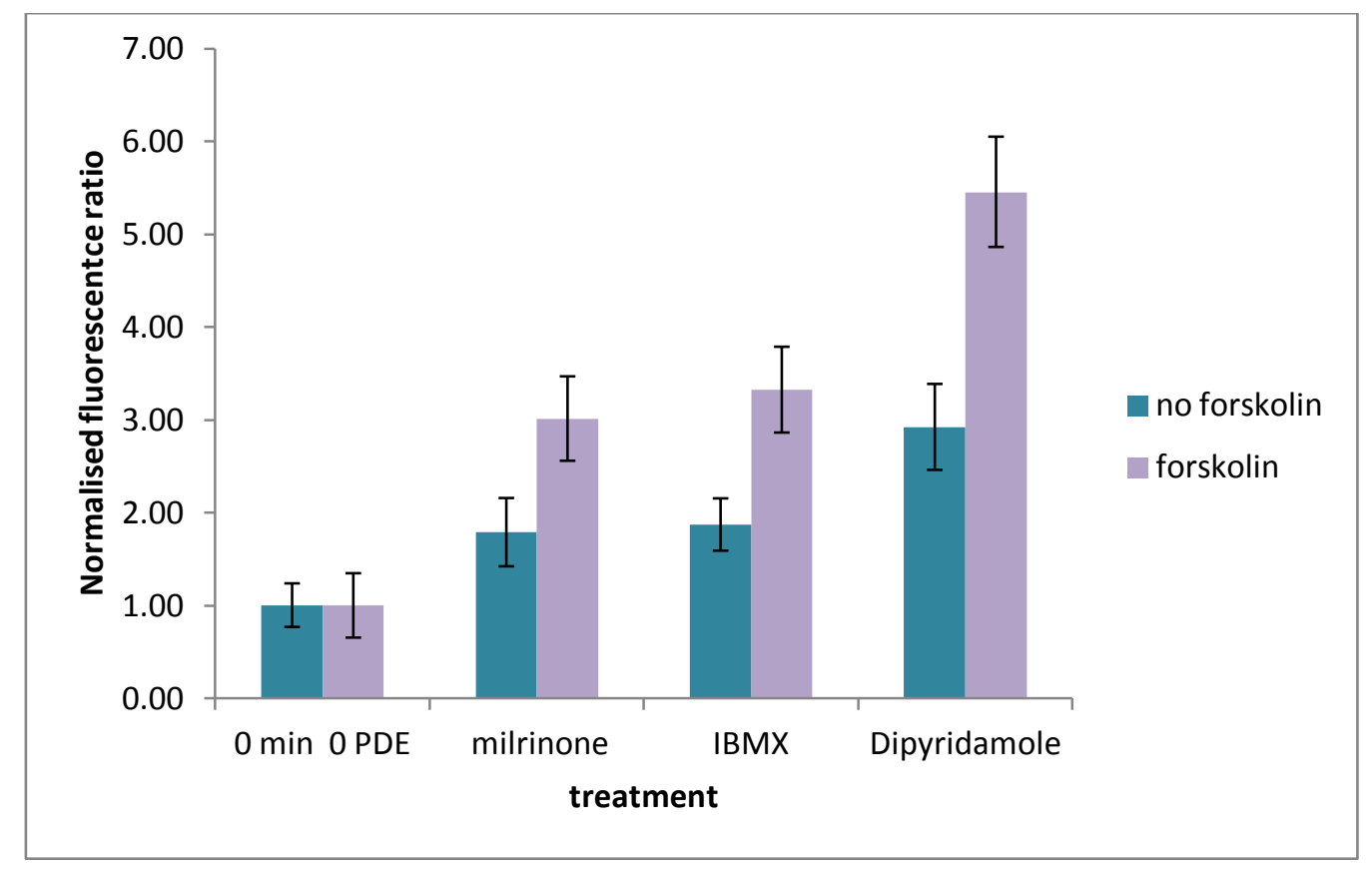

Figure 3.8: Effect of milrinone, IBMX, or dipyridamole with or without forskolin 10 $\mathrm{M}$ on the transfer of calcein dye from the cumulus cells to the oocyte after a 240 min incubation following a 15 min pulse of Calcein-AM. The values were normalised against the fluorescent values at Omin O PDE which was assigned a value of 1. The mean \pm SEM values were generated from 3 separate experiments.

When analysed by two-way ANOVA, there was no interaction. However, the addition of forskolin significantly increased the dye transfer for milrinone ( 3 fold), IBMX ( 3 fold) and dipyridamole (5.5 fold) compared to the control whereas dye transfer was increased only with the addition of dipyridamole ( 2 fold) in the absence of forskolin. 
For those COC that were incubated for $18.5 \mathrm{~h}$, all fluorescent values were normalised against those at $0 \min (190 \pm 70)$.

After $18.5 \mathrm{~h}$ incubation, and the addition of dipyridamole and forskolin the fluorescent values were increased compared to $0 \mathrm{~min}$. No effect was noted for milrinone or IBMX. (Figure 3.9)

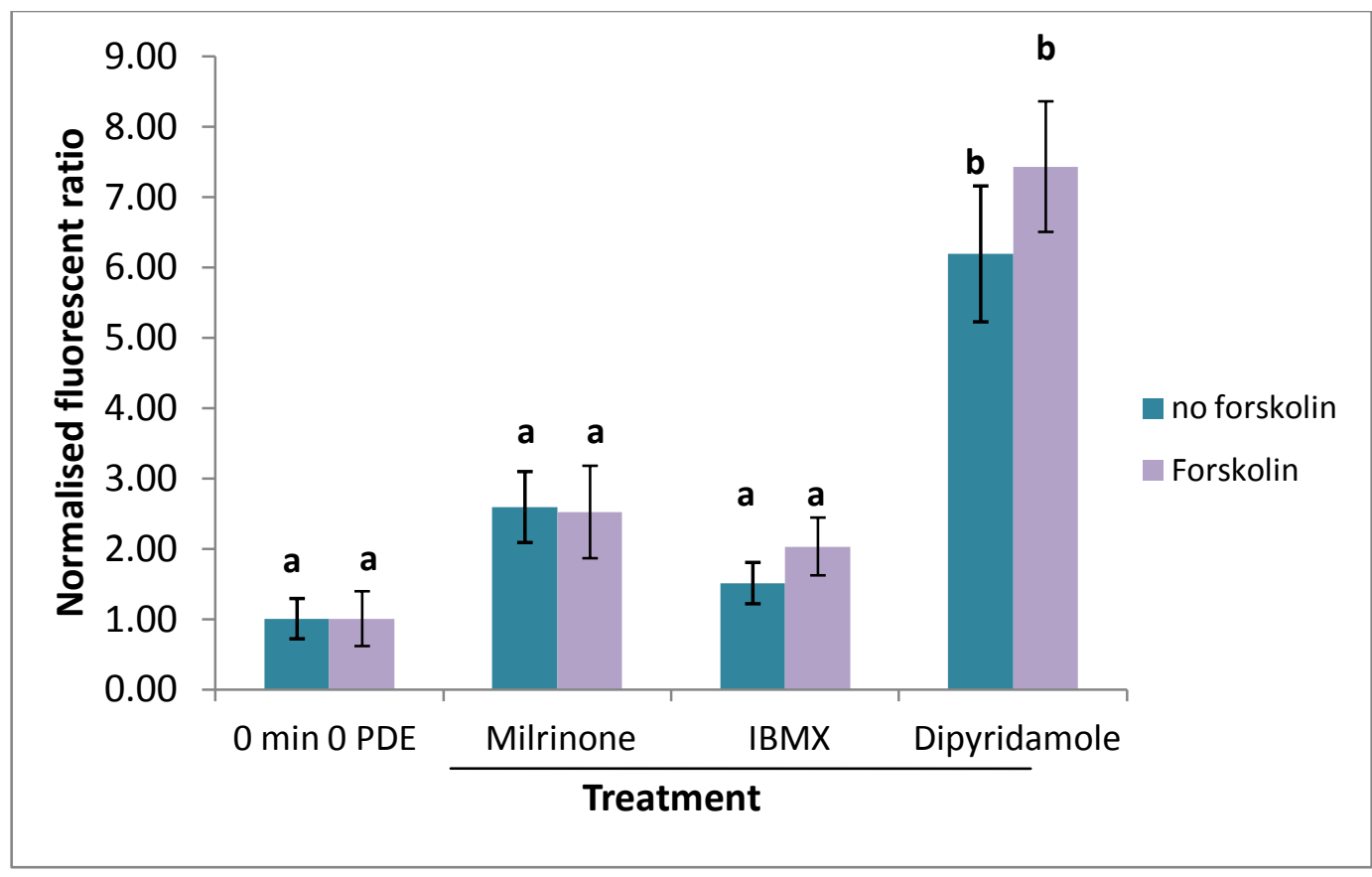

Figure 3.9: Effect of milrinone, IBMX, or dipyridamole with or without forskolin $10 \mu M$, on the transfer of calcein dye from the cumulus cells to the oocyte after an 18.5h incubation following a 15 min pulse of Calcein-AM. The mean $\pm S E M$ values were generated from 3 separate experiments. Means not sharing common alphabetical superscripts are significantly different, $P<0.01$. The values were normalised against the fluorescent values 0 which was assigned a value of 1 .

Significant enhancing effects of dipyridamole alone and dipyridamole + forskolin on dye transfer between cumulus cells and oocytes were noted after $18.5 \mathrm{~h}$ relative to no dipyridamole or no dipyridamole + forskolin at 0 . For the other PDE inhibitors used there 
were no beneficial effects of forskolin and none of these inhibitors with or without forskolin were as effective as dipyridamole alone.

On the basis of these results, all subsequent COC calcein dye transfer experiments with media compositions representative of those in dairy cows included dipyridamole at a concentration of $10 \mu \mathrm{M}$ but did not include a cAMP stimulator such as forskolin.

\section{5: The effect of media $\mathrm{pH}$ on dye transfer in the gap junction assay}

The role of media $\mathrm{pH}$ on the efficacy of dye transfer from cumulus cells to oocytes in the bovine gap junction assay has not been reported. The aim of the present experiments was to test the efficiency of dye transfer in bovine $\mathrm{COC}$ over a $\mathrm{pH}$ range from 6.8 to 8.0. The COC were incubated for $240 \mathrm{~min}$ with or without dipyridamole.

The aim of the first experiment was to test the effects of $\mathrm{pH}$ 6.8, compared with $\mathrm{pH}$ 7.4. All fluorescent values were normalised against the mean \pm SEM fluorescent value of controls at pH $6.8(149 \pm 29)$ and $\mathrm{pH} 7.4(243 \pm 45)$ which were not significantly different. Relative to 0, oocytes in the controls (no dipyridamole) had significantly higher $(\mathrm{P}<0.01)$ fluorescent values

after $240 \mathrm{~min}$ incubation in both $\mathrm{pH} 6.8$ and $\mathrm{pH}$ 7.4. However, in the presence of dipyridamole this effect was much greater $(\mathrm{P}<0.001)$, and $\mathrm{COC}$ incubated at $\mathrm{pH} 6.8$ had lower gap junction transfer than those at $\mathrm{pH} 7.4$ (see Figure 3.10). 


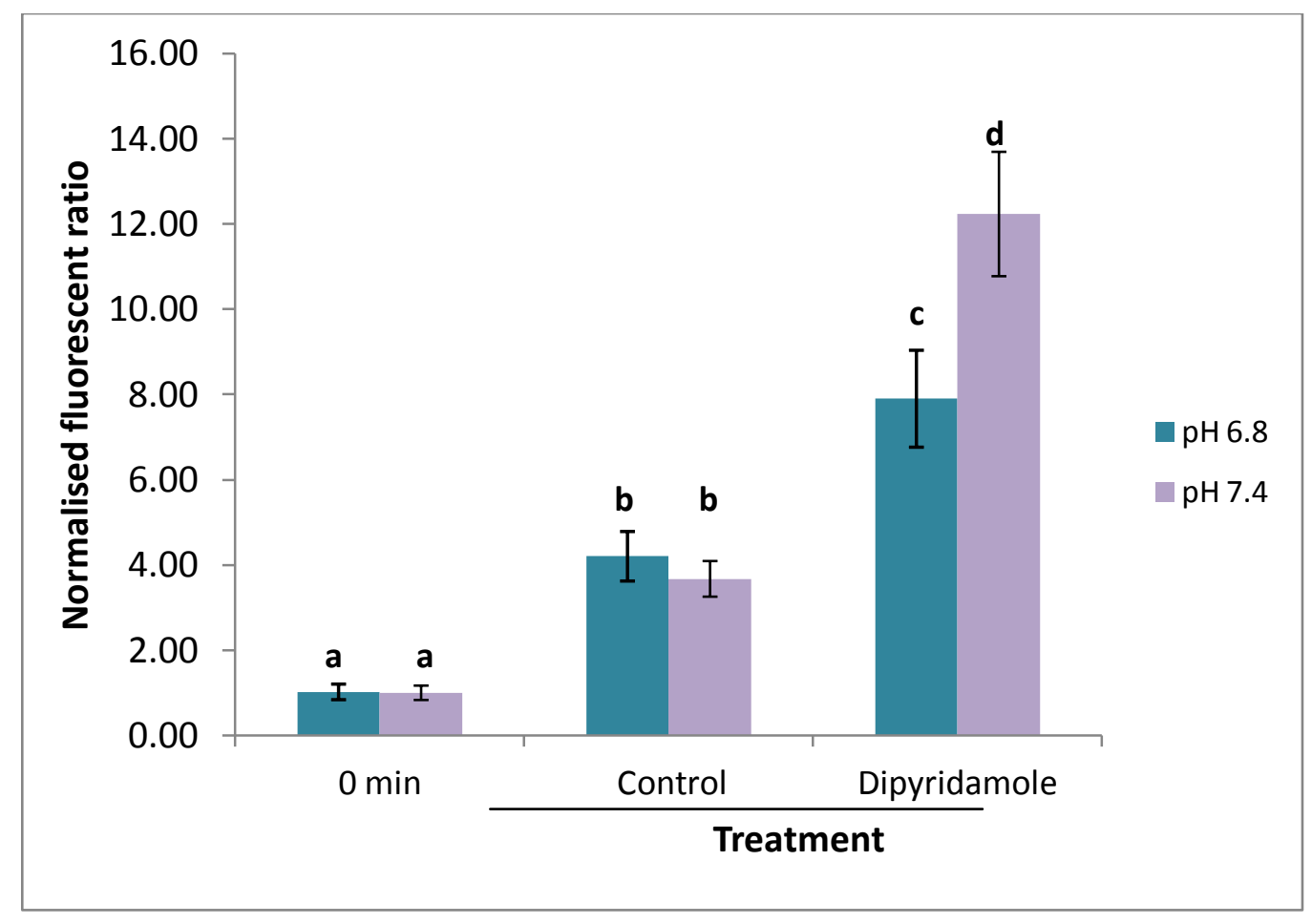

Figure 3.10: The effect of $p H$ on the transfer of calcein dye from the cumulus cells to the oocyte. The mean \pm SEM values were generated from 3 separate experiments and expressed as ratios relative to the values at 0 min (assigned a value of 1). The control (no dipyridamole) and dipyridamole treatment values are those after 240 min incubation whereas those indicated by 0 refer to the 0 min incubation. Means not sharing common alphabetical superscripts are significantly different from one another, $P<0.01$.

The aim of the next experiment was to investigate the effect of $\mathrm{pH} 8.0$ compared to $\mathrm{pH} 7.4$ on gap junction activity. All fluorescent values were normalised against the mean \pm SEM fluorescent value of controls (at $0 \mathrm{~min})$ at $\mathrm{pH} 7.4(224 \pm 52)$ and $\mathrm{pH} 8.0(250 \pm 65)$ which were not significantly different. Relative to 0 , the controls (no dipyridamole) had significantly higher $(\mathrm{P}<0.01)$ fluorescent values after 240 min incubation at $\mathrm{pH} 7.4$ and $\mathrm{pH}$ 8.0. In the presence of dipyridamole this effect was greater $(\mathrm{P}<0.001)$ and COC incubated at both $\mathrm{pH}$ 7.4 and $\mathrm{pH} 8.0$ had a higher dye transfer than controls. 


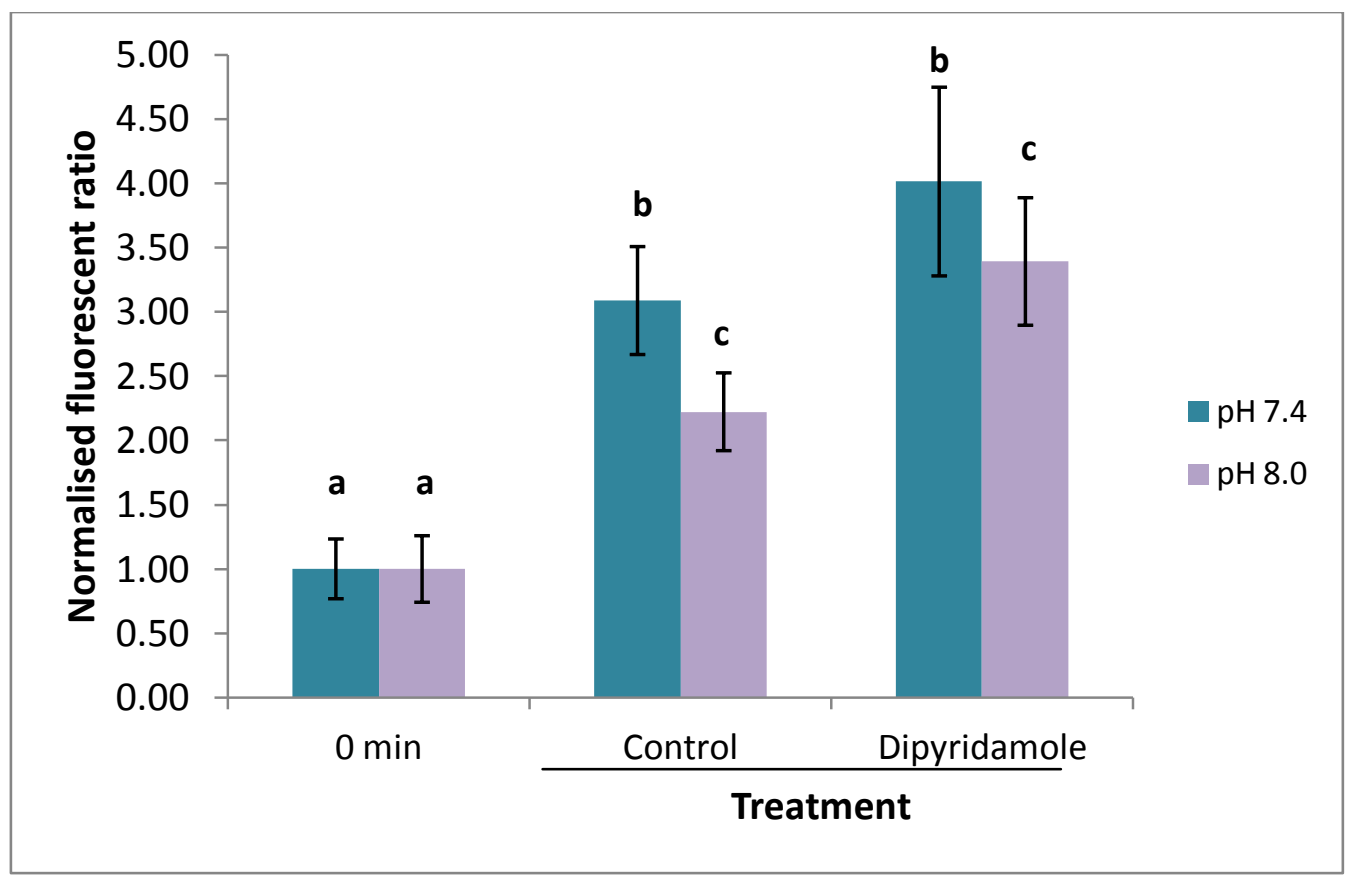

Figure 3.11: The effect of $p H$ on the transfer of calcein dye from the cumulus cells to the oocyte. The mean \pm SEM values were generated from 3 separate experiments and expressed as ratios relative to the values at 0 min (assigned a value of 1). The control (no dipyridamole) and dipyridamole treatment values are those after 240 min incubation whereas those indicated by 0 refer to 0 min incubation. Means not sharing common alphabetical superscripts are significantly different, $P<0.01$.

Overall, these results indicate that the ideal conditions for the bovine gap junction assay include the incubation of COC for $240 \mathrm{~min}$ in a media containing $10 \mu \mathrm{M}$ dipyridamole at $\mathrm{pH}$ 7.4 . 


\section{Studies with in-house media representing follicular fluid}

\section{compositions of lactating and non-lactating dairy cows}

The media for these studies were based on the averaged amino acids, non-esterified fatty acids (NEFA) and cholesterol concentrations in lactating dairy cows and non-lactating beef cows in a New Zealand pastoral situation (MP Green, AJ Peterson, and KP McNatty, unpublished data). See Appendix for recipes.

\subsection{Comparison of M199, non-lactating and lactating media on calcein dye transfer via gap junctions in the bovine COC.}

The aim of this experiment was to compare non-lactating and lactating media with both cholesterol and fatty acids added in the same concentrations as found in M199 with M199. Following isolation COC were washed twice in $2 \mathrm{ml} \mathrm{BTCM}$ pH7.4. Subsequently, 10-12 COC were transferred to individual wells in a 48 well tissue culture plate containing $200 \mu \mathrm{l}$ BTCM pH 7.4 for further washing. They were then transferred to another well containing 200 $\mu \mathrm{l}$ of non-lactating or lactating media $\mathrm{pH} 7.4$ with $10 \mu \mathrm{M}$ Calcein-AM and subjected to a 15 min treatment with Calcein-AM under the standard conditions previously described i.e. $5 \%$ $\mathrm{CO}_{2}$ in air, $96 \%$ humidity and $37^{\circ} \mathrm{C}$ for $15 \mathrm{~min}$. After the Calcein-AM treatment, the COC were transferred to new wells containing media and $10 \mu \mathrm{M}$ dipyridamole and incubated for 240 min under the standard conditions established. Only readings over 20 were considered.

All fluorescent values were corrected against the mean \pm sem fluorescent value at 240 min $(990 \pm 161)$ for M199, $(1291 \pm 149)$ for non-lactating media and $(1064 \pm 120)$ for lactating media. The mean values for the media were not significantly different from one another. 


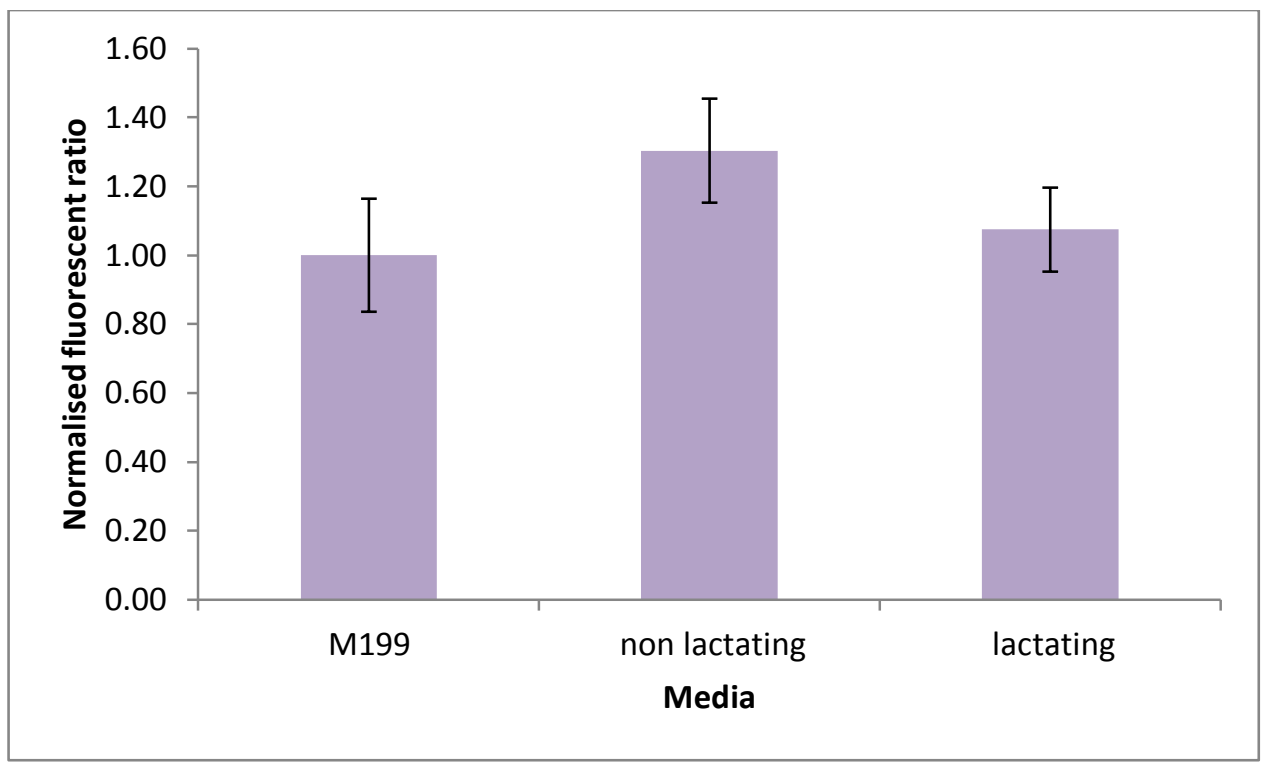

Figure 4.1: Comparison of M199, non-lactating and lactating media on calcein dye transfer via gap junctions in the bovine COC after 240 min normalised against the mean fluorescent value of M199 which was assigned a value of 1 . Values are expressed as mean \pm SEM $(N=3$ separate experiments).

\subsection{Effect of differing amounts of cholesterol on calcein dye transfer via gap junctions in the bovine COC}

Cholesterol is utilised for steroid synthesis by ovarian tissue with low density lipoproteins (LDL)-derived cholesterol-being preferentially used for ovarian steroid synthesis by most species-(Grummer \& Carroll, 1988). Because no significant differences were noted for results between non-lactating and lactating media, it was decided that for all remaining experiments, the data from both would be pooled. Measurement of cholesterol in follicular fluid from small, medium and large follicles ranges from 1.4 to $1.6 \mu \mathrm{M} / \mathrm{ml}$ with plasma levels being 41-45\% higher than in follicular fluid (Grummer \& Carroll, 1988; Leroy et al., 2004). These measurements formed the basis of the concentrations tested. 
The aim of this experiment was to determine the effect on the gap junction activity in COC of various concentrations of cholesterol following a 15 min treatment with Calcium-AM. In the first of these experiments the effect of having no cholesterol present was tested.

Following isolation COC were washed twice in $2 \mathrm{ml}$ BTCM pH7.4. 10-12 COC were transferred to a well in a 48 well tissue culture plate containing $200 \mu \mathrm{lBTCM}$ pH7.4 for further washing and subjected to the gap junction assay as described previously for either 0 min or $240 \mathrm{~min}$. Thereafter, the experiment was repeated under the same conditions but using $0.5,1,2,5$, or $10 \mu \mathrm{M}$ cholesterol which was added to both media in all experiments. The results are summarised in Figure 4.2 for all concentrations tested. The mean \pm SEM fluorescent values at $0 \mu \mathrm{M}$ cholesterol were $(635 \pm 114)$.

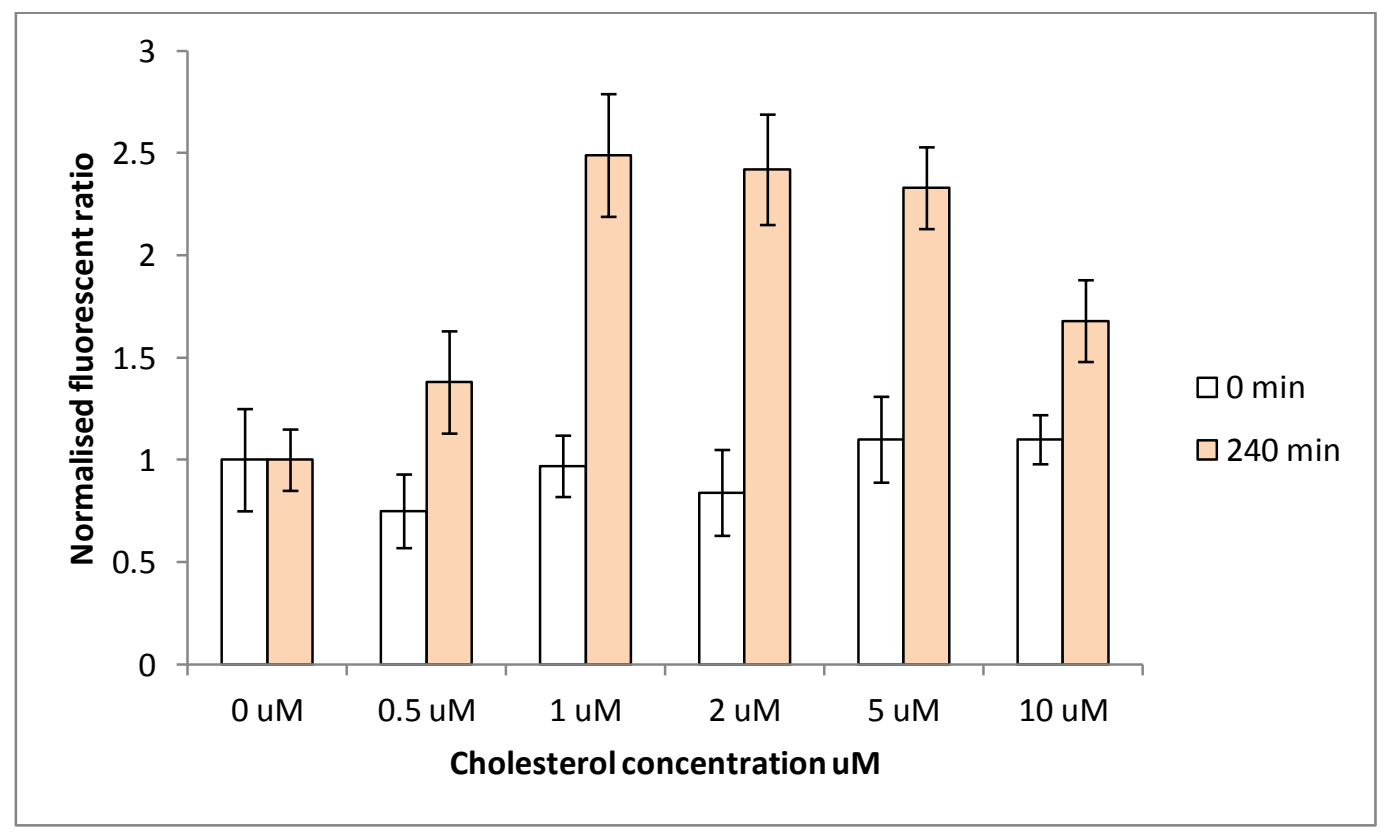

Figure 4.2: Effect of different concentrations of cholesterol on fluorescent dye transfer after 240 min. Values were normalised against the mean fluorescent value at 0 min which was assigned a value of 1 . Values are expressed as mean \pm SEM. 
When analysed by two-way ANOVA, there was a significant interaction between cholesterol and time $(\mathrm{P}<0.05)$. However, there was no effect of different concentrations of cholesterol at $0 \mathrm{~min}$ but there were effects at $240 \mathrm{~min}$. Dye transfer increased from $0.5 \mu \mathrm{M}$ reaching a peak at 1-2 $\mu \mathrm{M}$ which was 2.5 fold higher than that at $0 \mu \mathrm{M}$ after which the effect diminished.

Based on these results it was decided that the ideal amount of cholesterol to use in the inhouse media would be $1.0 \mu \mathrm{M}$. This is twice the amount found in M199 and slightly less than what was measured in the follicular fluid in the NZ herds (MP Green, AJ Peterson, and KP McNatty, unpublished data) and reported by Grummer \& Carroll, 1988 and Leroy et al., 2004.

It was noticed in all experiments that there were a lot of broken zona pellucida when there was no cholesterol present further enforcing the need for its presence to support oocyte viability.

\section{3: Effect of differing amounts of fatty acids on calcein dye transfer via gap junctions in the bovine $\mathrm{COC}$}

Oleic acid, along with stearic and palmitic acids are non-esterified fatty acids known to be predominant in bovine follicular fluid and linked to the maturation of oocytes (Leroy et al., 2005; Fouladi-Nashta et al., 2007; Fouladi-Nashta et al., 2009). The amount of lipid in the bovine oocyte consists of approximately 50\% tricylglycerol, 20\% phospholipid, 20\% cholesterol and $10 \%$ fatty acid. Palmitic and stearic acid, which are saturated fatty acids, have been shown to be the most abundant whereas $<20 \%$ of the total fatty acids is reported to be polyunsaturated linoleic acid (Santos et al., 2008). Oleic acid was also present in relatively high amounts and is an unsaturated fatty acid. Linoleic acid is an essential fatty acid and because of this was added to all the experiments but the amount was not titrated. Instead the amount present in media M1999 was used. The concentrations decided on were based on the measurements made by Bender in follicular fluid concentrations of oleic acid $(209 \mu \mathrm{g} / \mathrm{ml})$, 
palmitic acid $(46 \mu \mathrm{g} / \mathrm{ml})$, and stearic acid $(54 \mu \mathrm{g} / \mathrm{ml})$ in the dominant follicle of the cow (Bender et al., 2010).

\section{3(i). Effect of Oleic acid.}

The effect of various concentrations of oleic acid on the transfer of calcein dye by bovine oocytes via gap junctions was investigated by the assay described previously. The additives added to each well in comparing the effects of oleic acid are outlined in Table 2.1 (see Materials and Methods).

The effects of different oleic acid concentrations in the presence or absence of fatty acids on dye transfer over a $240 \mathrm{~min}$ incubation period is summarised in Figure 4.3. The mean \pm SEM fluorescent values at $0 \mu \mathrm{g}$ oleic acid were $(930 \pm 115)$.

The concentrations of oleic acid tested were $0,50,100$ and $200 \mu \mathrm{g} / \mathrm{ml}$ : these concentrations were based on measurements in follicular fluid in cows reported by Bender et al., 2010.

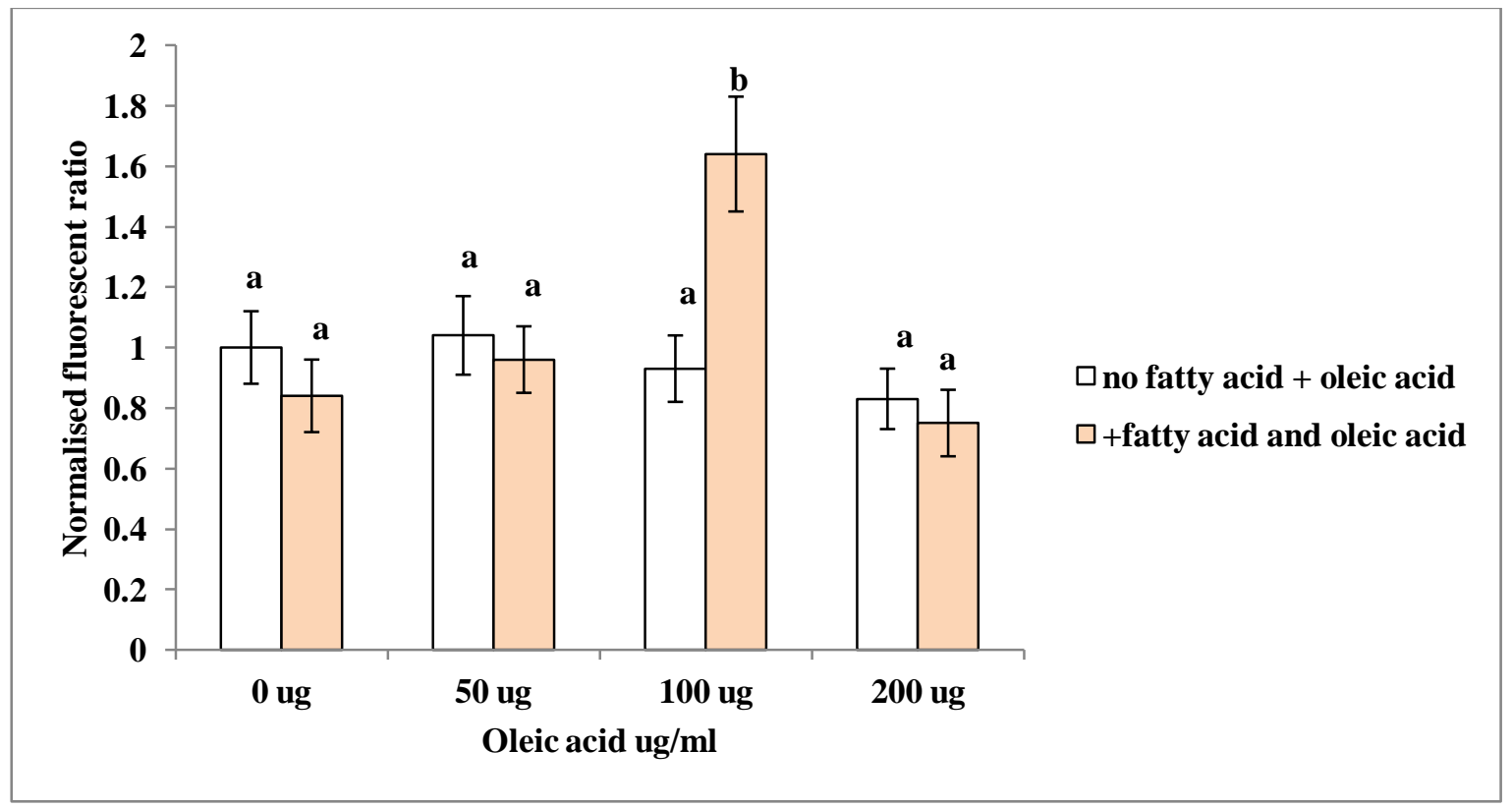

Figure 4.3: Effect of different concentrations of oleic acid with and without fatty acids on fluorescent dye transfer after $240 \mathrm{~min}$. Means not sharing a common alphabetical superscript are significantly different, $P<0.05$. Values are expressed as mean \pm SEM. 
From these results it can be concluded that the presence of fatty acids with $100 \mu \mathrm{g} / \mathrm{ml}$ of oleic acid has a significant beneficial effect on dye transfer from cumulus cells to the oocyte.

\section{3(ii). Effect of stearic acid}

The effect of various concentrations of stearic acid on the transfer of calcein dye by bovine oocytes via gap junctions was investigated as described previously. The additives added to each well in comparing the effects of stearic acid are outlined in Table 2.2 (see Materials and Methods).

The effects of different stearic acid concentrations in the presence or absence of fatty acids on dye transfer over a 240 min incubation period is summarised in Figure 4.4. The mean \pm SEM fluorescent values at $0 \mu \mathrm{g}$ stearic acid were $(803 \pm 84)$.

The concentrations of stearic acid tested were $0,25,50$ and $100 \mu \mathrm{g} / \mathrm{ml}$ these concentrations were based on measurements in follicular fluid in cows reported by Bender et al., 2010.

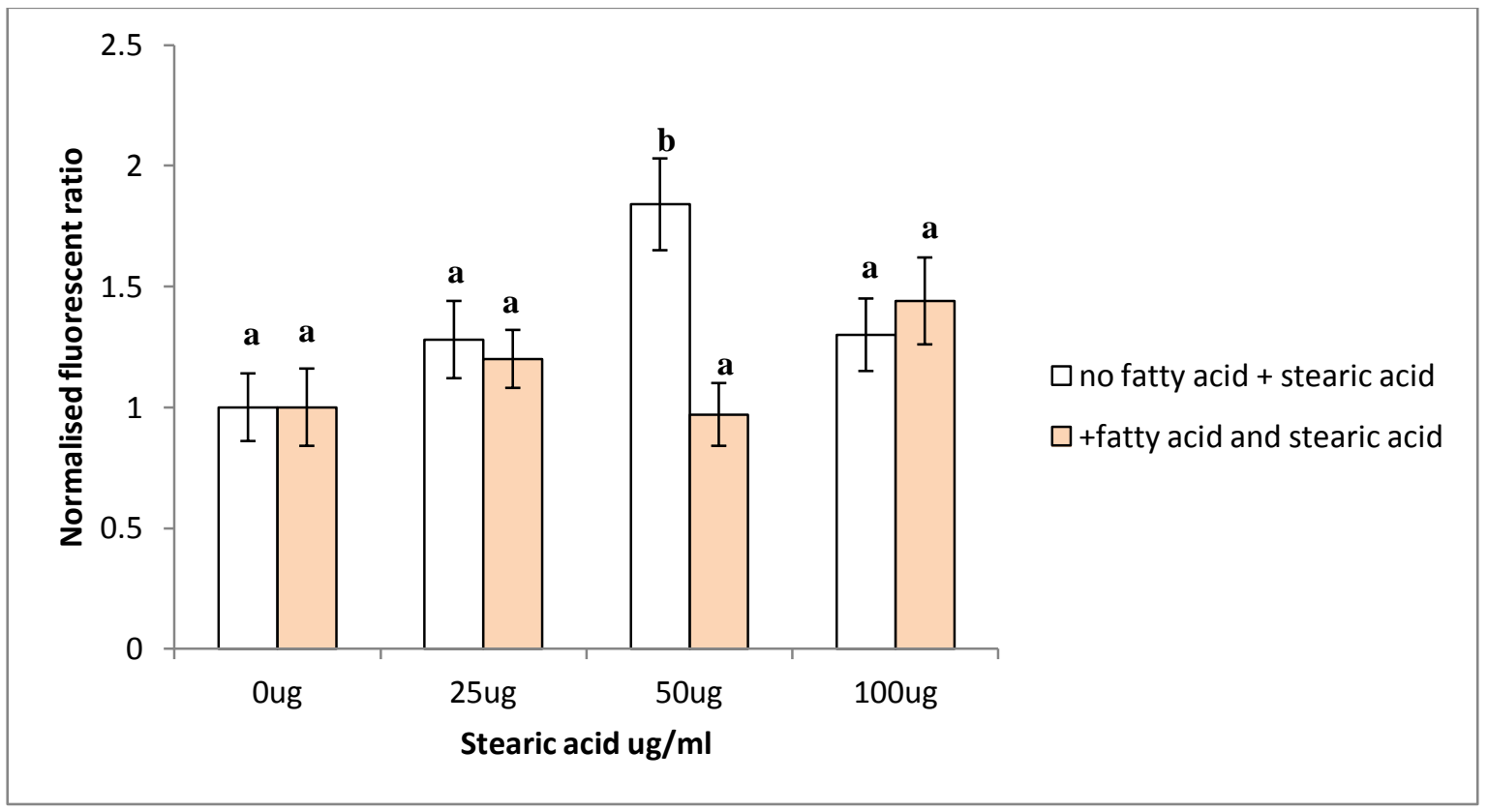

Figure 4.4: Effect of different concentrations of stearic acid with and without fatty acids on fluorescent dye transfer after $240 \mathrm{~min}$. Means not sharing common alphabetical superscripts are significantly different, $P<0.05$. Values are expressed as mean $\pm S E M$. 
The addition of $50 \mu \mathrm{g} / \mathrm{ml}$ of stearic acid without other fatty acids indicate a significant higher level of dye transfer over $240 \mathrm{~min}$. Therefore based on these results, a stearic acid concentration of $50 \mu \mathrm{g} / \mathrm{ml}$ would be an optimal amount to be present in the media.

\section{3(iii). Effect of palmitic acid}

The effect of various concentrations of palmitic acid on the transfer of calcein dye by bovine oocytes via gap junctions was investigated described previously. The additives added to each well for comparing the effects of palmitic acid are outlined in Table 2.3 (see Materials and Methods). The concentrations for palmitic acid tested in this study were $0,25,50$ and 100 $\mu \mathrm{g} / \mathrm{ml}$ for non-lactating and lactating media. These concentrations were based on measurements taken in follicular fluid of cows as reported by Bender et al., 2010.

The effects of different concentrations of palmitic acid in the presence or absence of other fatty acids on dye transfer over a 240 min incubation period is summarised in Figure 4.5. The mean \pm SEM fluorescent values at $0 \mu \mathrm{g}$ palmitic acid were $(963 \pm 131)$.

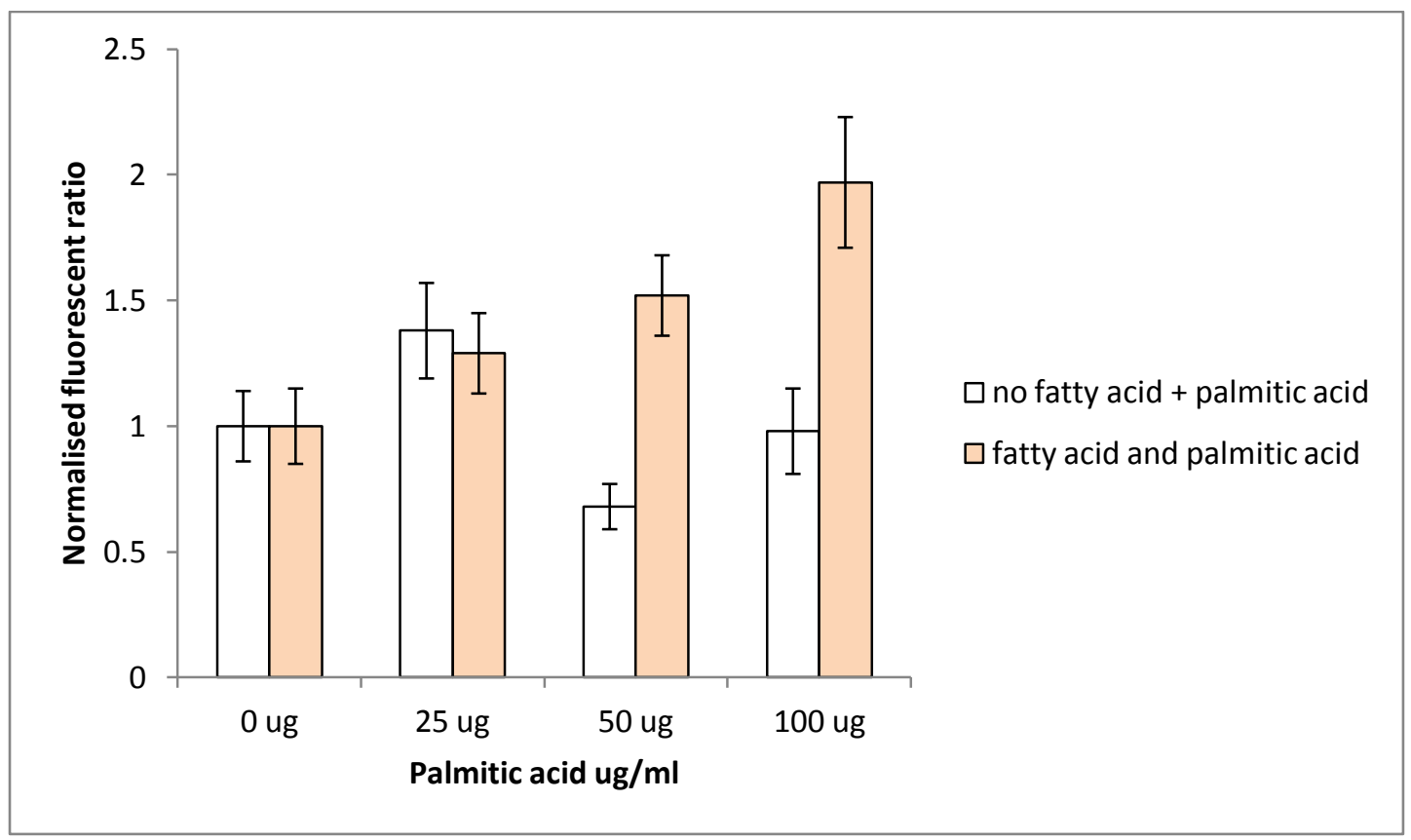

Figure 4.5: Effect of different concentrations of palmitic acid with and without fatty acids on fluorescent dye transfer after $240 \mathrm{~min}$. Values are expressed as mean \pm SEM. 
When analysed by two-way ANOVA there was a significant interaction $(\mathrm{P}<0.05)$ between the media (with or without fatty acid) and the concentration of palmitic acid. The presence of fatty acid and palmitic acid together showed progressive increases in dye transfer with increasing concentrations of palmitic acid. The largest increase (i.e. 2-fold) was noted with $100 \mu \mathrm{g} / \mathrm{ml}$ of palmitic acid. 


\section{Discussion}

The major aims of this thesis were to: (1) develop, validate and extend the utility of a fluorescence-based gap junction assay, (2) assess using the validated gap junction assay the level of nutrient exchange between bovine cumulus cells and adjacent oocytes incubated under in vitro conditions, and (3) subsequently evaluate the effects of different nutrients, substrates and PDE inhibitors on gap junction activity in bovine COC. The overall objective was to identify the consequences of the microenvironments likely to be experienced by COC in lactating and non-lactating cattle and to elucidate the most favourable incubation conditions for future COC gap junction studies. The microenvironments tested were based on measurements of the follicular fluid concentrations of amino acids, cholesterol and fatty acids identified in lactating and non-lactating dairy cows under pastoral conditions typical to NZ dairy farming. The outcomes from these studies were compared with those for COC that were incubated in the commercially available media M199.

Measures of fluorescent dye transfer from cumulus cells to oocytes after a 15 min exposure to Calcein-AM indicated that, in M199 and in the absence of a PDE inhibitor, a significant accumulation of dye (2-2.5-fold) in the oocyte occurred after a 240 min incubation period. However, dye transfer could be greatly enhanced in the presence of some, but not all, of the PDE inhibitors that were tested. In the presence of IBMX or dipyridamole, dye accumulation in oocytes over $240 \mathrm{~min}$ could be increased to 4-fold with IBMX and $\sim 8$-fold with dipyridamole, compared to untreated controls. With milrinone, no significant increase above control was observed. When COC were incubated for an extended time interval (e.g. $18.5 \mathrm{~h}$ ) only dipyridamole remained effective with a $\sim 6$-fold accumulation of dye evident in oocytes. Collectively, these findings suggest that the removal of COC from their in vivo environments impairs or disrupts gap junction function and that these junctional contacts can be restored, at 
least in part, by the use of specific PDE inhibitors especially dipyridamole. Given that cumulus cells are interconnected with the mural GC via connexin 43 , the removal of COC from its mural GC is likely to place significant stress on the oocyte, including a significant drop in cAMP and/or cGMP. Some preliminary experiments were undertaken with the PDE inhibitor Rolipram (a PDE4 inhibitor) and while indications were that it enhanced gap junction activity, it appeared much less effective than dipyridamole, and was not investigated further. Milrinone has been shown to be effective in holding oocytes in meiotic arrest in vitro in the rat, mouse and pig (Tsafriri et al., 1996; Thomas et al., 2004b; Sasseville et al., 2006; Downs, 2011) but is not effective at preventing bovine meiotic resumption. The present studies confirm previous reports that there are species differences in the regulation of oocyte maturation that is in part influenced by iso-enzyme specific phosphodiesterase (PDE) inhibitors (Tsafriri et al., 1996; Thomas et al., 2004b; Sasseville et al., 2006; Barretto et al., 2007).

Sasseville et al., 2009a, were the first to report that PDE8 was expressed in the bovine ovarian follicle. PDE3 is thought to be the predominant PDE expressed in the oocyte while PDE8 is thought to be expressed in CC (Sasseville et al., 2009a). PDE8 is not inhibited by IBMX which is consistent with the findings herein which showed that IBMX was relatively ineffective. In the present study, only dipyridamole was effective after $240 \mathrm{~min}$ and $18.5 \mathrm{~h}$ in sustaining calcein accumulation in oocytes and maintaining oocytes in the GV stage. As there was a possibility that a combination of PDE inhibitors might enhance gap junction activity and prevent for longer, oocytes undergoing GVBD, the effects of milrinone and dipyridamole were tested together. However, the results showed that this combination was no better than dipyridamole alone indicating that there was no additive or synergistic effect.

The aforementioned results suggest that gap junction activity might be improved by stimulating further the intracellular levels of cAMP. Forskolin is an adenylate cyclase 
stimulator and is known to be effective in increasing intracellular levels of cAMP. The role of forskolin in bovine COC has been studied previously and showed that its addition could prolong the duration of gap junction communication, and maintenance of oocytes at the GV stage especially in the presence of milrinone (Thomas et al., 2002; 2004a). The results of this study show that forskolin increased the dye accumulation in oocytes in the presence of all the PDE inhibitors tested after $240 \mathrm{~min}$ (milrinone, IBMX, and dipyridamole) but the most effective combination was forskolin plus dipyridamole. However, after $18.5 \mathrm{~h}$ incubation, forskolin with IBMX or milrinone were ineffective and forskolin with dipyridamole was no more effective than dipyridamole alone. Overall, dipyridamole was the most effective for maintaining gap junction activity and meiotic arrest.

It has been shown that high levels of cAMP synthesis are required for gap junction permeability (Modina et al., 2001). Cyclic AMP appears to increase the permeability of Cx43 gap junctions by increasing the assembly of $\mathrm{Cx} 43$ to gap junctional plaques in the plasma membrane (Burghardt et al., 1995). In this context, cAMP plays a crucial role in mammalian oocyte maturation perhaps by a high level of cAMP exchange between GC and CC as well as between CC and oocytes. High levels of intra-oocyte cAMP enable the oocyte to maintain meiotic arrest. However a drop in intracellular cAMP allows meiosis to resume. Even though there were some modest effects of forskolin in the present studies, dipyridamole alone was as effective in maintaining oocytes in meiotic arrest. Therefore, in subsequent studies, dipyridamole alone was used as the key additive for maintaining intracellular cAMP and meiotic arrest.

Under in vitro conditions, the metabolic activity and viability of cells is profoundly influenced by $\mathrm{pH}$. However, there appeared to be no reports as to the effects of $\mathrm{pH}$ on gap junction activity in COC. Given that an objective in this study was to examine different media compositions on COC gap junction activity, the effect of $\mathrm{pH}$ of the incubation media 
was investigated. Media at $\mathrm{pH} 6.8$ and $\mathrm{pH} 8.0$ was compared to media at $\mathrm{pH} 7.4$. At $\mathrm{pH} 6.8$, the accumulation of calcein in oocytes after $240 \mathrm{~min}$ in the presence of dipyridamole was significantly lower compared to $\mathrm{pH} 7.4$ (8-fold vs 12 -fold increase, $\mathrm{P}<0.01$ ). At $\mathrm{pH} 8.0$, there was also a lower level of dye accumulation (3.5-fold) compared to that for oocytes incubated at $\mathrm{pH} 7.4$ (4-fold) and while this was significant the effect in the presence of dipyridamole was much smaller. These data established, as might be expected, that under normal physiological $\mathrm{pH}$ conditions, the level of dye transfer between $\mathrm{CC}$ and the oocyte is optimal.

The objective of the second part of this study was to evaluate the effects of the bovine follicular microenvironment on COC gap junction activity. From a comparison of the amino acid composition in follicular fluid of lactating and non-lactating cows under pasture conditions in New Zealand, it was evident that the overall mean concentrations in follicular fluid were approximately $70 \%$ of those in UK cows (see Appendix); (Orsi et al., 2005; Sinclair et al., 2008; Bender et al., 2010), and 50\% of those in M199 media. Surprisingly, when bovine COC were incubated for $240 \mathrm{~min}$ in the presence of dipyridamole in M199 media, or media representing the amino acid composition of a non-lactating or lactating cow, no effect on the accumulation of calcein in oocytes was observed. This finding suggests that, in short term incubations, gap junction activity in bovine COC is not acutely sensitive to the amino acid composition. In addition, the activity of COC gap junction nutrient transfer is unlikely to be affected by the relatively smaller difference in amino acid composition in lactating or non-lactating cows, either in the NZ or UK environment.

Another important component of plasma and follicular fluid is cholesterol. The precursor for all steroid and androgen/oestrogen hormones is cholesterol and its utilisation for steroidogenesis affects the oestradiol to progesterone ratio in the follicular fluid. This is associated with follicle dominance (Renaville et al., 2010). Therefore, cholesterol is an important contributor to ovarian progesterone production and improved fertility in cows is 
associated with high concentrations of progesterone in the oestrous cycle. A high peripheral plasma progesterone at the peak of the luteal phase before insemination is correlated positively with conception (Bender et al., 2010). High and low density lipoproteins deliver cholesterol to ovarian tissues for steroidogenesis. The cholesterol utilised for steroid synthesis can be derived from two sources. It can be synthesised by the liver, or from cellular uptake of dietary-derived lipoprotein cholesterol. In most species the majority of the cholesterol used in steroid production is lipoprotein-derived (Grummer \& Carroll, 1988).

In bovine follicles, there are only a limited number of reports as to the concentrations of cholesterol that might be expected. The physiological concentration range in lactating and non-lactating dairy cows is between 0.6 and $3 \mu \mathrm{M} / \mathrm{ml}$ (Green, Petersen, Black \& McNatty, unpublished data). In the present studies, cholesterol concentrations ranging from 0-10 $\mu \mathrm{M}$ were examined. At cholesterol concentrations of $\leq 0.5$ or $>5 \mu \mathrm{M}$, calcein dye transfer from $\mathrm{CC}$ to oocytes was seriously compromised. However, at physiological concentrations (i.e.1-5 $\mu \mathrm{M}$ ), optimal dye transfer was observed. It seems that COC gap junction activity is most sensitive to disruption at low rather than high cholesterol concentrations. Low concentrations i.e. $\sim 0.5 \mu \mathrm{M}$ were most frequently observed in early lactation (i.e. day 21 ) and may be a cause of poor oocyte quality in some cases. It is of interest to note from the present study that in the absence of cholesterol many oocytes that were studied had severely damaged zona pellucida.

In the final part of this study, the effects of certain NEFA, oleic acid, stearic acid and palmitic acid were examined. During periods of negative energy balance as experienced in lactating cows, the total serum concentrations of oleic, palmitic and stearic acid are increased. These serum concentrations are also reflected in the follicular fluid especially that of large antral follicles (Bender et al., 2010; Renaville et al., 2010). Studies have shown that high NEFA concentrations inhibit granulosa cell proliferation and steroidogenesis (Vanholder et al., 
2005). When milk production increases at a higher rate than the ability to take in food, a massive mobilisation of fatty acids occurs. A number of fatty acids have been found to be positively or negatively correlated with the grade of the COC. In follicular fluid, higher levels of palmitic acid were associated with morphologically poor COC while higher concentrations of stearic acid were correlated to morphologically good COC (Sinclair et al., 2008). The mobilisation of fatty acids results in a big increase in the plasma and follicular fluid concentration of NEFAs and there is a high uptake of fatty acids by the liver - in a lot of cases leading to lipidosis. This can lead to reproduction problems (Wensing et al., 1997). In antral follicles of the cow, the mean follicular fluid concentrations of oleic acid, palmitic acid and stearic acid were approximately 200, 50 and $50 \mu \mathrm{g} / \mathrm{ml}$ respectively (Bender et al; 2010). The results from the present study show that all of these acids are capable of influencing the transfer of dye from CC to oocytes over a short-term (i.e. 240 min incubation interval). While oleic acid concentrations in follicular fluid are reported to be $\sim 200 \mu \mathrm{g} / \mathrm{ml}$, no beneficial effects were found at this concentration in the COC gap junction assay. However, at 100 $\mu \mathrm{g} / \mathrm{ml}$ of oleic acid in the presence of other fatty acids, the accumulation of fluorescent dye in oocytes was increased $\sim 1.8$-fold $(\mathrm{P}<0.05)$ over that at 0,50 or $200 \mu \mathrm{g} / \mathrm{ml}$. The effects of stearic acid were tested at $0,25,50$ and $100 \mu \mathrm{g} / \mathrm{ml}$. No increase or decrease in fluorescent dye accumulation in oocytes was noted over this range of concentrations when other fatty acids were present. The only difference noted was that in the absence of other fatty acids, there was a significant increase in calcein dye transfer after 240 min incubation in COC exposed to media containing $50 \mu \mathrm{g} / \mathrm{ml}$ of stearic acid. The results for exposure of COC to differing concentrations of palmitic acid indicated beneficial effects on dye transfer from $\mathrm{CC}$ to oocytes as the concentrations increased from $0-100 \mu \mathrm{g} / \mathrm{ml}$ in the presence of other fatty acids. In contrast when other fatty acids were absent, no beneficial effects of palmitic acid were 
noted. High concentrations of palmitic acid have been reported to have a negative impact on oocyte and embryo quality leading to reproduction failure (Bender et al., 2010).

Collectively, these data indicate that there are significant effects of oleic, stearic and palmitic acid on COC function but they are dose dependent and influenced by the presence or absence of other fatty acids. To better understand the effects of fatty acids and whether they have physiological effects on oocyte quality, there is a need to examine their concentrations in follicular fluid in individual follicles of lactating and non-lactating pasture fed dairy cows under NZ farmed conditions.

When the results of this study are considered together, it is suggested that the most appropriate media composition for further studies of gap junction activity in bovine COC would be to utilise an amino acid composition representing that present in follicular fluid of a lactating cow. Despite the amino acid composition in follicular fluid of lactating cows being substantially different from that in the commercial media M199, no differences were observed in the gap junction activity of COC incubated in the modified media, compared to M199 media. The additional additives to lactating media should include cholesterol 1-2 $\mu \mathrm{M}$ and $100 \mu \mathrm{g} / \mathrm{ml}$ oleic acid, $50 \mu \mathrm{g} / \mathrm{ml}$ stearic acid and $100 \mu \mathrm{g} / \mathrm{ml}$ palmitic acid. Linoleic acid should be added at the same concentration as that found in media M199, i.e. $2 \mu \mathrm{g} / \mathrm{ml}$.

There is evidence in the literature to suggest that in dairy cows the quality of an oocyte is related to the fatty acid composition. Moreover, a change in fatty acid composition in follicular fluid is related to the fatty acid content of the oocyte and excessive lipid accumulation impairs the quality of the embryo (Leroy et al., 2008b).

Aardema et al., 2011 have shown that mammalian oocytes import and metabolise external fatty acids. However, it is also possible that the effects of fatty acids on oocytes are direct rather than indirect via GC and CC. In the present study the direct effect of fatty acids on 
oocyte function was not tested. It has been reported that high levels of palmitic and stearic acids reduce the ability of the maturing oocyte to store lipid and impaired post-fertilisation competence. Interestingly high concentrations of oleic acid had the opposite effect for both the maturing oocyte and the developmental competence of the embryo. This suggests that the ratio of saturated and unsaturated fatty acids is important (Aardema et al., 2011). Compared to the dominant follicle the fatty acids found in the subordinate follicles were significantly lower apart from palmitic acid (Renaville et al., 2010).

Studies have shown that concentrations of cholesterol, oleic, stearic and palmitic acids are higher in plasma than in follicular fluid (Bender et al., 2010; Green, Peterson, and McNatty, unpublished data). This is most likely due to the large size of the lipoprotein molecule which would have trouble passing through the basement membrane of the follicle (Grummer \& Carroll, 1988). As the follicle grows, the follicular wall becomes more permeable thus allowing a higher concentration of cholesterol to be present in the large follicle which is represented by the HDL fraction (Leroy et al., 2004).

This study showed that high concentrations of fatty acids impaired the dye transfer in bovine COC via the gap junctions, thus suggesting that high concentrations impaired the competence of the oocyte. This in turn suggests that the follicle is vulnerable to some of the metabolic alterations caused by negative energy balance. Because embryo quality is dependent on the quality of the oocyte, oocytes that are exposed to high fatty acids and go on to ovulate and are fertilised could be expected to produce poor quality embryos (Leroy et al., 2008a). One strategy to overcome negative energy balance and enhance lactation is to supplement the feed of lactating dairy cows with long chain fatty acids. Long chain fatty acids are used because dietary fats can undergo modification in the rumen and fatty acid bio-hydrogenation can occur. Some long chain fatty acids have been shown to be partially resistant to biohydrogenation and are thus able to reach the duodenum (Mattos et al., 2000). However, the 
results of this study show that too much of specific fatty acids could cause reproductive problems. Because cows in the early stage of lactation mobilise large quantities of triacylglycerols in adipose tissue, fatty acid concentration in blood is high in the first few weeks of lactation. This can cause an imbalance in substrate supply which in turn can compromise appetite. If fat is incorporated into dairy cow diets it must be in moderate amounts and the type of fatty acid needs to carefully considered (Santos et al., 2008).

There is no one cause of post-partum infertility in the high producing dairy cow but evidence suggests that the microenvironment of the follicle plays a big part in the quality and competence of the oocyte.

Where to from here? It would be of interest to look at the intraoocyte cAMP content of oocytes that have been cultured in lactating media with $1 \mu \mathrm{M}$ cholesterol and $10 \mu \mathrm{M}$ dipyridamole with and without forskolin. This could be done using a ${ }^{125}$ I radio immunoassay. Also qPCR could be carried out on oocytes treated the same way and the gene expression of BMP15, GDF9 and connexins 37 and 43 looked at. These experiments would give an indication how efficient the 'ideal' media was. Looking at gene expression of COC that have been incubated in media with high concentrations of fatty acids might give an insight into how these high concentrations are affecting the quality and competence of the oocyte. 


\section{Conclusion}

It is hypothesized that one reason for post-partum infertility in dairy cows is poor oocyte quality due to an inappropriate nutrient microenvironment in the developing antral follicle. There is increasing evidence to suggest that the maturation of oocytes depends upon an efficient nutrient and/or energy supply from cumulus cells. This is achieved, in part, by the materials being delivered to the oocyte through gap junction channels linking the cumulus cells and the oocyte.

In order to test this hypothesis, a fluorescent calcein dye assay for measuring the in vitro gap junction activity for bovine cumulus-oocyte-complexes was developed, and optimised, after testing a range of phosphodiesterase inhibitors (milrinone, IBMX and dipyridamole) with or without the cAMP stimulator forskolin, using the commercial media M199. From a knowledge of the amino acid, cholesterol and non-esterified fatty acids concentrations in follicular fluid from ovarian follicles of post-partum dairy cows under NZ pastoral conditions, two synthetic media representing the overall mean amino acid compositions in either lactating or non-lactating animals were prepared. The objective was to test the efficiency of cumulus dye transfer to the oocyte using the optimised gap junction assay in the presence or absence of cholesterol and/or fatty acids.

The results showed that dye transfer in the bovine gap junction assay was significantly compromised by high concentrations of cholesterol and/or modified by the fatty acids oleic, palmitic and stearic acid. However, media representing the amino acid compositions of either lactating or non-lactating cows did not affect the efficiency of dye transfer from the cumulus cells to the oocyte in spite of the fact that these overall compositions were $\sim 50 \%$ lower than those in M199. 
In conclusion, the evidence suggests that nutrient transfer between cumulus cells and the oocyte can be compromised by inappropriate concentrations of cholesterol and /or fatty acids. These findings add support to the hypothesis that the nutrient and energy microenvironment is critical for maintenance of oocyte health. 


\section{Appendix}

Recipe for M199 for lactating and non lactating cows

Inorganic salts

$\mathrm{CaCL}_{2}$

0.265

$\mathrm{Fe}\left(\mathrm{NO}_{3}\right) \cdot 9 \mathrm{H}_{2} \mathrm{O}$

0.265

$\mathrm{MgSO}_{4}$ (anhyd)

0.09767

$\mathrm{KCL}$

0.4

$\mathrm{Na}$ Acetate (anhyd)

0.05

$\mathrm{NaHCO}_{3}$

2.2

$\mathrm{NaCl}$

6.8

$\mathrm{NaH}_{2} \mathrm{PO}_{4}$ (anhyd)

0.122

\section{Vitamins}

Ascorbic acid.Na

0.000056

Biotin

0.00001

Calciferol

0.0001

Choline Chloride

0.0005

Folic acid

0.00001

Menadione (sodium bisulfite)

0.000016

Myo-Inositol

0.00005

Niciamide

0.000025

Nicotinic acid

0.000025

Amino Benzoic acid

0.00005

Di Pantothenic Acid. ${ }_{1 / 2} \mathrm{Ca}$

0.00001

Pyridoxal HCL

0.000025

Pyridoxine HCL

0.000025

Retinol Acetate

0.00014

Riboflavin

0.00001

DL $\alpha$-Tocopherol Phosphate Na

0.00001

Thiamine HCL

0.0001 


\section{Other}

Adenine Sulphate

0.01

Adenosine triphosphate $2 \mathrm{Na}$

0.001

Adenosine monophosphate

0.000238

deoxyribose

0.0005

Glucose

1.000

Glutathoione

0.00005

Guanine HCL

0.0003

Hypoxanthine

0.0003

Tween 80

0.0213

Ribose

0.0005

Thyamine

0.0003

uracil

0.0003

Xanthine $\mathrm{Na}$

0.000344 


\section{Amino Acids}

Glycine

L-Alanine

L-Arginine HCL

L-Asparagine

L-Aspartic acid

L-Cystine

L-Glutamic acid

L-Glutamine

L-Histadine HCL

L-Isoleucine

L-Lysine HCL

L-Methionine

L-Phenyalanine

L-Proline

L-Serine

L-Threonine

L-Tryptophan

L-Tyrosine

L-Valine

L-Hydroxyproline
Non lactating/l

$28.5266 \mathrm{mg}$

$22.2725 \mathrm{mg}$

$670 \mu \mathrm{l}$ of $100 \mathrm{mM}$

$4.88844 \mathrm{mg}$

$11.979 \mathrm{mg}$

$9.612 \mathrm{mg}$

$50.0242 \mathrm{mg}$

$33.17378 \mathrm{mg}$

$410 \mu \mathrm{l}$ of $100 \mathrm{mM}$

$18.75731 \mathrm{mg}$

$109 \mu \mathrm{l}$ of $100 \mathrm{mM}$

$4.4763 \mathrm{mg}$

$9.9114 \mathrm{mg}$

$8.17423 \mathrm{mg}$

$14.50242 \mathrm{mg}$

$10.24432 \mathrm{mg}$

$4.0846 \mathrm{mg}$

$11.05259 \mathrm{mg}$

$33.38775 \mathrm{mg}$

$0.91791 \mathrm{mg}$
Lactating/l

$36.33388 \mathrm{mg}$

$20.31252 \mathrm{mg}$

$560 \mu \mathrm{l}$ of 100.M

$2.90664 \mathrm{mg}$

$14.9072 \mathrm{mg}$

$9.612 \mathrm{mg}$

$33.17378 \mathrm{mg}$

$32.88815 \mathrm{mg}$

$230 \mu \mathrm{l}$ of $100 \mathrm{mM}$

$15.7404 \mathrm{mg}$

$760 \mu \mathrm{l}$ of $100 \mathrm{mM}$

$1.4921 \mathrm{mg}$

$8.42469 \mathrm{mg}$

$9.44066 \mathrm{mg}$

$13.45152 \mathrm{mg}$

$11.55464 \mathrm{mg}$

$4.0846 \mathrm{mg}$

$8.69712 \mathrm{mg}$

$28.116 \mathrm{mg}$

$1.18017 \mathrm{mg}$ 


\section{Method for Orcein staining of Oocytes}

Fixative: 1 part acetic acid to 3 parts ethanol.

Stain: $0.5 \mathrm{~g}$ Orcein powder dissolved in $22.5 \mathrm{ml}$ distilled water. Heat and stir gently for 60 minutes. Add to $27.5 \mathrm{ml}$ distilled water. Filter twice through a Whatman No1 filter. If a precipitate has formed on standing when you come to use it filter again before use.

Destain: 1 part glycerol, 1 part acetic acid and 3 parts ethanol. Mix gently.

Method: Mount oocytes (3-4) on a slide with a little media (5-10 $\mu 1)$. Put a small strip of Vaseline on 2 opposite sides of a cover slip and carefully place over the oocytes. Press down gently while observing through the microscope until the oocytes bulge. Too much pressure will cause them to break. Coat the edges that have Vaseline with clear nail polish, allow to dry, then place into fixative for at least 24 hours. I flow fixative under the cover slip with a syringe to ensure the oocytes get the fixative before putting the slides in the fixative.

At the end of fixation remove from the container and replace the fixative under the cover slip. Put the dye on the bottom edge of the slide and using a tissue as a wick along the top edge replace the fixative with dye. Place the slide in a humid box for 1-2 hours. The time depends on the intensity of staining you require. Remove the dye and destain in the same manner. When all the stain has been removed put nail polish on the other two edges and observe under the microscope. 


\section{References}

Aardema H, Vos PL, Lolicato F, Roelen BA, Knijn HM, Vaandrager AB, Helms JB \& Gadella BM (2011) Oleic acid prevents detrimental effects of saturated fatty acids on bovine oocyte developmental competence. Biol Reprod, 85(1), 62-69.

Adams GP (1999) Comparative patterns of follicle development and selection in ruminants. $J$ Reprod Fertil Suppl, 54, 17-32.

Adams GP, Jaiswal R, Singh J \& Malhi P (2008) Progress in understanding ovarian follicular dynamics in cattle. Theriogenology, 69(1), 72-80.

Aerts JMJ \& Bols PEJ (2010a) Ovarian Follicular Dynamics. A review with Emphasis on the Bovine Species. Part 2: Antral Development, Exogenis Influence and Future Prospects. Reproduction in Domestic Animals, 45, 180-187.

Aerts JMJ \& Bols PEJ (2010b) Ovarian Follicular Dynamics: A Review with Emphasis on the Bovine Species. Part 1: Folliculogenesis and Pre-antral Follicle Development. Reproduction in Domestic Animals, 45, 171-179.

Barretto LS, Caiado Castro VS, Garcia JM \& Mingoti GZ (2007) Role of roscovitine and IBMX on kinetics of nuclear and cytoplasmic maturation of bovine oocytes in vitro. Anim Reprod Sci, 99(1-2), 202-207.

Bender K, Walsh S, Evans AC, Fair T \& Brennan L (2010) Metabolite concentrations in follicular fluid may explain differences in fertility between heifers and lactating cows. Reproduction, 139(6), 1047-1055.

Bodensteiner KJ, Clay CM, Moeller CL \& Sawyer HR (1999) Molecular cloning of the ovine Growth/Differentiation factor-9 gene and expression of growth/differentiation factor9 in ovine and bovine ovaries. Biol Reprod, 60(2), 381-386.

Braw-Tal R (2002) The initiation of follicle growth: the oocyte or the somatic cells? Mol Cell Endocrinol, 187(1-2), 11-18. 
Braw-Tal R \& Yossefi S (1997) Studies in vivo and in vitro on the initiation of follicle growth in the bovine ovary. J Reprod Fertil, 109(1), 165-171.

Burghardt RC, Barhoumi R, Sewall TC \& Bowen JA (1995) Cyclic AMP induces rapid increases in gap junction permeability and changes in the cellular distribution of connexin43. J Membr Biol, 148(3), 243-253.

Burkhart MN, Juengel JL, Smith PR, Heath DA, Perry GA, Smith MF \& Garverick HA (2010) Morphological development and characterization of aromatase and estrogen receptors alpha and beta in fetal ovaries of cattle from days 110 to 250. Anim Reprod Sci, $117(1-2), 43-54$.

Butler WR (2000) Nutritional interactions with reproductive performance in dairy cattle. Anim Reprod Sci, 60-61, 449-457.

Chagas LM, Bass JJ, Blache D, Burke CR, Kay JK, Lindsay DR, Lucy MC, Martin GB, Meier S, Rhodes FM, Roche JR, Thatcher WW \& Webb R (2007) Invited review: New perspectives on the roles of nutrition and metabolic priorities in the subfertility of high-producing dairy cows. J Dairy Sci, 90(9), 4022-4032.

Conti M, Andersen CB, Richard F, Mehats C, Chun SY, Horner K, Jin C \& Tsafriri A (2002) Role of cyclic nucleotide signaling in oocyte maturation. Mol Cell Endocrinol, 187(12), 153-159.

Cruciani V \& Mikalsen SO (2005) Ilimaquinone inhibits gap junctional communication in a connexin isotype-specific manner. Exp Cell Res, 304(1), 136-148.

Dekel N (2005) Cellular, biochemical and molecular mechanisms regulating oocyte maturation. Mol Cell Endocrinol, 234(1-2), 19-25.

Dong J, Albertini DF, Nishimori K, Kumar TR, Lu N \& Matzuk MM (1996) Growth differentiation factor-9 is required during early ovarian folliculogenesis. Nature, 383(6600), 531-535. 
Downs SM (2011) Mouse versus rat: Profound differences in meiotic regulation at the level of the isolated oocyte. Mol Reprod Dev, 78(10-11), 778-794.

Driancourt MA (2001) Regulation of ovarian follicular dynamics in farm animals. Implications for manipulation of reproduction. Theriogenology, 55(6), 1211-1239.

Drummond AE (2006) The role of steroids in follicular growth. Reprod Biol Endocrinol, 4, 16.

Edry I, Sela-Abramovich S \& Dekel N (2006) Meiotic arrest of oocytes depends on cell-tocell communication in the ovarian follicle. Mol Cell Endocrinol, 252(1-2), 102-106.

Forde N, Beltman ME, Lonergan P, Diskin M, Roche JF \& Crowe MA (2010) Oestrous cycles in Bos taurus cattle. Animal Reproduction Science.

Fortune JE (2003) The early stages of follicular development: activation of primordial follicles and growth of preantral follicles. Anim Reprod Sci, 78(3-4), 135-163.

Fouladi-Nashta AA, Gutierrez CG, Gong JG, Garnsworthy PC \& Webb R (2007) Impact of dietary fatty acids on oocyte quality and development in lactating dairy cows. Biol Reprod, 77(1), 9-17.

Fouladi-Nashta AA, Wonnacott KE, Gutierrez CG, Gong JG, Sinclair KD, Garnsworthy PC \& Webb R (2009) Oocyte quality in lactating dairy cows fed on high levels of n-3 and n-6 fatty acids. Reproduction.

Galloway SM, McNatty KP, Cambridge LM, Laitinen MP, Juengel JL, Jokiranta TS, McLaren RJ, Luiro K, Dodds KG, Montgomery GW, Beattie AE, Davis GH \& Ritvos O (2000) Mutations in an oocyte-derived growth factor gene (BMP15) cause increased ovulation rate and infertility in a dosage-sensitive manner. Nat Genet, 25(3), 279-283.

Ganong WF. (1995). The Gonads: development and Function of the Reproductive System Review of Medical Physiology (17 ed., pp. 379 - 418). San Francisco: Prentice Hall. 
Gershon E, Plaks V \& Dekel N (2008) Gap junctions in the ovary: expression, localization and function. Mol Cell Endocrinol, 282(1-2), 18-25.

Gilchrist RB, Lane M \& Thompson JG (2008) Oocyte-secreted factors: regulators of cumulus cell function and oocyte quality. Hum Reprod Update, 14(2), 159-177.

Gilchrist RB, Ritter LJ \& Armstrong DT (2004) Oocyte-somatic cell interactions during follicle development in mammals. Anim Reprod Sci, 82-83, 431-446.

Gittens JE, Barr KJ, Vanderhyden BC \& Kidder GM (2005) Interplay between paracrine signaling and gap junctional communication in ovarian follicles. J Cell Sci, 118(Pt 1), $113-122$.

Goodenough DA \& Paul DL (2009) Gap junctions. Cold Spring Harb Perspect Biol, 1(1), a002576.

Grummer RR \& Carroll DJ (1988) A review of lipoprotein cholesterol metabolism: importance to ovarian function. J Anim Sci, 66(12), 3160-3173.

Hanrahan JP, Gregan SM, Mulsant P, Mullen M, Davis GH, Powell R \& Galloway SM (2004) Mutations in the genes for oocyte-derived growth factors GDF9 and BMP15 are associated with both increased ovulation rate and sterility in Cambridge and Belclare sheep (Ovis aries). Biol Reprod, 70(4), 900-909.

Harris BL \& Kolver ES (2001) Review of Holsteinization on Intensive Pastoral Dairy Farming in New Zealand. J. Dairy Sci., 84(E-Suppl), E56-61.

Hunter MG, Robinson RS, Mann GE \& Webb R (2004) Endocrine and paracrine control of follicular development and ovulation rate in farm species. Anim Reprod Sci, 82-83, 461-477.

Johnson ML, Redmer DA, Reynolds LP \& Grazul-Bilska AT (1999) Expression of gap junctional proteins connexin 43, 32, and 26 throughout follicular development and atresia in cows. Endocrine, 10(1), 43-51. 
Juengel JL, Bodensteiner KJ, Heath DA, Hudson NL, Moeller CL, Smith P, Galloway SM, Davis GH, Sawyer HR \& McNatty KP (2004) Physiology of GDF9 and BMP15 signalling molecules. Anim Reprod Sci, 82-83, 447-460.

Juengel JL, Hudson NL, Berg M, Hamel K, Smith P, Lawrence SB, Whiting L \& McNatty KP (2009) Effects of active immunization against growth differentiation factor 9 and/or bone morphogenetic protein 15 on ovarian function in cattle. Reproduction, 138(1), 107-114.

Juengel JL, Hudson NL, Heath DA, Smith P, Reader KL, Lawrence SB, O'Connell AR, Laitinen MP, Cranfield M, Groome NP, Ritvos O \& McNatty KP (2002) Growth differentiation factor 9 and bone morphogenetic protein 15 are essential for ovarian follicular development in sheep. Biol Reprod, 67(6), 1777-1789.

Juengel JL \& McNatty KP (2005) The role of proteins of the transforming growth factor-beta superfamily in the intraovarian regulation of follicular development. Hum Reprod Update, 11(2), 143-160.

Kanitz W, Brussow K-P, becker F, Torner H, Schneider F, Kubelka M \& Tomek W (2001) Comparative Aspects of Follicular Development, Follicular and Oocyte Maturation and Ovulation in Cattle and Pigs. Arch.Tierz.Dummerstorf, 44(Special issue), 9-23.

Kidder GM \& Mhawi AA (2002) Gap junctions and ovarian folliculogenesis. Reproduction, 123(5), 613-620.

Kidder GM \& Vanderhyden BC (2010) Bidirectional communication between oocytes and follicle cells: ensuring oocyte developmental competence. Can J Physiol Pharmacol, 88(4), 399-413.

Leroy JL, Van Soom A, Opsomer G \& Bols PE (2008a) The conseqences of metabolic changes in high-yielding dairy cows on oocyte and embryo quality. Animal, 2(8), $1120-1127$. 
Leroy JL, Van Soom A, Opsomer G, Goovaerts IG \& Bols PE (2008b) Reduced fertility in high-yielding dairy cows: are the oocyte and embryo in danger? Part II. Mechanisms linking nutrition and reduced oocyte and embryo quality in high-yielding dairy cows. Reprod Domest Anim, 43(5), 623-632.

Leroy JL, Vanholder T, Delanghe JR, Opsomer G, Van Soom A, Bols PE \& de Kruif A (2004) Metabolite and ionic composition of follicular fluid from different-sized follicles and their relationship to serum concentrations in dairy cows. Anim Reprod Sci, 80(3-4), 201-211.

Leroy JL, Vanholder T, Mateusen B, Christophe A, Opsomer G, de Kruif A, Genicot G \& Van Soom A (2005) Non-esterified fatty acids in follicular fluid of dairy cows and their effect on developmental capacity of bovine oocytes in vitro. Reproduction, 130(4), 485-495.

Leroy JL, Vanholder T, Van Knegsel ATM, Garcia-Ispierto I \& Bols PEJ (2008c) Nutrient prioritization in dairy cows early postpartum: Mismatch between metabolism and fertility? Reproduction in Domestic Animals, 43, 96-103.

Lopez H, Satter LD \& Wiltbank MC (2004) Relationship between level of milk production and estrous behavior of lactating dairy cows. Anim Reprod Sci, 81(3-4), 209-223.

Lucy MC (2001a) Reproductive loss in high-producing dairy cattle: where will it end? $J$ Dairy Sci, 84(6), 1277-1293.

Lucy MC (2001b) Reproductive Physiology and Management of High Yielding Cattle. Proc.NZ Society of Animal Production(61), 120-127.

Lucy MC (2007) Fertility in high-producing dairy cows: reasons for decline and corrective strategies for sustainable improvement. Soc Reprod Fertil Suppl, 64, 237-254.

Mattos R, Staples CR \& Thatcher WW (2000) Effects of dietary fatty acids on reproduction in ruminants. Rev Reprod, 5(1), 38-45. 
Mayes MA \& Sirard MA (2002) Effect of type 3 and type 4 phosphodiesterase inhibitors on the maintenance of bovine oocytes in meiotic arrest. Biol Reprod, 66(1), 180-184.

McNeilly JR, Watson EA, White YA, Murray AA, Spears N \& McNeilly AS (2011) Decreased Oocyte DAZL Expression in Mice Results in Increased Litter Size by Modulating FSH-Induced Follicular Growth. Biol Reprod.

Mehlmann LM (2005) Stops and starts in mammalian oocytes: recent advances in understanding the regulation of meiotic arrest and oocyte maturation. Reproduction, 130(6), 791-799.

Mihm M \& Bleach ECL (2003) Endocrine regulation of ovarian antral follicle development in cattle. Animal Reproduction Science, 78, 217-237.

Modina S, Luciano AM, Vassena R, Baraldi-Scesi L, Lauria A \& Gandolfi F (2001) Oocyte developmental competence after in vitro maturation depends on the persistence of cumulus-oocyte comunications which are linked to the intracellular concentration of cAMP. Ital J Anat Embryol, 106(2 Suppl 2), 241-248.

Nett TM, Turzillo AM, Baratta M \& Rispoli LA (2002) Pituitary effects of steroid hormones on secretion of follicle-stimulating hormone and luteinizing hormone. Domest Anim Endocrinol, 23(1-2), 33-42.

Orsi NM, Gopichandran N, Leese HJ, Picton HM \& Harris SE (2005) Fluctuations in bovine ovarian follicular fluid composition throughout the oestrous cycle. Reproduction, 129(2), 219-228.

Palumbo A \& Yeh J (1995) Apoptosis as a basic mechanism in the ovarian cycle: follicular atresia and luteal regression. J Soc Gynecol Investig, 2(3), 565-573.

Paulini F \& Melo EO (2010) The Role of Oocyte-Secreted Factors GDF9 and BMP15 in Follicular Development and Oogenesis. Reprod Domest Anim. 
Peter AT, Vos PL \& Ambrose DJ (2009) Postpartum anestrus in dairy cattle. Theriogenology, 71(9), 1333-1342.

Reik W \& Dean W (2002) Back to the beginning. Nature, 420(6912), 127.

Renaville B, Bacciu N, Comin A, Motta M, Poli I, Vanini G \& Prandi A (2010) Plasma and follicular fluid fatty acid profiles in dairy cows. Reprod Domest Anim, 45(1), 118-121.

Ruggiu M SR, Taggart M, McKay SJ, Kilanowski F, Saunders P, Dorin J, Cooke HJ (1997) The mouse Dazla gene encodes a cytoplasmic protein essential for gametogenesis. Nature, 389(September 1997).

Santos JE, Bilby TR, Thatcher WW, Staples CR \& Silvestre FT (2008) Long chain fatty acids of diet as factors influencing reproduction in cattle. Reprod Domest Anim, 43 Suppl 2, 23-30.

Sasseville M, Albuz FK, Cote N, Guillemette C, Gilchrist RB \& Richard FJ (2009a) Characterization of novel phosphodiesterases in the bovine ovarian follicle. Biol Reprod, 81(2), 415-425.

Sasseville M, Cote N, Guillemette C \& Richard FJ (2006) New insight into the role of phosphodiesterase 3A in porcine oocyte maturation. BMC Dev Biol, 6, 47.

Sasseville M, Gagnon MC, Guillemette C, Sullivan R, Gilchrist RB \& Richard FJ (2009b) Regulation of gap junctions in porcine cumulus-oocyte complexes: contributions of granulosa cell contact, gonadotropins, and lipid rafts. Mol Endocrinol, 23(5), 700-710.

Scaramuzzi RJ, Baird DT, Campbell BK, Driancourt MA, Dupont J, Fortune JE, Gilchrist RB, Martin GB, McNatty KP, McNeilly AS, Monget P, Monniaux D, Vinoles C \& Webb R (2011) Regulation of folliculogenesis and the determination of ovulation rate in ruminants. Reprod Fertil Dev, 23(3), 444-467.

Segretain D \& Falk MM (2004) Regulation of connexin biosynthesis, assembly, gap junction formation, and removal. Biochim Biophys Acta, 1662(1-2), 3-21. 
Shimasaki S, Moore RK, Otsuka F \& Erickson GF (2004) The bone morphogenetic protein system in mammalian reproduction. Endocr Rev, 25(1), 72-101.

Sinclair KD, Lunn LA, Kwong WY, Wonnacott K, Linforth RS \& Craigon J (2008) Amino acid and fatty acid composition of follicular fluid as predictors of in-vitro embryo development. Reprod Biomed Online, 16(6), 859-868.

Sosinsky GE \& Nicholson BJ (2005) Structural organization of gap junction channels. Biochim Biophys Acta, 1711(2), 99-125.

Sugiura K, Pendola FL \& Eppig JJ (2005) Oocyte control of metabolic cooperativity between oocytes and companion granulosa cells: energy metabolism. Dev Biol, 279(1), 20-30.

Thatcher WW, Santos JEP, Silvestre FT, Kim IH \& Staples CR (2010) Perspective on Physiological/Endocrine and Nutritional Factors Influencing Fertility in Post-partum Dairy Cows. Reproduction in Domestic Animals, 45(Suppl.3), 2-14.

Thomas RE, Armstrong DT \& Gilchrist RB (2002) Differential effects of specific phosphodiesterase isoenzyme inhibitors on bovine oocyte meiotic maturation. Dev Biol, 244(2), 215-225.

Thomas RE, Armstrong DT \& Gilchrist RB (2004a) Bovine cumulus cell-oocyte gap junctional communication during in vitro maturation in response to manipulation of cell-specific cyclic adenosine 3',5'-monophosophate levels. Biol Reprod, 70(3), 548556.

Thomas RE, Thompson JG, Armstrong DT \& Gilchrist RB (2004b) Effect of specific phosphodiesterase isoenzyme inhibitors during in vitro maturation of bovine oocytes on meiotic and developmental capacity. Biol Reprod, 71(4), 1142-1149.

Tsafriri A, Chun SY, Zhang R, Hsueh AJ \& Conti M (1996) Oocyte maturation involves compartmentalization and opposing changes of cAMP levels in follicular somatic and 
germ cells: studies using selective phosphodiesterase inhibitors. Dev Biol, 178(2), 393-402.

Vanholder T, Leroy JL, Soom AV, Opsomer G, Maes D, Coryn M \& de Kruif A (2005) Effect of non-esterified fatty acids on bovine granulosa cell steroidogenesis and proliferation in vitro. Anim Reprod Sci, 87(1-2), 33-44.

Walsh SW, Williams EJ \& Evans ACO (2011) A review of the causes of poor fertility in high milk producing dairy cows. Animal Reproduction Science, 123, 127-138.

Wensing T, Kruip T, Geelen M, Wentink G \& van den Top A (1997) Postpartum Fatty Liver in High-Producing Dairy Cows in Practice and in Animal Studies. The Connection with Health, Production and Reprduction Prblems. Comparative Haematology International, 7, 167-171.

Yan C, Wang P, DeMayo J, DeMayo FJ, Elvin JA, Carino C, Prasad SV, Skinner SS, Dunbar BS, Dube JL, Celeste AJ \& Matzuk MM (2001) Synergistic roles of bone morphogenetic protein 15 and growth differentiation factor 9 in ovarian function. $\mathrm{Mol}$ Endocrinol, 15(6), 854-866.

Yeo CX, Gilchrist RB \& Lane M (2009) Disruption of bidirectional oocyte-cumulus paracrine signaling during in vitro maturation reduces subsequent mouse oocyte developmental competence. Biol Reprod, 80(5), 1072-1080. 